Florida International University FIU Digital Commons

$4-12-2002$

\title{
Embedded heat speaders in low temperature cofired ceramic substrates
}

\author{
Guangnan Deng \\ Florida International University
}

DOI: $10.25148 /$ etd.FI14062240

Follow this and additional works at: https://digitalcommons.fiu.edu/etd

Part of the Mechanical Engineering Commons

\section{Recommended Citation}

Deng, Guangnan, "Embedded heat speaders in low temperature cofired ceramic substrates" (2002). FIU Electronic Theses and Dissertations. 2770.

https://digitalcommons.fiu.edu/etd/2770 
Miami, Florida SUBSTRATES

\author{
A thesis submitted in partial fulfillment of the \\ requirements for the degree of \\ MASTER OF SCIENCE \\ in \\ MECHANICAL ENGINEERING
}

by

Guangnan Deng

2002 
To: Dean Vish Prasad

College of Engineering

This thesis, written by Guangnan Deng, and entitled Embedded Heat Spreaders in Low Temperature Cofired Ceramic Substrates, having been approved in respect to style and intellectual content, is referred to you for judgment.

We have read this thesis and recommend that it be approved.

Norman D.H. Munroe

Kuang-Hsi Wu

W. Kinzy Jones, Major Professor

Date of Defense: Aprtil 12, 2002

The thesis of Guangnan Deng is approved.

Dean Vish Prasad College of Engineering

Dean Douglas Wartzok University Graduate School

Florida International University, 2002 


\section{EMBEDDED HEAT SPREADERS IN LOW TEMPERATURE COFIRED CERAMIC}

\section{SUBSTRATES}

by

\section{Guangnan Deng}

Florida International University, 2002

Miami, Florida

Professor W. Kinzy Jones, Major Professor

A new heat spreader that operates on a principle similar to heat pipes has been developed in Low Temperature Cofired Ceramic (LTCC) substrate. The heat spreader use sintered metal powder as the wick structure and water as the working fluid. Key topics related to the fabrication of embedded heat spreaders in LTCC substrate were studied. The conventional LTCC procedure has been improved to suit the requirement of heat spreader. A novel sintered porous silver powder has been developed to provide high capillary pressure and permeability for the wick structure. The maximum mass transport rate of the wick was about $0.692(\mathrm{~g} / \mathrm{min})$ at wick height of $4.5 \mathrm{~cm}$. The thermal performance test demonstrated that the prototype heat spreader could work properly at power density of more than $70 \mathrm{~W} / \mathrm{cm}^{2}$ without any sign of dry out occur. The successful fabrication of the prototype integrated heat spreader provides concept validation of using advanced two-phase heat management system to greatly improve the effective thermal conductivity of LTCC substrate. 
I . OVERVIEW OF LTCC AND HEAT SPREADER $\ldots \ldots \ldots \ldots \ldots \ldots \ldots \ldots \ldots \ldots$

Introduction of Low Temperature Cofired Ceramic .......................... 1

Introduction of heat pipe and heat spreader...............................6 6

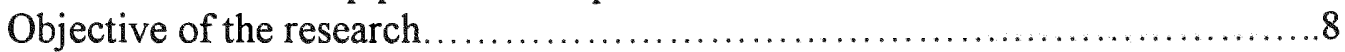

Significance of the research ............................................ 9

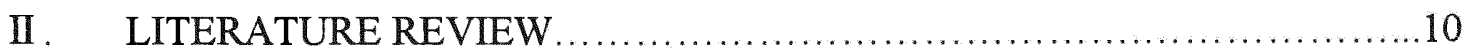

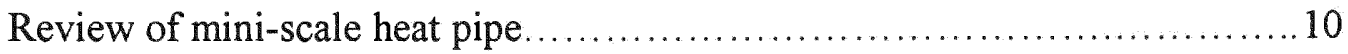

Review of fabricating 3-D structure using LTCC ......................... 15

III. DEVELOPMENT OF MAJOR COMPONENTS OF HEAT SPREADER .....20

Thermal via ......................................................... 20

Hermetic LTCC container.............................................. 26

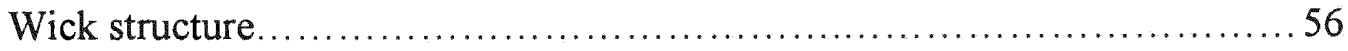

Working fluid ...................................................... 78

IV. DEVELOPMENT OF PROTOTYPE EMBEDDED HEAT SPREADER ..... 82

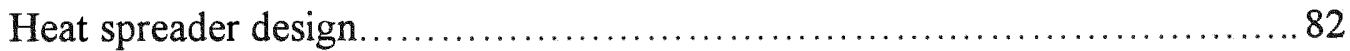

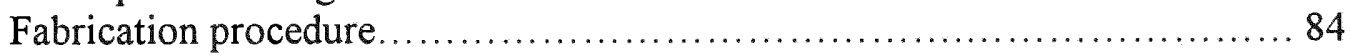

V. THERMAL PERFORMANCE TESTING $\ldots \ldots \ldots \ldots \ldots \ldots \ldots \ldots \ldots \ldots \ldots \ldots$

Experimental setup .................................................. 90

Experimental procedure .............................................. 91

Testing Result and analysis........................................ 92

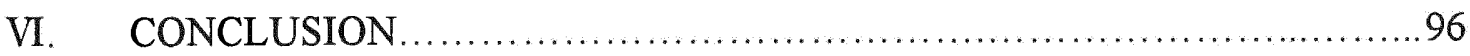

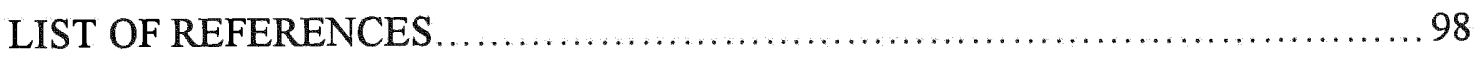




\section{LIST OF TABLES}

TABLE

Table 1.1 Geometrical capacities of thick film and thin film processing 1

Table 1.2 Thermal conductivities of some ceramics in electronic packaging 5

Table 3.1 Comparison of major properties of some commonly used wick structure 60

Table 3.2 Mass transmit rate at different input power level (wick height $=7.5 \mathrm{~cm}$ ) $\quad 72$

Table 3.3 Maximum mass transfer rates at various wick heights 73

Table 3.4 Compare powder cluster wick with normal powder wick 74

$\begin{array}{lll}\text { Table 3.5 Typical working fluids and temperature ranges } & 80\end{array}$

Table 3.6 Thermo physical properties of saturated water, methanol, Ethanol and acetone at $100^{\circ} \mathrm{C}$

Table 5.1 Location of the thermocouples

Table 5.2 Temperature data of heat spreader at various power levels

Table 5.3 Comparison of temperature data of charged mode and uncharged mode at power level of $5.2 \mathrm{~W}$ 


\section{LIST OF FIGURES}

FIGURE

PAGE

Fig 1.1 Illustration of the working principle of heat pipe

Fig 1.2 Illustration of a heat spreader $\quad 8$

Fig 3.1 Cross section of a via hole with bad alignment 22

Fig 3.2 Distortion of via hole after lamination 23

Fig 3.3 Via hole drilled on pre-laminated piece showing no shape distortion 24

Fig 3.4 Cross section of the via hole drilled on pre-laminated piece 24

Fig 3.5 Illustration of filling via using extrusion via filler 25

Fig 3.6 The stacked vias and the embedded silver layer 26

Fig 3.7 Sample with small cracks on the edge 29

Fig 3.8 Illustration of how insert material can result in inhomogeneous density 30

Fig 3.9 A crack develops along the via array 31

Fig3.10 Sagging caused by laminating green tape with interior cavity 33

Fig 3.11 Sagging in sample made by conventional LTCC technology 36

Fig 3.12 Sagging in sample made by multiple lamination process 36

Fig 3.13 The effect on sagging due to variations in cavity width of: (A) $0.25 \mathrm{inch}$, (B)

0.125 inch, and (C) 0.0625 inch.

Fig 3.14 The effect on sagging due to variations in lamination pressure of: (A) $3000 \mathrm{psi}$

(B) 2000 psi, (C) 1000 psi and(D) 500psi

Fig 3.15 De-lamination due to the low pressure. 40

Fig 3.16 TGA curve of wax 43

Fig 3.17 Recommended sintering profile of Dupont 951 tape 44 
Fig 3.18 Green state sample with wax deposited in the cavity

Fig 3.19 Sintered sample using insert wax

Fig 3.20 Sample fabricated by post fire process

Fig 3.21 Sample fabricated by cofire and using binding paste method

Fig 3.22 Sample fabricated by cofire and using binding paste method (big cavity)

Fig 3.23 Crack between the ceramic part and the paste

Fig 3.24 Small pores in the paste

Fig 3.25 Cut section of binding paste after constrained sintering

Fig 3.26 Micro crack at edge of thermal via

Fig 3.27 Schematic show of the pressure distributions in the vapor and liquid along the heat pipe length

Fig 3.28 Some commonly used wick structures

Fig 3.29 Illustration of the porous silver powders

Fig 3.30 Schematically show of two spherical particles connected by a neck

Fig 3.31 Picture of a big particle congregated from many small particles

Fig 3.32 TGA curve of PVB

Fig 3.33 Picture of big silver particle sintered from numerous small particles

Fig 3.34 Experimental setup for testing mass transmit rate

Fig 3.35 Mass transmit rate at various power levels, for wick height $=7.5 \mathrm{~cm}$

Fig 3.36 Maximum mass transmit rate at various wick heights

Fig 3.37 Temperature plateau in powder cluster wick and normal powder wick

Fig 4.1 Design of a typical heat spreader

Fig 4.2 Single vapor chamber heat spreader 
Fig 4.3 Schematic showing vapor chamber heat spreader operation

Fig 4.4 Heat spreader fabrication procedure

Fig 5.1 Experimental setup for testing thermal performance of heat spreader

Fig 5.2 Temperature distribution at various input power levels

Fig 5.3 Comparison between charged and uncharged operation mode of heat spread 94 


\section{I .Overview of LTCC and heat spreader}

\section{Introduction of Low Temperature Cofired Ceramic}

Because of their unique combination of mechanical, dielectric, physical and chemical properties, ceramic has played an important role in electronic packaging. Mainly, there are four ceramic-based technologies in electronic packaging: thick film, thin film, HTCC and LTCC.

The difference between thick film and thin film is the way they pattern the circuit on ceramic substrate. Thick film refers to the process of fabricating an electronic network through the sequential printing of conductive, resistive and dielectric patterns on an alumina ceramic substrate. After high temperature firing of the printed layers, the network is then integrated with active and passive components to realize the desired circuit function. While in thin film technology, thin films are formed by either evaporating or sputtering the desired material onto the ceramic substrate. The films are then patterned using photolithography and etching.

Because of the different circuitry patterning technology used, thick film and thin film processing have different geometrical capacity and hence different electrical performance. Table 1.1 lists the geometrical capacity of thick film and thin film processing.

\begin{tabular}{|c|c|c|}
\hline Technology & $\begin{array}{c}\text { Typical elements } \\
\text { thickness }\end{array}$ & $\begin{array}{c}\text { Typical elements } \\
\text { width }\end{array}$ \\
\hline Thick film & $>10$ to $25 \mathrm{um}$ & $125 \mathrm{um}$ \\
\hline Thin film & 0.1 to $1 \mathrm{um}$ & $25 \mathrm{um}$ \\
\hline
\end{tabular}

Table 1.1 Geometrical capacities of thick film and thin film processing 
Therefore, thick film technology has been widely used for medium performance packaging solutions; while thin film technology is very competitive for high performance application.

Both thick film and thin film process are adaptable to single-layer and multiple layer applications. The multiple layer circuitry is produced by alternating circuitry layers with dielectric layers. The connections between two or more layers are achieved by metallized holes, called vias, formed in the dielectric layer.

Since both of them require sequential build up of layers, there are some obvious limitations in conventional thick film and thin film multi-layer technology. First of all, they are not cost effective because the yield and quality are determined by the layer with the lowest yield rate and the poorest quality. Secondly, they require multiple processing steps, which add additional cost and more complicity to the process. To solve this problem, new packaging and interconnect technologies known as High Temperature Cofired Ceramic (HTCC) and Low Temperature Cofired Ceramic (LTCC) have entered the main stream of electronic packaging.

These two technologies are actually developed from improved thick film technology. In these technologies, slurry of ceramic powders, organic binders, solvents and plastic materials are cast onto a smooth surface. The slurry layer is dried into a flexible, easy processable green tape. The green sheet is then cut into pieces. Then the registration holes, vias and cavities are formed in the green sheet by mechanical technologies such as punching, drilling, emboss or cutting. The conductor ink is screen printed onto the tape to fill the interlayer vias and form the circuit patterns. The tapes for 
all the layers of the final substrate are then stacked and laminated together under pressure. Finally the laminated multiple layers are sintered into a highly compact ceramic structure by a single burn out and firing step.

Unlike the thick film technology, HTCC and LTCC are parallel processes. Each layer is fabricated separately and independent of each other. Also the multipliers including the dielectric layers and the passive elements are fired together in a single step, called "Cofired".

With HTCC and LTCC, each tape layer can be fully customized with conductor lines, via fills, embedded resistors, capacities and cavities. Individual layer can then be examined and inspected. If failure is found prior to lamination, only the defective layer, instead of the whole structure, needs to be fabricated again. High yield, reduction in cost and timesaving can be achieved. The whole process of HTCC and LTCC are almost the same. The only differences between them are their tape composition and thus the firing temperature. HTCC mainly consists of alumna material and thus require a firing temperature of $1600-1800^{\circ} \mathrm{C}$, which is substantially above the melting temperature of high conducting materials. Therefore HTCC conductors are limited to refractory metals such as W or Mo. While LTCC are made from alumna filled glasses or glass ceramic. Usually it is fired at $850-1000^{\circ} \mathrm{C}$, thus enable to use higher conductivity materials such as $\mathrm{Ag}$ and $\mathrm{Au}$.

In addition, the basic LTCC composition can be modified to give dielectric material different electrical and physical properties. The dielectric constant can be varied in a wide rang from 4 to 12000 ; and the coefficient of thermal expansion can be adopted to match 
alumna, gallium or silicon. Many standard thick film conductor, resistor and capacitor materials can thus be used in LTCC as buried or surface element.

Since LTCC has the unique ability to integrate a broad variety of components into a very compact arrangement, it is known as one of the most advanced approaches in miniaturization of electronic packaging. To achieve improved performance in data processing equipment, trends in electronic packaging have moved toward larger circuit chips, higher $\mathrm{I} / \mathrm{O}$, increased circuit density and improved reliability. There are constant pressures on military and commercial system designer to reduce system volume while increasing electronics complexity and power density. The primary advantage of LTCC technology in this miniaturization trend lies on its capacity to reduce weight, size and cost while improving reliability. Integrating resistors and capacitors into the LTCC substrate can eliminate many solder joints and wire bonds. Because of the excellent insulation provided by the thin layers of ceramic material, circuits can be alternately stacked, allowing digital, analog and micro wave assemblies to be embedded in the same LTCC structure. This eliminates the need for separate housing and provides significant space and weight reductions.

However, there is no perfect material in the world; LTCC also has its disadvantages. One of the major drawbacks to LTCC in many applications is its low thermal conductivity, which mainly limits the application of LTCC in high power density area. Over last 15 years, power density has increased exponentially with time and it appears that it will continue to do so in the near future. ${ }^{1}$ As power density increase, the heat generated as a by-product become more severe. With the heat build up, increase the temperature of the system, which is an important parameter for reliability at all levels of electronic 
packaging. Temperature related issues might include one or more of the following problems:

1. High operating temperature can accelerate various failure mechanisms such as creep, corrosion and electro migration.

2. Temperature difference that occurs as a system is cycled between power-on and power-off can lead to fatigue in composite structure.

3. In electronic packaging, a large variety of materials are used in order to meet performance, density and cost objectives. These materials have different coefficient of thermal expansion; therefore on/off cycles give rise to alternating stress at material interface.

Because too high operating temperature can introduce so many failures, removal of heat has played a key role in ensuing the reliability from chip to system level in electronic packaging. Heat build up is becoming one of the major limitations to creating tomorrow's more compact, complex micro electronic devices. Thermal management in LTCC technology is more severe in that LTCC has very low thermal conductivity. Table 1.2 list the thermal conductivities of some commonly used ceramics in electronic packaging.

\begin{tabular}{|c|c|}
\hline Ceramics & $\begin{array}{c}\text { Thermal conductivity } \\
(\mathrm{w} / \mathrm{m}-\mathrm{k})\end{array}$ \\
\hline $\mathrm{Al} 2 \mathrm{O} 3$ & 20 \\
\hline $\mathrm{AlN}$ & 230 \\
\hline $\mathrm{SiC}$ & 270 \\
\hline $\mathrm{BeO}$ & 260 \\
\hline $\mathrm{LTCC}$ & $3-4$ \\
\hline
\end{tabular}

Table 1.2 Thermal conductivities of some commonly used ceramics in electronic packaging 
It should be note that LTCC materials have the lowest thermal conductivity compared with other ceramics used as substrate. Although it is better that organic laminate material (around $0.1 \mathrm{w} / \mathrm{m}-\mathrm{k}$ ), LTCC is not suit for applications where thermal management is an issue.

\section{Introduction of heat pipe and heat spreader}

A heat pipe is a closed-loop cooling device wherein heat is transferred from the "evaporator" end to the "condenser" end of a sealed tube using the latent heat of vaporization as the principal means of energy transfer. Taking advantage of high latent heat of vaporization, heat pipe is one of the most efficient heat transport systems known today.

The heat pipe consists of a sealed container, a wick structure and a small amount of working fluid, which is in equilibrium with its own vapor. Typically a heat pipe can be divided into three sections: evaporate section, adiabatic section and condenser section. Heat applied to the evaporate section by an external source is conducted through the container wall and the wick structure, where it vaporizes the working fluid. When that happens, the liquid picks up the latent heat of vaporization. The resulting vapor pressure drives the vapor through the adiabatic section to the condense section, where it condenses and gives up the latent heat of vaporization. Thus heat is moved from the input to the output end of the heat pipe. The capillary pressure created by the menisci in the wick structure pumps the condensed fluid back to the evaporate section, and the process begins again. Fig 1.1 illustrates the working principle of heat pipe. 


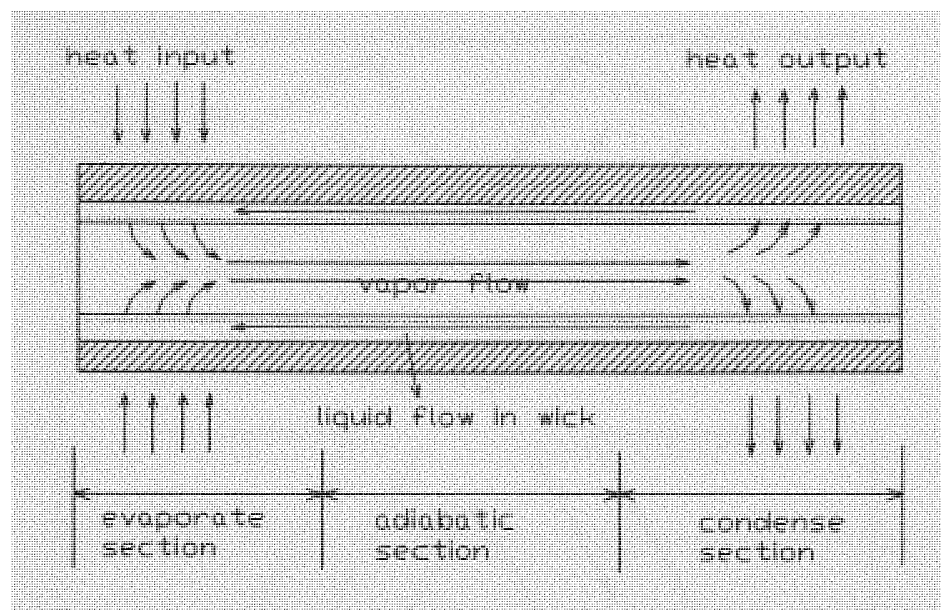

Fig 1.1 Illustration of the working principle of heat pipe

The benefits of heat pipe lies on many aspects.

1. Large amount of heat can be transported through small cross sectional area over a considerable distance without additional power input to the system

2. Easy to design and manufacture.

3. Small end-to-end temperature drop.

4. Can control and transport high heat rate at various temperature level.

Due to the enormous latent heat of vaporization of some fluids, the capabilities of heat pipes can be enormous, easily 10,000 times that of solid copper rods. In addition, the difference in temperature between heat source and the condenser can be as low as a few degrees. Therefore heat pipe can be used as a very efficient means to distribute heat from a concentrated heat load to a surface area many times greater than the original, thus reducing the overall component temperature. This is the principle under which the heat spreader involved in our investigation works. 


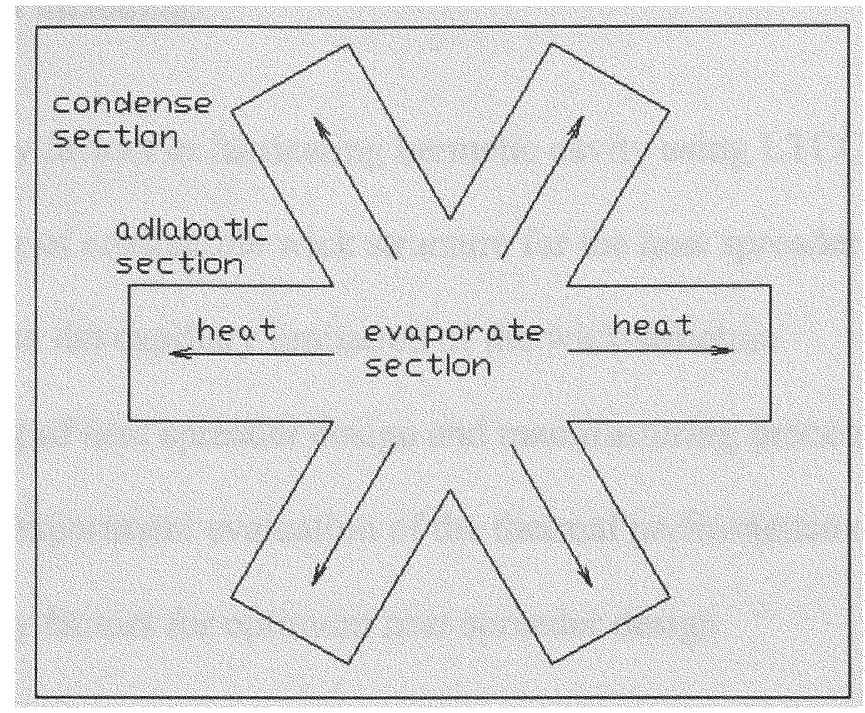

Fig 1.2 Illustration of a heat spreader

Fig 1.2 shows the illustration of a heat spreader. Essentially it can be deemed as an array of heat pipes shared with a common evaporator section. The heat spreader can be embedded in a LTCC substrate with the heat source mounted on the center of the heat spreader, which act as the evaporator section of the joined heat pipes. The heat pipes then distribute the heat to the surrounding area, acting as a "superconductor" of heat.

\section{Objective of the research}

The primary objective of this project is to fabricate a prototype heat spreader using LTCC technology.

This prototype heat spreader is meant to demonstrate validation of the concept of integrate heat spreader into LTCC substrate. With this advanced thermal management system, LTCC technology will be suit for the high power density application. 
Specific objectives including:

1. Identify key factors in fabricating hermetic cavity using LTCC

2. Developing of compatible wick structure for the heat spreader

3. Characterize the capillary limitation of the wick structure

4. Developing of heat spreader design and manufacturing process

5. Perform a experiment evaluation of the thermal performance of the heat spreader

6. Identify key factors for optimum heat spreader design

\section{Significance of the research}

The research is unique in that the embedded heat spreader is the first of its kind that is fabricated using LTCC technology. The heat spreader operates on a principle similar to heat pipe. Taking advantage of high latent heat of vaporization, the integrated heat spreader can greatly improve the effective thermal conductivity of LTCC substrate and thus provide very high level of cooling technology for LTCC application. The heat spreader is also significant in that it has a novel porous sintered silver powder wick. The new wick improved the permeability of sintered powder wick while maintain the advantage of high capillary pressure. Furthermore, due to the complex nature of the heat spreader structure, technique problems such as sagging, cracking and leaking are unavoidable. Successful solution to these problems will lead to better understand on how to make complex three-dimension structure using LTCC technique. These structures can be used not only in cooling systems but also in complex sensors and Microsystems. 


\section{II.Literature review}

\section{Review of mini-scale heat pipe}

The micro heat pipe is one of the most promising technologies for the achievement of high local heat removal rates and uniform temperatures in electronic packaging. Therefore many scientists have conducted research in this field. Cotter $(1984)^{2}$ was recognized as the first scientist who proposed the micro heat pipe concept. He defined the micro heat pipe as a heat pipe in which the mean curvature of the liquidvapor interface is comparable in magnitude to the reciprocal of hydraulic radius of the total flow channel. Based on Cotter's concept, early research for miniature heat pipe was conducted ITOH Research \& Development Corporation, Babin et al, Wu and Peterson (1990) and Plesh et al. ITOH manufactured flat micro heat pipes with dimension of $0.6(\mathrm{~W}) * 0.1(\mathrm{~T}) * 25(\mathrm{~L}) \mathrm{mm}$, using silver and copper. They obtained a heat transport rate of $0.3 \mathrm{w}$, which correspond to heat flax on the order of $1 \mathrm{~W} / \mathrm{cm}^{2}$. Babin et al. ${ }^{3}(1989)$ tested a trapezoidal heat pipe with dimension of $1(\mathrm{w})^{*} 1(\mathrm{~T})^{*} 57(\mathrm{~L}) \mathrm{mm}$. Their heat pipes had no wick structures inside, only using the four corners of the flow channel to provide the capillary pumping. Obviously the capillary force is not large enough to pump sufficient amount of fluid back to the evaporator section. The maximum heat transport rate was about $0.5 \mathrm{w}$ at working temperature of 60 to $70{ }^{\circ} \mathrm{C}$, which corresponds to heat fluxes of about $1 \mathrm{w} / \mathrm{cm}^{2}$. Wu and Peterson (1990) ${ }^{4}$ tested a flat miniature heat pipes. The maximum heat transport rate was about $1.3 \mathrm{w}$, which corresponds to a heat flux of $5 \mathrm{w} / \mathrm{cm}^{2}$. Plesh et al. $(1991)^{5}$ fabricated and tested micro heat pipes with very fine axial grooves on the 
surface of the inner wall, the maximum heat flux were much higher at $60 \mathrm{~W} / \mathrm{cm}^{2}$ vertically and $35 \mathrm{~W} / \mathrm{cm}^{2}$ horizontally. Lee et al. $(1992)^{6}$ and Chen et al. (1992) conducted visual study to demonstrate the two phases flow patterns. Zhou et al. $(1992)^{8}$ found that while the cooling air temperature had important effect, the maximum operating power of the micro heat pipes may be limited by their capillary limit. Li et al. $(1992)^{9}$ found that the effects of the amount of the working fluid on heat transfer and the influence of entrainment on the capillary limitation are more important for small diameter heat pipe than large ones.

Cao et al. (1993) ${ }^{10}$ reviewed and summarized the operating limitation of miniature heat pipes. In 1997, they fabricated and tested two copper-water miniature heat pipes with an axial grooved wick structure ${ }^{11}$. The maximum heat flux of $20.6 \mathrm{~W} / \mathrm{cm}^{2}$ was obtained. Gao et al. (1999) ${ }^{12}$ applied numerical optimization technologies to optimize Cao's heat pipes. They found that the optimized heat pipe had a maximum capillary limitation of 50W and 70W in horizontal and vertical orientation respectively.

Koichiro Tke et al. (2000) ${ }^{13}$ fabricate and tested a roll bond heat pipe. By using Roll bonding process, they bonded two individual aluminum plates together into one plate. The heat pipe passage is created between these two bonded plates by printing a pattern with release lubricant to prevent bonding. The roll bond heat pipe does not have the conventional wick structure such as groove or screen. The capillary effect is provided by the arch-shaped flow passages. The authors presented prediction data on the maximum capillary limit and investigated the optimum working fluid charge volume and number of capillary loops for the heat pipe. They concluded that their model reasonably predict the 
capillary limit of the roll bond heat pipe. Also they found that the optimum charge volume for roll bond heat pipe is $25 \%$ and the eight-loop channel design has the best thermal performance.

Z. Jou Zao et al. (2001) ${ }^{14}$ discussed an advanced heat pipe mechanism that has the potential of achieving heat flux over $200 \mathrm{w} / \mathrm{cm}^{2}$. This advanced heat pipe mechanism uses thermal driven pulsating two-phase flow to achieve high heat flux capacity and low thermal resistance. The authors developed theoretical model to predict the thermal performance of the pulsating heat pipe. Also they fabricated a concept prototype heat pipe using copper and glass. They reported that the heat pipes could dissipate over $200 \mathrm{w} / \mathrm{cm}^{2}$ without signs of evaporate dry out.

Some scientists focus on the application of miniature heat pipe in cooling electronic devices. Kenichi Namba et al.(2000) ${ }^{15}$ evaluated the thermal properties and reliability of the heat pipe for cooling notebook computer. Their thermal results show that the temperature difference between evaporator and condense section at the maximum heat transfer rate was within $2-3{ }^{\circ} \mathrm{C}$. The long term accelerated test of miniature heat pipe was performed by test the life test up to 20000 hours. Their conclusion is that miniature heat pipe is extremely efficient for cooling notebook computers.

I.yusuf et al. $(2000)^{16}$ tried to manufacture an optimal thermal solution, combing the heat pipe and fold fin heat sink technology. Unlike the current extruded heat sink technology, they integrated the fold fin heat sink with heat pipe. Their results show a 
heat-sink to ambient resistance of $0.20 \mathrm{C} / \mathrm{W}$, which is four times better conventional heat sink.

Seok Hvan Moon et al. $(2000)^{17}$ performed experiment study on miniature heat pipe with a woven-wired wick. They fabricated heat pipe with diameters of $3 \mathrm{~mm}$ and 4 $\mathrm{mm}$, all have a woven-wired type wick. The authors thoroughly studied the effects of various factors on the operational performance of heat pips, including charging ratio, pipe length, evaporator and condenser length, inclination of installation, number of wick strands, thermal loads et al.. they concluded that there is a high possibility of application if one or two miniature heat pipes are installed for cooling CPU with power bigger than $10 \mathrm{~W}$.

Rengasamy Ponnappan et al. (2000) ${ }^{18}$ investigated a novel screen wick design suitable for miniature heat pipes. Their major goal was to develop a new design, which is easy to fabricate and have improved performance. Unlike the ordinary machine methodology such as metal rolling and cutting, the authors use a commercially available metal wire cloth stock to make the wick structure. The wick was then inserted into a straight rectangle copper heat pipe. The heat pipe use distilled water as the working fluid. The authors investigated the heat transfer characteristics of the heat pipe with various charging ratio, at various heat rates, and different operating temperature. The experiment data was then compared with the literature data. Their heat pipe demonstrated $115 \mathrm{w} / \mathrm{cm}^{2}$ at a temperature difference of $370 \mathrm{C}$. Comparing under similar operating conditions the literature data show a q-max of $150 \mathrm{w} / \mathrm{cm}^{2}$ at unknown temperature difference. Hence 
they concluded that their simple and affordable wick design could replace the difficult and expensive fine groove machining process without compromising performance.

Besides experimental research, many scientists have conducted numerical analysis and theoretical research of miniature heat pipe.

The first analytical mode for micro heat pipes was introduced by Cotter(1984) ${ }^{2}$. This mode assumed several simplified assumptions:

1. The capillary pressure gradient was assumed to be the driving force of the liquid flow.

2. The liquid-vapor interface velocity was assumed to be zero

3. The vapor flow region was assumed to be both laminar and incompressible

Later, it was believed that the mode significantly over predicated the maximum heat transport capacity. The over prediction is due to the assumption of zero velocity at the liquid-vapor interface. Since the vapor velocity is much higher than the liquid velocity. The resistance on the liquid-vapor interface due to the counter flow retards the liquid velocity; Khrusher and Faghir (1994) ${ }^{19}$ investigated the effect of the shear stress by numerical analysis. Both demonstrated that neglecting the shear stress can lead to an overestimation of the maximum heat transport capacity. J.M Ha $(1998)^{20}$ believed that the assumption of a fixed evaporator section also lead to the over estimation. To developed a more accurate predict tool, They modified the model by incorporating the effects of the temperature intrusion of the evaporating region into the adiabatic section of the heat pipe; 
also they modified Cotter's original expression for the liquid flow shape factor to include a new analytical derivation of the dimensionless shape factor.

Peterson and Ma (1999) ${ }^{21}$ developed a detailed mathematical model for predict the heat transport capacity and temperature gradient in a micro heat pipe. Their mode indicated that the temperature drops occurring in the evaporator section is considerably larger that those occurring in the condenser, and with increase in the input power, both temperature drops increase. In order to verify the model, they conduct experiment investigations. They reported good agreement between the experiment results and analytical model, thus they concluded that since the temperature drop between condenser and evaporator increase significantly, their micro heat pipe couldn't transfer high level of heat flux.

\section{Review of fabricating 3-D structure using LTCC}

One of the big advantages of LTCC is that it is flexible and easy to be handled and manufactured in green state. Three dimension structures like hole, cavity and channel can be formed in green LTCC tape using conventional mechanical methods such as cutting, drilling and punching et al.; therefore make it possible to fabricate embedded liquid cooling systems in LTCC substrate.

However, due to the stress produced by the high-pressure lamination process and the material flowing and shrinking during the sintering process, mechanical failures such as crack and sagging often occur when making complex structure using LTCC. Therefore some researchers have investigated in the fabricating issue of LTCC. 
Espinoza et al. (1998) ${ }^{22}$ fabricated meso-scale LTCC structure using conventional LTCC process. They quantified the sagging and deformation in 3-D LTCC structures. They also explored several strategies to seeking control of sagging. In their investigation, the authors utilized Dupont 951 green tape as substrate material. The sagging of LTCC was measured optically in the green material after lamination. They found that the extents of the sagging in both green and fired ceramic tapes are function of the size of the suspended structures. The deformation was insignificant for feature sizes smaller than 16 mils. To control sagging, these researchers tried two strategies: screen printing tensile over layer and using sacrifice insert materials. They found that both strategies might be effective to control sagging.

Since the authors found ways to control the sagging, their method is a good reference to our research. However it should be noted that the feature size in their investigation is much smaller than the one discussed in this investigation. The sample structure consists of only about 3-4 layers, with the width of about $1.2 \mathrm{~mm}$. Since sagging is a function of the feature size, the problem of sagging in our investigation is much more serious. Also their sample structures did not include vias, which is an indispensable feature of the heat spreader in this investigation. The methods mentioned above may not adoptable to complex structures with both via and cavities.

Thelemann. et al. (1999) ${ }^{23}$ studied on making liquid cooled LTCC substrate for high power application. They use Nd:Yag laser to fabricate micro channels in the LTCC green tape. The height of this investigated micro channels are 500um in green state. In order to investigate the relationship between feature size and sagging, various samples were fabricated with various width. Also they studied the influence of lamination 
pressure on sagging. the authors didn't propose method to control sagging, they believed that, due to the higher requirement on mechanical component, the integration of liquid cooling system in substrate is an interesting but limited future of multiplayer ceramic.

Rebenklau et al. $(2000)^{24}$ also examined the possibility to realize "fluidic circuit board" using LTCC. Their main goal is to combine LTCC manifolds with silicon components to develop more complex fluidic modules, which has combined electrical and fluid functions. To demonstrate this concept, the authors developed a microscope chamber. The microscope chamber consists of a LTCC manifold, which contains the fluid channels with width varying in a range between 800 um to $1.5 \mathrm{~mm}$. The total length of the integrated channels is about $60 \mathrm{~cm}$ on three different fluid layers. The chamber is connected to different inputs by two controlled channels, where the flow rate is adjusted between $0 \mathrm{ul} / \mathrm{min}$ to $50 \mathrm{ul} / \mathrm{min}$ by one micro valve and one flow sensor. All the channels are made by conventional LTCC process. The chamber is also equipped with a buried thick film resistor, which is used as heating element. After assembling, several measurement were done to evaluate the function of the chamber. Their conclusion is that complex system can be developed in combination with electrical and micro fluidic components.

Kita et al. $(2000)^{25}$ also investigated on how to make three dimension structures in LTCC. Their researches concentrate on making channels and cavities. The influence of lamination process parameters on cavities and channels was studied. The results agree with other researchers. That is, the size of the cavity play big role in sagging. Also, lamination pressure is a key parameter to determine the quality of the embedded cavity or channel in LTCC. 
Since LTCC is easy to be handled and manufactured in green state. Mechanical methods are usually used to make structures in LTCC. However, other methods have been investigated by scientists to develop faster and more cost-effective process.

Taylor et al (2001). ${ }^{26}$ tried to combine photo-etching technology in LTCC fabrication process. They developed a new photo imaginable LTCC tape. This tape can be exposed and pattered using the standard photo-etching process. Espinoza et al. $(2000)^{27}$ also tried to develop a new patterning technique, but in a completely different way. Their goal is to develop a batch fabrication method based on laminable dry photo resist. Their new process includes five steps: partial sintering, resist lamination, resist UV exposure, developing and etching. It is well known that ceramic is hard to be etched. In order to combine pattern technology with LTCC, the authors introduced a new concept called "partial sintered tape". What they did is remove the tape at an early stage of the viscous sintering process. The resulting "partial sintered" tape is made of grains coated by thin glass neck. Since the glass is rich in silicon, it can be subjected to etching. The patterning is done by laminating the dry photo resist on the glass-ceramic substrate and exposing using UV light. After developing and etching, the partial sintered tapes are then fully sintered to get the final structure.

Zampino ${ }^{28}$ did a lot of work in embedding heat pipe into ceramic substrate. Their work has been the first of its kind. Unlike this research, their heat pipes are embedded in HTCC. Due to the relatively high thermal conductivity $(20 \mathrm{w} / \mathrm{m}-\mathrm{k})$ compared with LTCC (3-4 w/m-k), there is no need to use thermal via. Their research concentrate on the fabrication and design issue of miniature heat pipes that are compatible with co fired ceramics. Prototype miniature heat pipes were fabricated to provide validation of the 
concept. A lot of work was done to determine the design parameter value and ranges for optimum heat pipe design, which are compatible with current thermal management and packaging requirements. The heat pipe channels were fabricated at Coors Electronic Packaging Inc, Chattanooga TN. The channels have a width of $2.4 \mathrm{~mm}$ and $3.9 \mathrm{~mm}$. All channels had length of $101.6 \mathrm{~mm}$. The heights of the channels were varied by changing the numbers of layers used in substrate. Chanels with height of $0.36,0.71,1.30$ and 1.78 were fabricated. The top and bottom layer of all the heat pipes are $0.6 \mathrm{~mm}$. The authors used standard End-milling and routing techniques to fabricate Axial grooved wick structures in green tape of top and bottom surface of heat pipe. Additionally they developed axial grooves along the sidewalls of the heat pipe. The thermal performance of the heat pipes was then evaluated. The evaporator section of the heat pipe was insulated to prevent heat loss. A kapton foil heater was adhered to the heat pipe acting as the heat resource. The thermal load was controlled by using a variable transformer to adjust the $\mathrm{AC}$ across the foil. The adiabatic and condenser section of heat pipe was exposed to ambient condition, which was cooled by natural and forced convection.

The temperature distributions along the heat pipes were tested with various thermal loads., in both vertical and horizontal orientation. To provide a baseline for measuring the performance of the heat pipe, the heat pipe was also tested without any working fluid, which means heat was transferred only by conduction through the shell material. The test results showed that the heat pipe have an effective thermal conductivity of over $3000 \mathrm{w} / \mathrm{m}-\mathrm{k}$. While the overage effective thermal conductivity for the heat pipe's shell was found to be $32.5 \mathrm{w} / \mathrm{m}-\mathrm{k}$. That means the heat pipe have an effective heat conductance 100 times higher than the alumna it replaced within the substrate. 


\section{III.Development of major components of heat spreader}

\section{Thermal via}

As mentioned in the first chapter, LTCC has very low heat conductivity. That means, when using LTCC as the shell material, even through the hat pipe can distribute the heat efficiently we still need some method to lower the heat resistance between the heat resource and the wick. One of the simple and effective methods is using thermal vias.

Normally, vias are used in multiplayer circuitry technologies for electronic connection between conductors in different layers. In LTCC technology, vias are formed by creating via holes in green LTCC tape. These via holes are then filled with via ink. The via ink is mainly made of high conductivity metal, such as silver. The composition of the via ink are well adjusted so that their shrinkage rate, thermal expansion rate are matched with LTCC. Since vias are made from metal, their heat conductivity is much higher than LTCC. Hence another important use of via is to improve the heat conductivity of LTCC substrate. This kind of via is filled with a good thermal conductor material and do not necessarily have any electronic function. Since their solo use is for thermal management, they are called thermal via.

In our heat spreader, thermal vias are used in the top and bottom surface of the embedded heat spreader. The thermal vias on the top surface can help to conduct heat from heat resource to the evaporator section. The thermal vias on the bottom are designed to transfer heat from vapor condensation to the large surface for heat removal. In this 
section, the fabrication and design of thermal via are investigated to identify the key factors and find the optimum parameters.

\section{Fabrication procedure for thermal via}

\section{Forming via holes}

Via are made by two steps, via holes forming and via filling. In LTCC technology, via holes can be created on the green tape by mechanical methods, laser cutting or photoligraphy. In this research, we choose the most commonly used mechanical method.

The via holes are drilled by using an OZO SP model 17 manufacture system. This model is a numerically controlled micro-machining system capable of performing operations such as drilling, routing, etching and end milling with a precision of 0.001 inch. It is equipped with two high-speed spindle (100k) systems and a set of NC machining tools (bits and cutters).

Although LTCC offer simple handling, correct procedure is very important to get high quality via holes. The conventional procedure of via in LTCC technology is punching or drilling via holes on each layer of green tape. Then the tapes are stacked, aligned, and laminated. After that, the vias are filled with via ink In our investigation, it was found that this process could be adapted to be more suitable for fabrication of thermal via.

The major drawback of the conventional method is that it is not cost effective. Since each layer is processed separately, the same pattering has to be repeated on each 
layer, thus cost multiple times and cost. Also additional consideration in alignment is needed to control the quality of via.

Fig 3.1 show a via with bad alignment. The rough wall of this via hole may bring trouble to via filling. Since the viscosity of via ink is not high, it may be difficult to flow into the rough edges. That means the via cannot be completely filled. The tiny unfilled space may be the source of micro crack in the flowing sintering process.

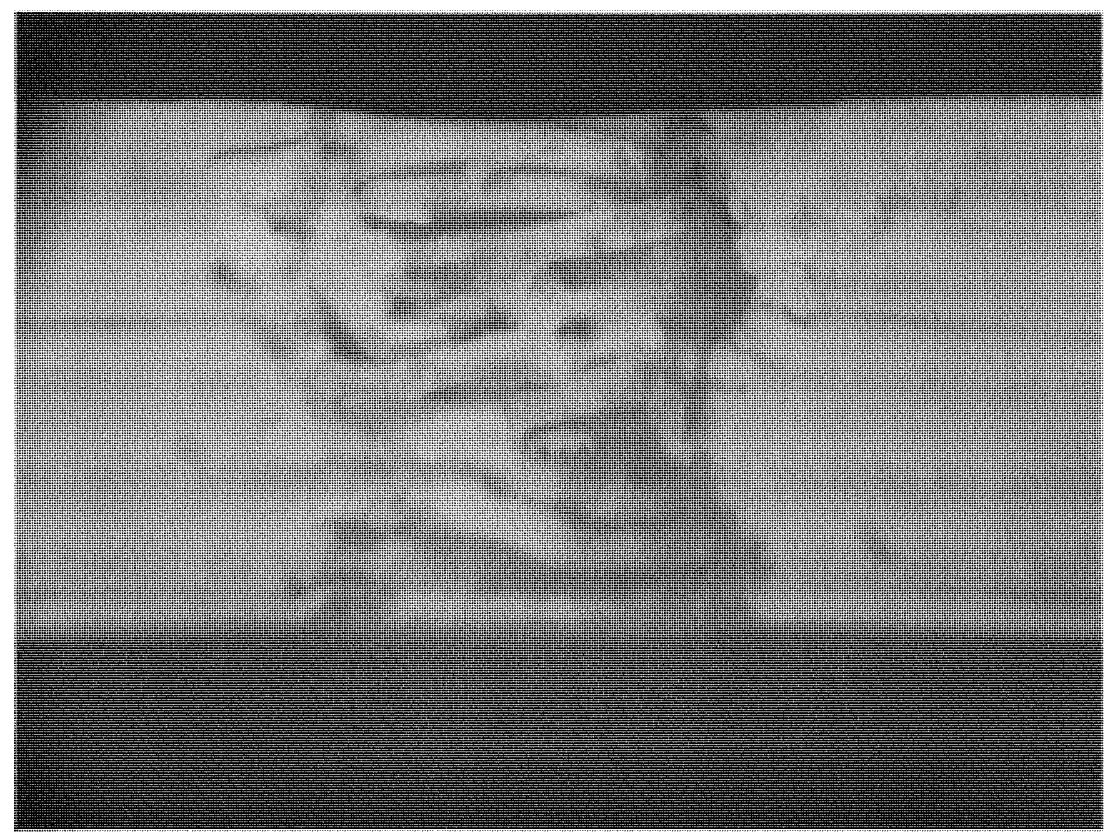

Fig 3.1 Cross section of a via hole with bad alignment

Another problem of the conventional process is that the high lamination pressure may introduce shape distortion of via hole. The purpose of lamination is to bind the individual tapes together. The material will flow under the high lamination pressure. This material flow may leads to the distortion at the edge of the via holes. Fig 3.2 shows how a via hole change its shape after lamination. This distortion can also bring trouble to the next via filling step. 


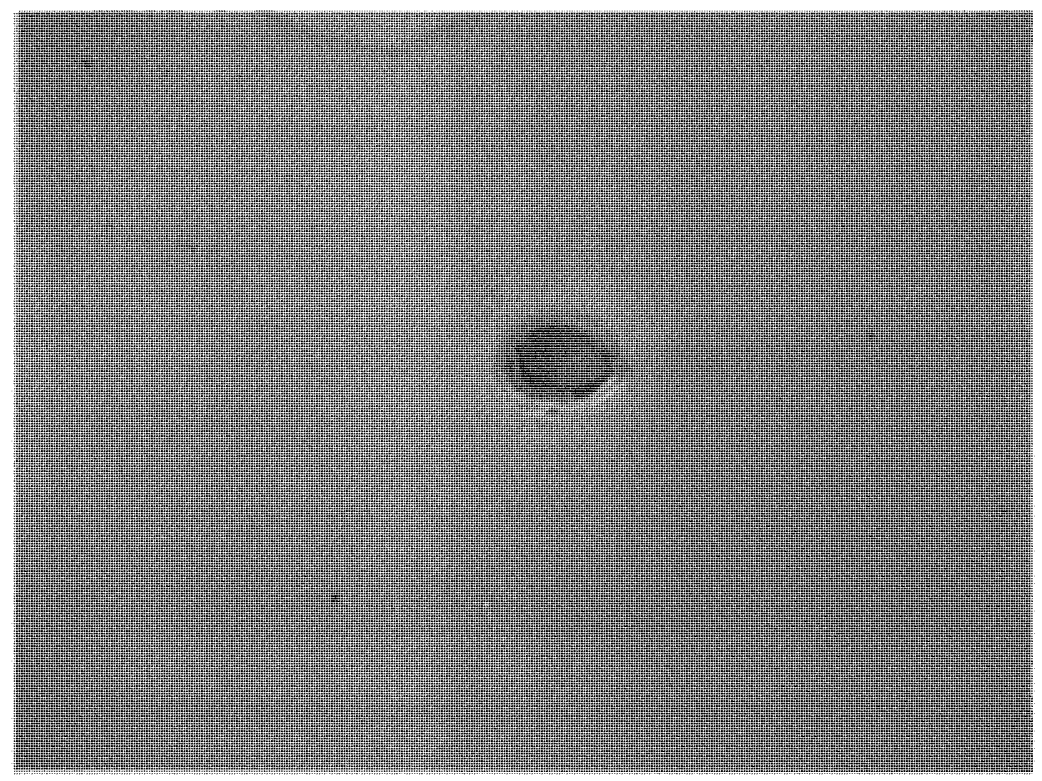

Fig 3.2 Distortion of via hole after lamination

To eliminate these technical problems, the simplest solution is laminating the layers together before forming via holes. Since thermal via holes are through holes, we can drill the thermal via holes after pattering the electrical circuit and lamination. Because the individual layers are laminated into a whole part, all the via holes on different layers can be drilled in one step and thus save a lot of time and cost. Also no additional alignment steps are needed because the holes are drilled at the same time. In addition, the material will flow and get densification before holes are drilled, therefore totally eliminate the shape distortion. Fig 3.3 show a via hole drilled after lamination. Fig 3.4 show its cross section. Compared with fig 3.2 and fig 3.3, it is clear that the quality of the via hole is much better in that it has no alignment problem and shape distortion. 


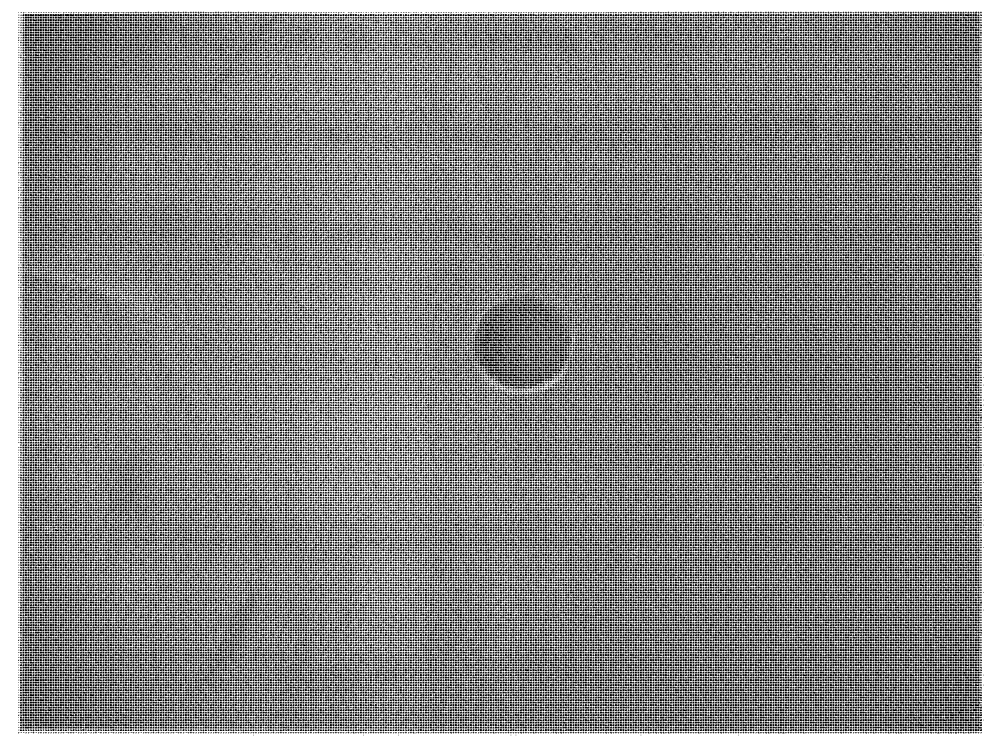

Fig 3.3 Via Hole drilled on pre-laminated piece showing no shape distortion

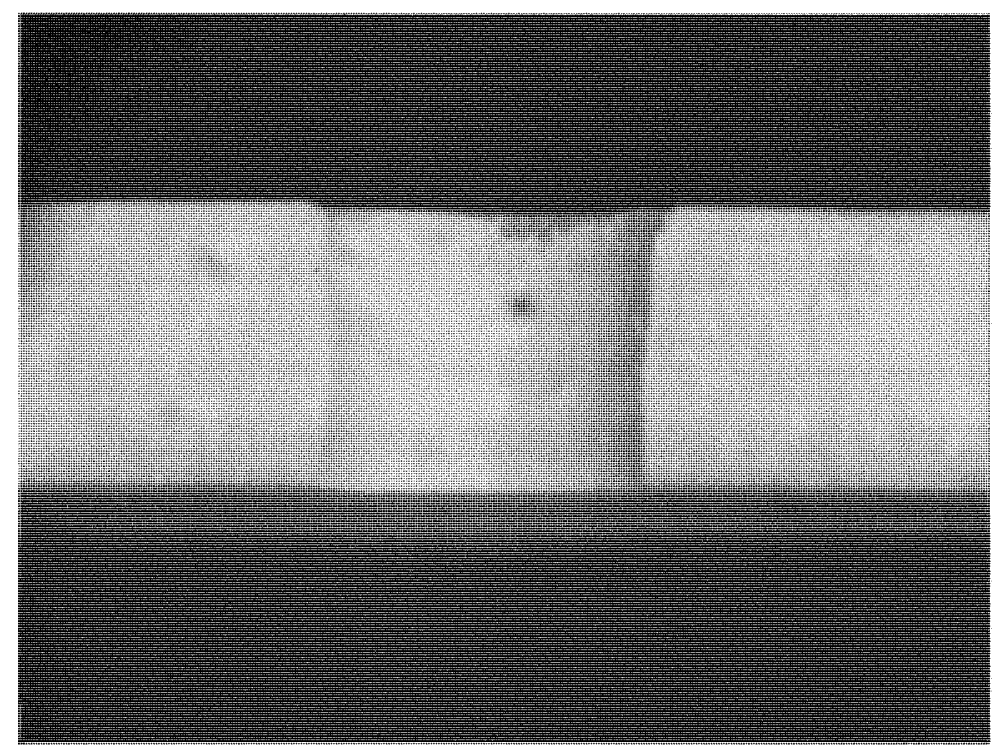

Fig 3.4 Cross section of the via hole drilled on pre-laminated piece

Via filling

Via holes are filled by via ink. Via filling is performed by using a conventional thick film screen printer. Vacuum, through a porous stone is used as an aid to via filling 
along with green sheet attached to the tooling fixture. Via ink is printed across the substrate by a blade, while the vacuum suck the ink into the via hole. Fig 3.5 illustrate how the via is filled by the using a conventional thick film screen printer.

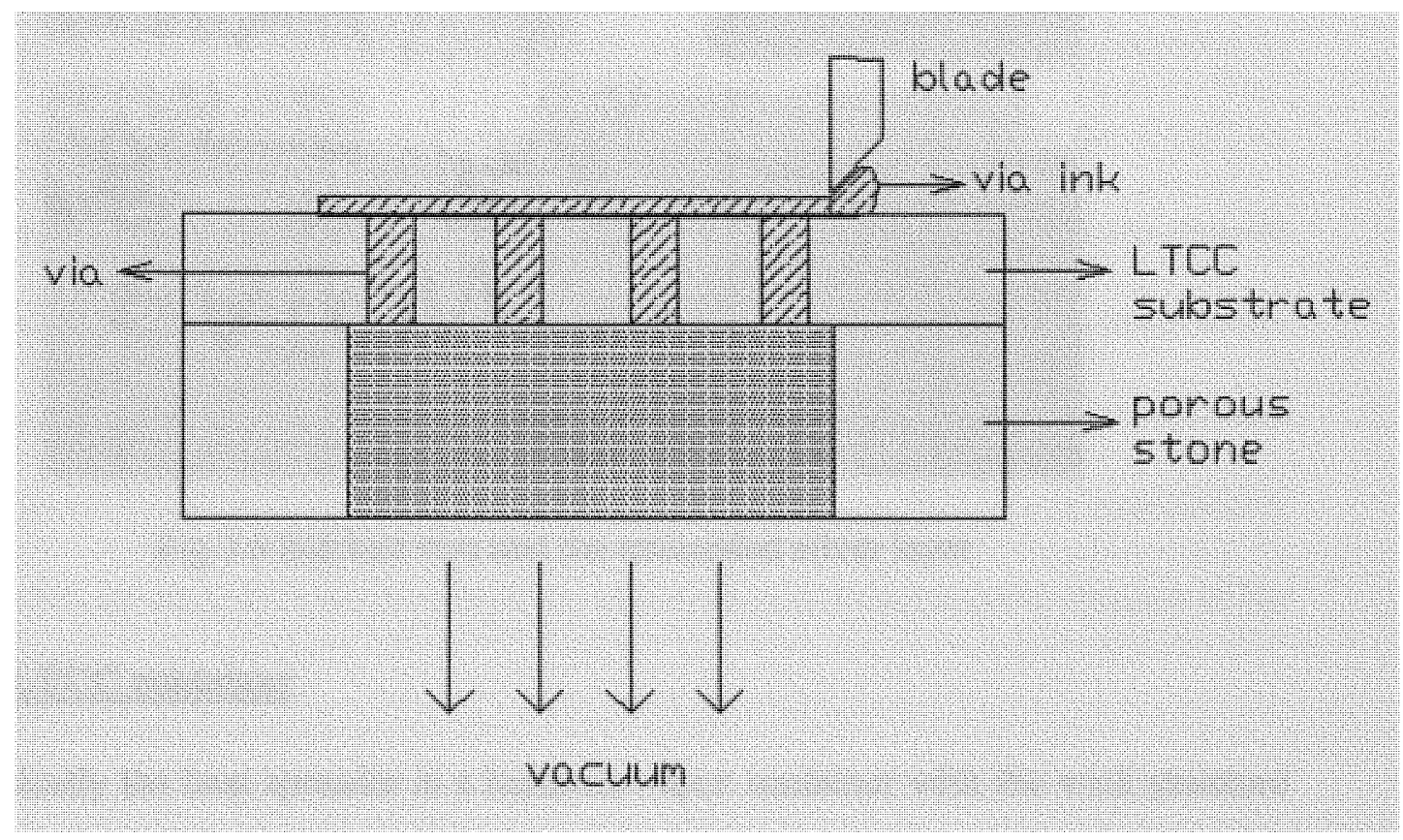

Fig 3.5 Illustration of filling via using extrusion via filler

After filling, vias are put into a box oven to be dried at $120^{\circ} \mathrm{C}$ for 5 minutes.

During the investigation, it was found that the thermal via could be stacked instead of through the tape to reduce the possibility of leakage from via. However, the thermal conductivity of stacked thermal via is lower than through hole thermal via. To solve this problem, a layer of via ink was printed between the stacked interfaces to act as a spreader plate of heat. Fig 3.6 shows the stacked vias and the silver layer 


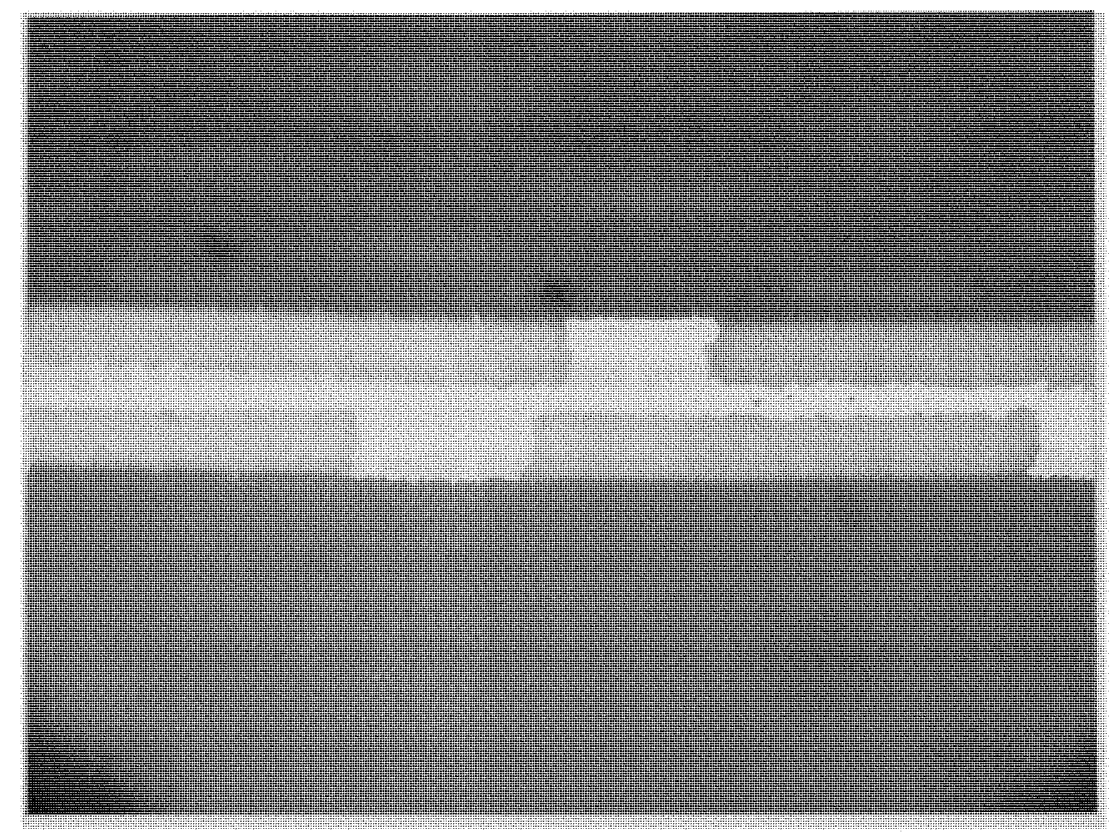

Fig 3.6 Stacked vias and the embedded silver layer

\section{Hermetic LTCC container}

Basically the heat spreader is a hermetic vapor container with the wick structure inside. The function of the container is to isolate the working fluid from the outside environment. It has to therefore be leak-proof, maintain the pressure differential across its walls, and enable transfer of heat to take place from and into the working fluid. In this investigation, the container is made by fabricating a hermetic cavity inside a LTCC substrate. In LTCC technology, it could be done by cutting slots on several green tapes, stacking theses tapes with the slots together forms a cavity within the substrate. Then the whole part is laminated and sintered into final ceramic. Due to the complex nature of the heat spreader structure, technical problems such as crack sagging and leaking are unavoidable. To solve these problems, the conventional LTCC process has to been modified. For this purpose, key parameters of the LTCC process are studied. Also 
several possible methods are investigated to select out the most suitable process for fabricating the hermetic cavity in LTCC substrate.

\section{Control of crack}

Cracking is a common failure in ceramic product. Ceramic is brittle compared to metals because the ionic nature male dislocation motion extremely difficult. LTCC is more subject to cracking because the high-pressure lamination process introduces various green density to the ceramic part. This situation may become worse when via or cavity were presented in the LTCC substrate, which can lead to greater uneven density and thus inhomogeneous shrinkage through the substrate. In this sense, cracking is an unavoidable problem in this investigation because both via and cavity are indispensable features of the heat spreader.

Detailed investigation of cracking in ceramic need a thorough investigation of density distribution and flow behaviors of LTCC during the lamination and sintering process, and therefore is beyond the scope of this research. However possible causes of cracks and methods to control them have been studied. It was believed that the following issues are some possible reasons to occur in LTCC substrate:

1. High pressure during the lamination process cause various density in the substrate.

2. The unsupported layers above the cavity in the LTCC substrate may get uneven density distribution during lamination and therefore leads to local shrinkage difference through the substrate. 
3. Although the via ink is shrinkage matched with LTCC, the interface between them is sensitive and thus subject to cracking. This situation could be worse when the thermal vias are located on the top and bottom layers of the cavity, because of the uneven stress distribution in these unsupported layers.

4. Cracks may occur during sintering when improper sintering profile is used. Also, cracks that occurred during the lamination process usually propagate in sintering process.

In the green state, LTCC tape is very flexible and workable. Normally, no crack will occur during mechanical process. However, since LTCC tapes have to be laminated together under high pressure and sintered at $850-875{ }^{\circ} \mathrm{C}$, cracks can be introduced by material flow and shrinkage in these two steps. Therefore these two steps are the key processes in controlling cracks in LTCC.

The lamination process is the most susceptible cause for cracks. Even cracks appearing after sintering may be the propagation of the existing micro cracks during lamination. When green ceramic tape is laminated, the tape material undergoes viscoplastic deformation under the lamination stress. There are both compressive and tensile stresses existing in the tape. In the z-axis, the entire tape stack has a uniform compressive stress, which gives the z-axis shrinkage. This compressive stress also makes the density of the tape material increase rapidly. While in the $x-y$ plane, there is a small expansion of the material, hence indicating a tensile stress state in the $x-y$ axes. Normally, the compressive stresses in the z-axis and the tensile stresses in the $x$-y plane are relatively uniform throughout the tape stack, resulting in a flat, highly compacted monolithic structure. However, when lamination pressure is too high or the size of the 
piece is too large, the tensile stress in $x-y$ plane can lead to cracks. These cracks usually occur at the edge of the tape, because of the free boundary condition. Fig 3.7 show a sample with small cracks on the edge. It was found that, the simplest way to eliminate these "edge cracks" is cut the edge off after lamination. Another samples was fabricated use the same procedure but the edge is cut off after lamination, no cracks was found on the edge

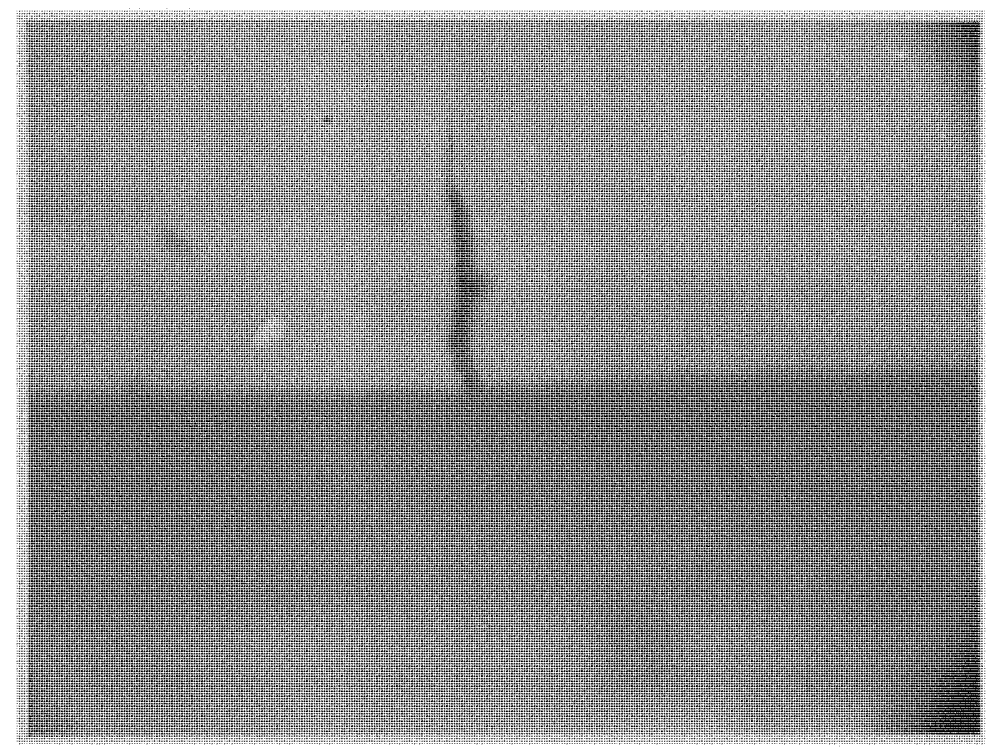

Fig 3.7 Sample with small cracks on the edge

The inhomogeneous density result from the lamination can lead to cracks, especially when different material was embedded in LTCC. Fig 3.8 illustrates how the insert material can result in inhomogeneous density. 


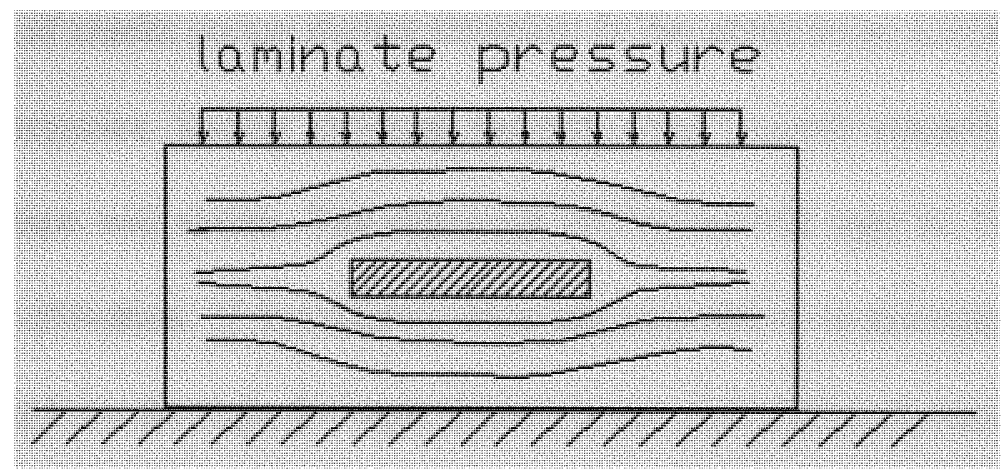

Fig 3.8 Illustration of how insert material can result in inhomogeneous density

When pressure is applied, the tape will have a compressive stress in z-direction. The tape material will then undergo viscous-plastic deformation and become densified. However if there are some different materials embedded between the tapes, the compressive stress through the tape is not homogeneous. For example, if the insert material is harder than the tape material, the tape material above and under the insert will sustain higher stress than the surrounding material, and thus flow to the surrounding area. In this case the tape has a higher density in the central area than the surrounding area. The different density will result in mismatched shrinkage during sintering process and therefore may lead to crack between central and surrounding area.

Sintering is also a very important process to control cracks. Cracks appear after sintering may come from different resource. One is the propagation of the existing micro cracks occur in the lamination step. These cracks may be too small to be noticed in the green tape. During sintering, some of these micro crack can even disappear because of the material flow during sintering, but others will propagate. Also cracks may initiate 
during sintering because of the residual stress. Shrinkage mismatches are the most susceptible resource of cracks occurs during sintering. In the green state, LTCC tape has a large volume of organics. During sintering process, these organic materials will be burned off and the tape will shrink. The shrinkage of Dupont 951 tape is: $15 \%$ in $x-y$ plane and $12 \%$ in $\mathrm{z}$-direction. If the density after the lamination is homogeneous the shrinkage will be uniform through the tape. If not, areas with different density would have different shrinkage rate, and thus introduce cracks. Residual stress is another possible cause of cracks. When the temperature profile is too steep, the residual stress may lead to cracks. To release the stress, cracks usually develop along the weakest direction in the material. In our investigation, it was found that crack often develop along the via array, indicating the thermal via array has low resistance to cracks. Fig 3.9 show a crack choose the via array as its develop path.

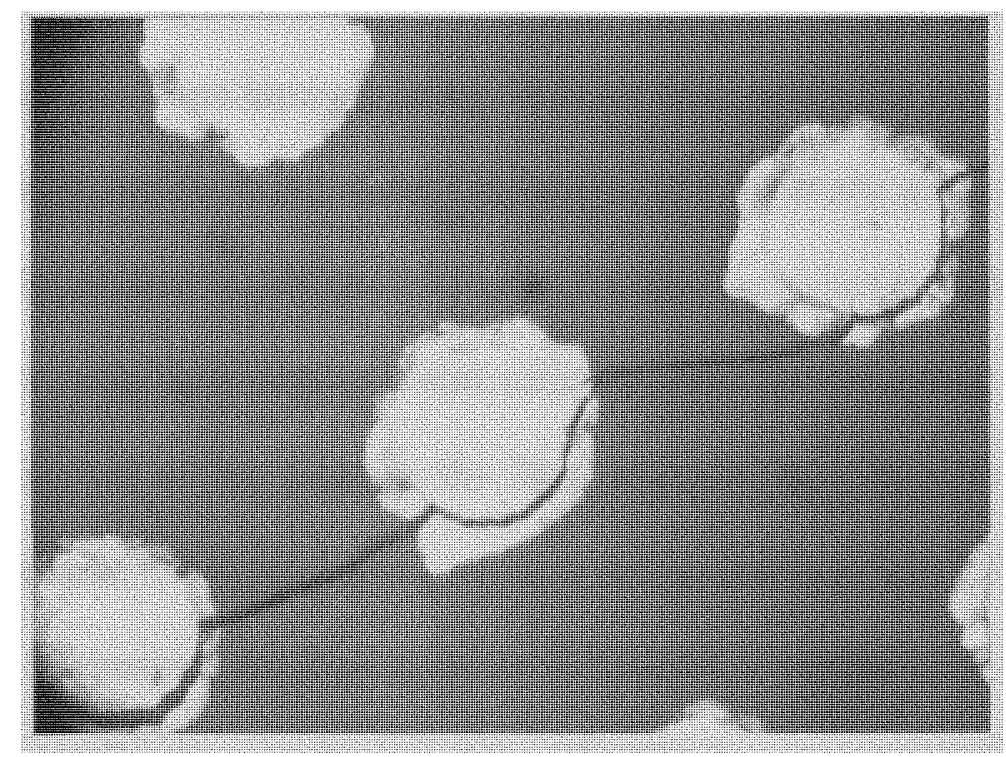

Fig 3.9 A crack develops along the via array 
Since the initiation and propagation of crack are both depend on the stress release rate, an effective and simple way to prevent crack in sintering is slowing down the sintering process. The recommended sintering process for green tape 951 is $3^{\circ} \mathrm{C} / \mathrm{min}$. it was found that cracks may occur if the sample had complex features. In order to minimum the possibility of crack to occur during sintering, $1.5^{\circ} \mathrm{C} / \mathrm{min}$ was use in our investigation.

\section{Control of sagging}

Sagging is a common failure in making cavity or suspended structure in LTCC. This problem occurs mainly during the lamination process. The lamination process is fairly universal among the various manufacturers. For Dupont 951 tape, it is recommended to laminate the green material under a pressure ranging from $1500 \mathrm{psi}$ to $3000 \mathrm{psi}$ at $60-80 \mathrm{C}$ for a period of about 10 minutes. The primary purpose of lamination is bonding the individual tape layers together. Without lamination, the layers may separate from each other during the firing cycle. Lamination also gives the green material a high density, which is required for effective sintering to occur between the ceramic particles in the tape. Further more, high density is also very important for the quality of the ceramic. Without densification of the ceramic, the fired structure may be porous, making the ceramic non-hermetic. Therefore lamination is an indispensable step in LTCC process.

During lamination, the high pressure will cause a compressive stress in the $\mathrm{z}$ direction and a tensile stress in the $x-y$ plane. Usually the green material has a uniform stress distribution through out the tape, resulting in a homogeneous structure. However when laminating a LTCC substrate with complex structure inside such as cavity, the 
stress distributions in the material will not be uniform and therefore leads the sagging to occur. [Bauer et. al, 1997].

As shown in Figure 3.10, when a LTCC substrate with a interior cavity was laminated, the material on the top and bottom layers of the cavity are unsupported. Hence, in these areas, there is no compressive stress state in the z-axis because the lack of the resisting force inside the cavity. The materials in these unsupported regions have no reason to compress in the $z$ direction compare to other region. As the remaining material undergoes $x-y$ expansion due to the compressive load, excess material will flow toward the unsupported regions on the top and bottom of the cavity. This flow of material causes the unsupported regions to gain material without any densification, and hence, the material deforms causing the unsupported material to sag into the cavity. [Zampino, 2001].

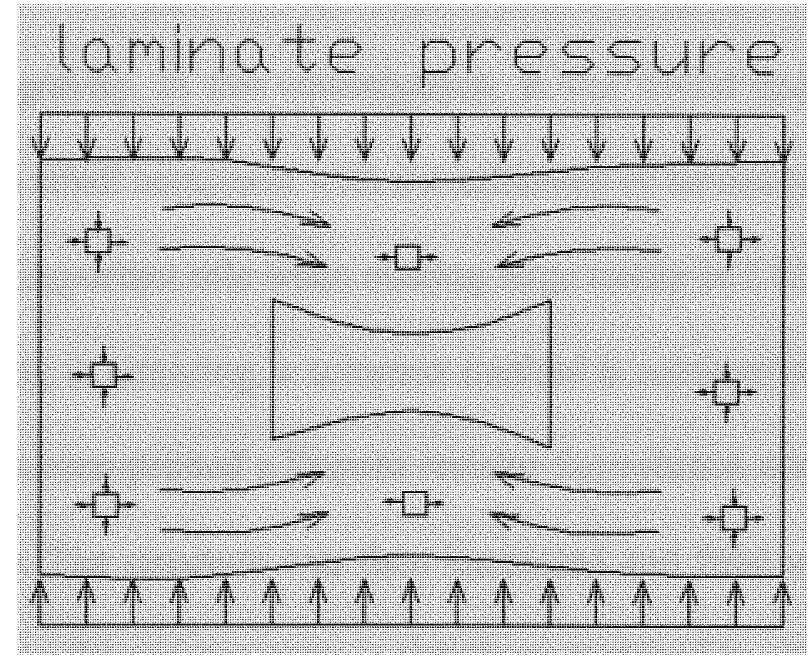

Figure 3.10 Sagging caused by laminating green tape with interior cavity 
During their efforts to embed a heat pipe in HTCC. Zampino et al. found that the sagging could be minimized by laminating parts of the total tape stack individually (for densification) and then laminating the parts together as a final group. By using this multiple lamination process, the whole part can get a relatively uniform density in the first lamination step. The second lamination step is only used to bond the parts together and would not change the density very much. As the result, the final whole part has a relatively uniform density and therefore controls the problem of sagging. This process is simple and effective; in addition it is compatible to other advanced process. In this investigation, we use this multiple lamination process as a standard process and combine it to other technique to control sagging.

Sintering can be another cause of sagging. During sintering the unsupported green tape is subjected to gravity. Since the green tape is soft and flexible before it is sintered into rigid ceramic, the unsupported tape region may undergo plastic deformation under the influence of its gravity. In this investigation, it was found that the influence of the gravity on sagging is small compared with the influence of lamination pressure. However it could also play an important role when making large cavity in LTCC.

To control the sagging in sintering, a common method is using printed tensile over-layer. Patrici et al. (1998) screen-printed a Dupont resistor formulation onto the bridge structure to compensate stress. The structure was then laminated and fired using the conventional sintering profile. Since the resistor paste is shrinkage matched to alumna substrate, which have a higher coefficient of thermal expansion than LTCC, the over layer apply a tensile force on the structure surface during sintering, hence compensate the sagging of LTCC. According to their conclusion, sagging can be effectively controlled using this method. 
However they pointed out that it is important to closely match the tensile force with the gravity. If the anti-sagging force is too great, it may drag the structure toward the resistor side.

Zampino et al. used a similar method in their attempt to fabricate an embedded heat pipe inside HTCC substrate. They add additional sacrificial layers to the top and bottom sides of the tape stack. The additional layers of tape provide increased strength and resistance to sag in the top and bottom layers. After firing, the fired piece is polished, hence, grinding off the additional layers of tape to achieve the desired thickness of the final product.

\section{Key parameter in sagging}

Since sagging is occurring because the material flows under the high pressure, the extent of sagging is a function of the cavity size and the lamination pressure. To get an understanding on the problem of sagging, we have made some samples to study the influence of lamination pressure and cavity size on sagging. Kita ${ }^{25}$ et al. in 2000 and Thelemann ${ }^{23}$ in 1999 did similar works. Their investigation is different from ours in that they use the conventional lamination process while we use the multiple lamination technology. In addition, the feature size studied by the authors was very small compared with the heat spreader involved in this investigation. Kita studied the influence of width on sagging ranging from $100 \mathrm{um}$ to $1000 \mathrm{um}$. The height of the cavity is only 1 layer of Dupont 951 tape (114-254 um). Thelemann's features are also small, width vary from 0.4 to $1 \mathrm{~mm}$ with height of $500 \mathrm{um}$. In this investigation, the heat spreader must have a cavity big enough to contain the wick structure; in addition too small vapor chamber would 
retain the vapor flow. Hence methods are needed to be developed to fabricate cavity larger than $10 \mathrm{~mm}$.

It was found that, although the multiple lamination step cannot eliminate the sagging, it is quite effective to reduce the amount of the sagging, thus larger cavities can be made compare to using conventional lamination process.

Fig 3.11 show a sample made by conventional LTCC technology. Fig 3.12 show a sample with the same size cavity, but made by the multiple lamination technology.

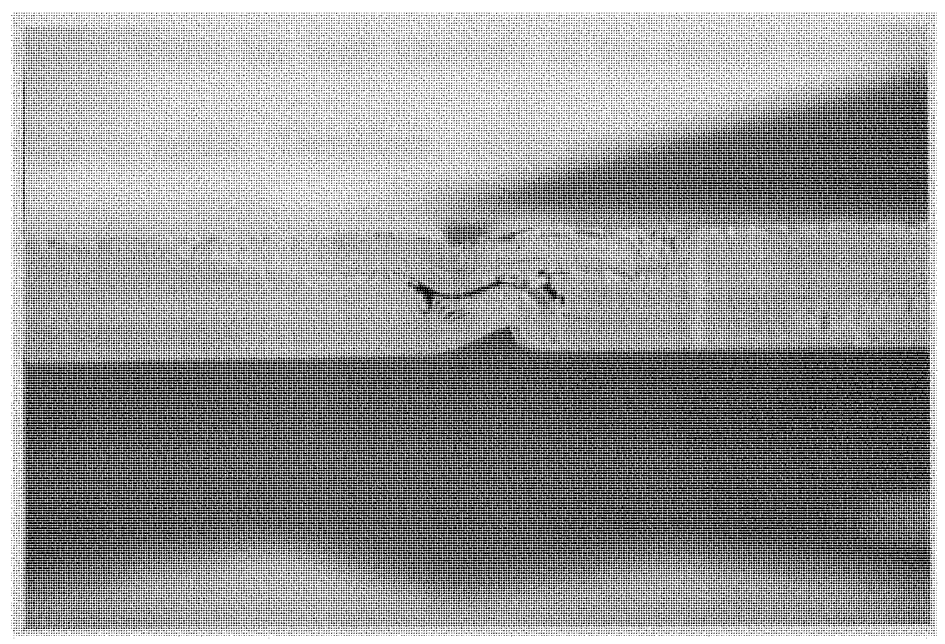

Fig 3.11 Sagging in sample made by conventional LTCC technology

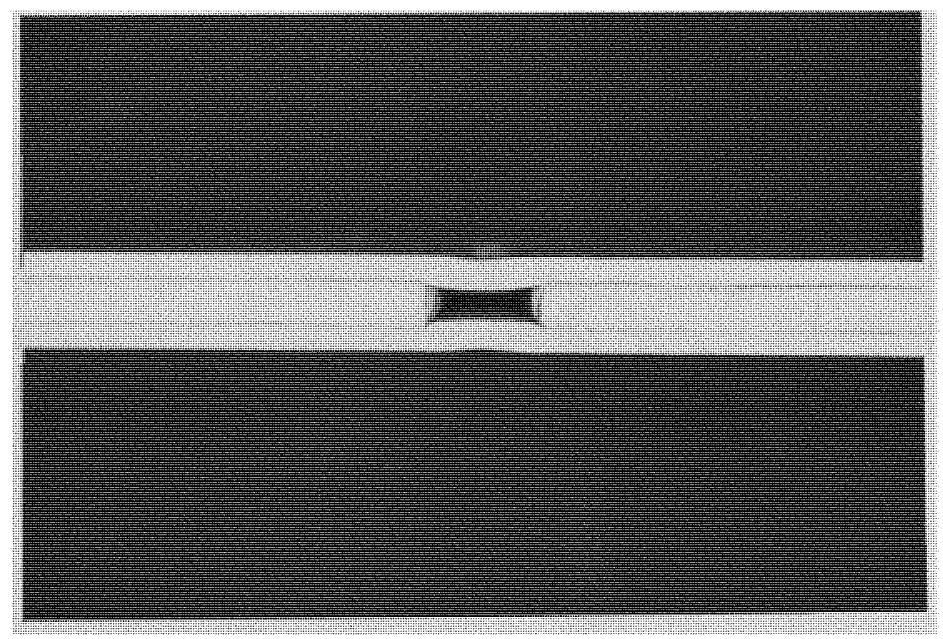

Fig 3.12 Sagging in sample made by multiple lamination process 
Compared these two pictures, it is clear that the pre-lamination process can really help to control the problem of sagging. By the conventional process, the sagging is so severe that the entire cavity is almost completely collapsed. Using multiple laminations, the sample still has some sagging but the overall sagging is much better. It should be note that this multiple lamination process cannot totally eliminate the sagging because of the material flow in the second lamination step. Although the material flow and is densitified during the pre-lamination step, the material doesn't reach their final density until after the final lamination. Actually, under the high pressure of the second lamination step, these material will flow slightly again. Therefore, other processes are needed to eliminate sagging. However the multiple lamination process is effective in sagging control, and it is simple and compatible with other techniques. Therefore we tried to find the capacity of this technique and combine it with other techniques to control sagging.

To study the influence of size and pressure, several samples have been fabricated. The samples are made by Dupont 951 tapes with geometry of $8 * 8 \mathrm{~mm}^{2}$. All the samples are made using the multiple lamination process. The tape stacks are firstly broken into 3 groups, the top, bottom and inner layers. Each of the group consists of 6 layers of LTCC green tapes. These groups are then laminated individually to form 3 parts----top, bottom and inner pieces respectively. Cavity is then cut on the inner pieces. Finally the three individual pieces are laminated again to be bind into a whole part. To investigate the influence of cavity size and lamination pressure on sagging, various width and pressure are used. 
Fig 3.13 show how sagging is influenced by cavity size. the lamination pressure is $3000 \mathrm{psi}$, which is the recommended lamination pressure of 951 green tape. The widths of the cavities are 0.25 inch, 0.125 inch and $0.0625 \mathrm{inch}$.

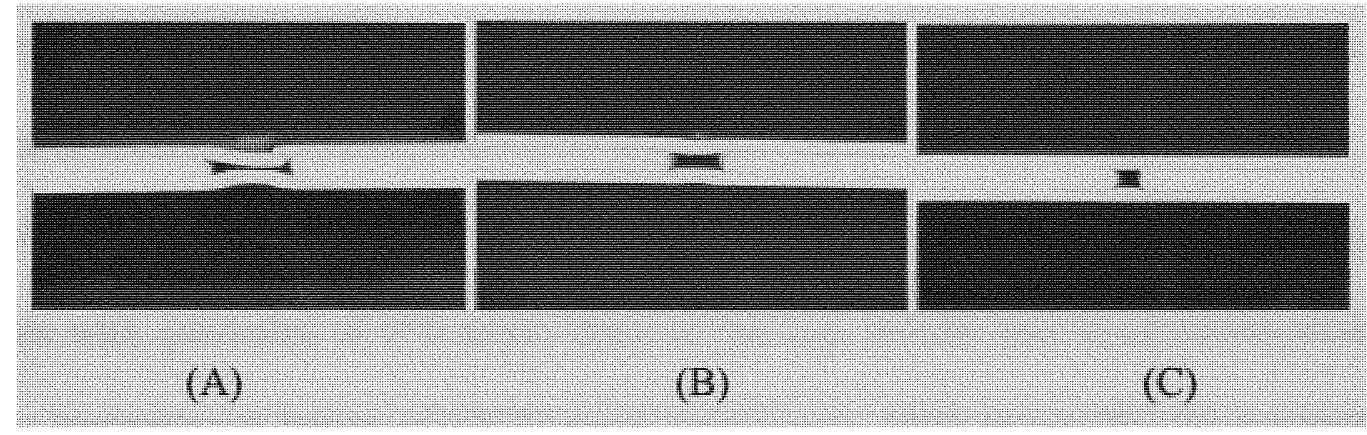

Fig 3.13 The effect on sagging due to variations in cavity width of: (A) 0.25 inch, (B) 0.125 inch, and (C) 0.0625 inch.

In the case of small width of 0.0625 inch, the sagging is not obvious. To the larger size of 0.125 inch, sagging can be easily identified by the curved inner surface of the cavity. this extent of sagging is still acceptable, because there is no too much shape distortion of the cavity. However, to the cavity with width of 0.25 inch, sagging is very severe and hence not acceptable. From the picture it could be seen that the top and bottom are badly curved into the cavity and the whole cavity is almost cracked down.

Therefore, using the conventional lamination parameter, the multiple lamination process alone can only help to control sagging in a cavity with a width no larger than 0.125 inch. To develop heat spreader in LTCC substrate, we need other advanced processes or to combine this process with other techniques.

To study the influence of lamination pressure on sagging, samples with the same feature size are fabricated using various lamination pressures. In multiple lamination processes, the pre lamination step is used to give the individual pieces a uniform density. 
While the second lamination step is used to bind the pieces into a whole part, sagging occurs in this step because of the additional material flow. Therefore the pressure of the second lamination step is the key parameter to control sagging. In our experiment, we used the recommended lamination pressure in the pre lamination step and studied the influence of second lamination pressure on sagging.

All the samples used have the same feature size. Samples are made by Dupont 951 tapes with geometry of $8 * 8 \mathrm{~mm} 2$. Each of the top, bottom and inner pieces were made by laminating 6 layers of LTCC green tapes under 3000 psi at $70 \mathrm{C}$ for a period time of 10 minutes. A cavity with width of 0.25 inch was then cut on the inner piece. The three parts were laminated together under various pressure of 500,1000, 2000 and 3000 psi.

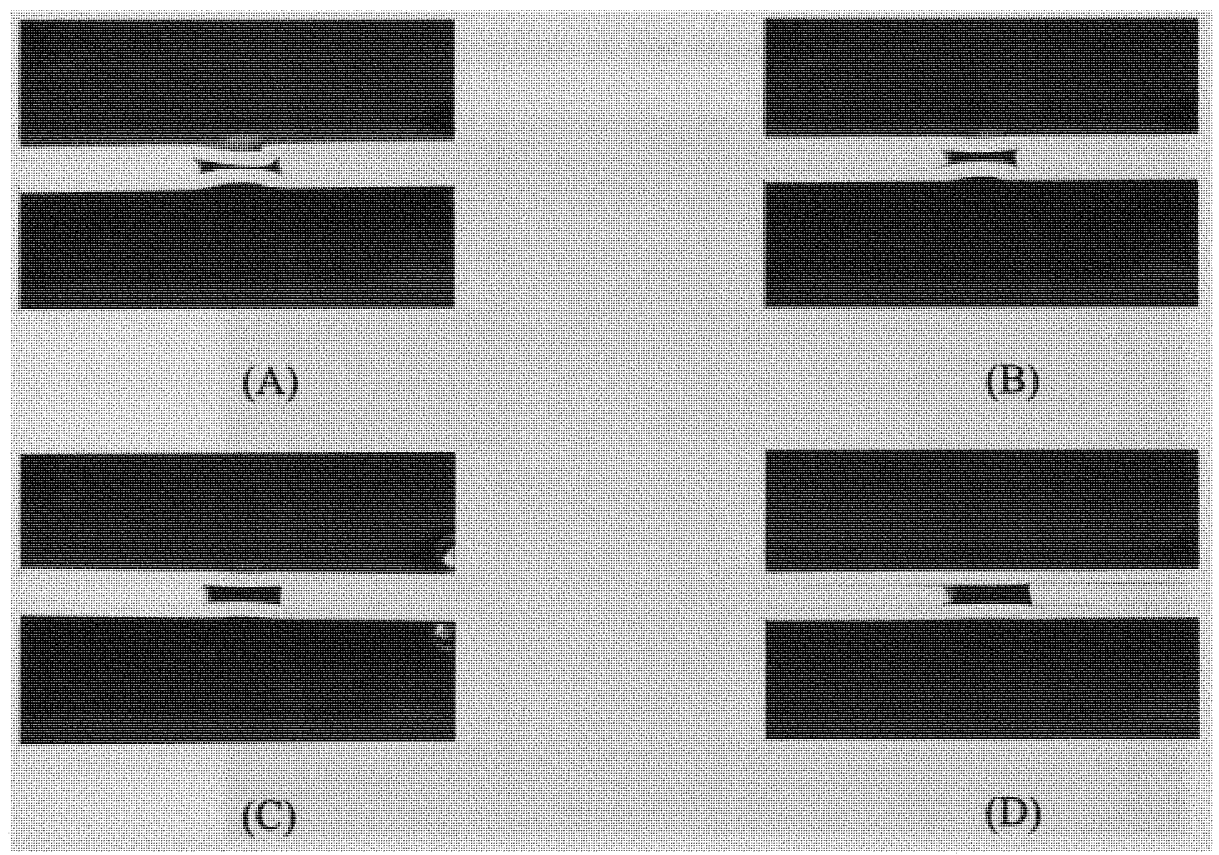

Fig 3.14 The effect on sagging due to variations in lamination pressure of: (A) 3000 psi (B) 2000 psi, (C) 1000 psi and(D) 500psi 
Fig 3.17 to fig 3.20 show how the lamination pressure influent the quality of cavity. Fig 3.17 show the sample made under 3000 psi. the sagging is very serious; even the cavity shape distorted. For the sample made using 2000 psi, sagging is much better but still obvious from the curved shape of the top and bottom surface. Logically, the best sample is the one laminated using 500 psi. from fig 3.14 (D), almost no sagging is found in this sample. However, de-lamination is found at the corner of the cavity. This delamination occurs because of the high pressure of the pre-lamination step followed by too low a lamination process. During the pre-lamination step, the materials flowed and densitified; so it is relatively difficult to flow again at low pressure. When the pressure of the second lamination is too low, the material may not be able to undergo enough plastic deformation to be bonded together and therefore resulting ineffective sintering between layers. Fig 3.15 shows the de-lamination at the corner of the cavity.

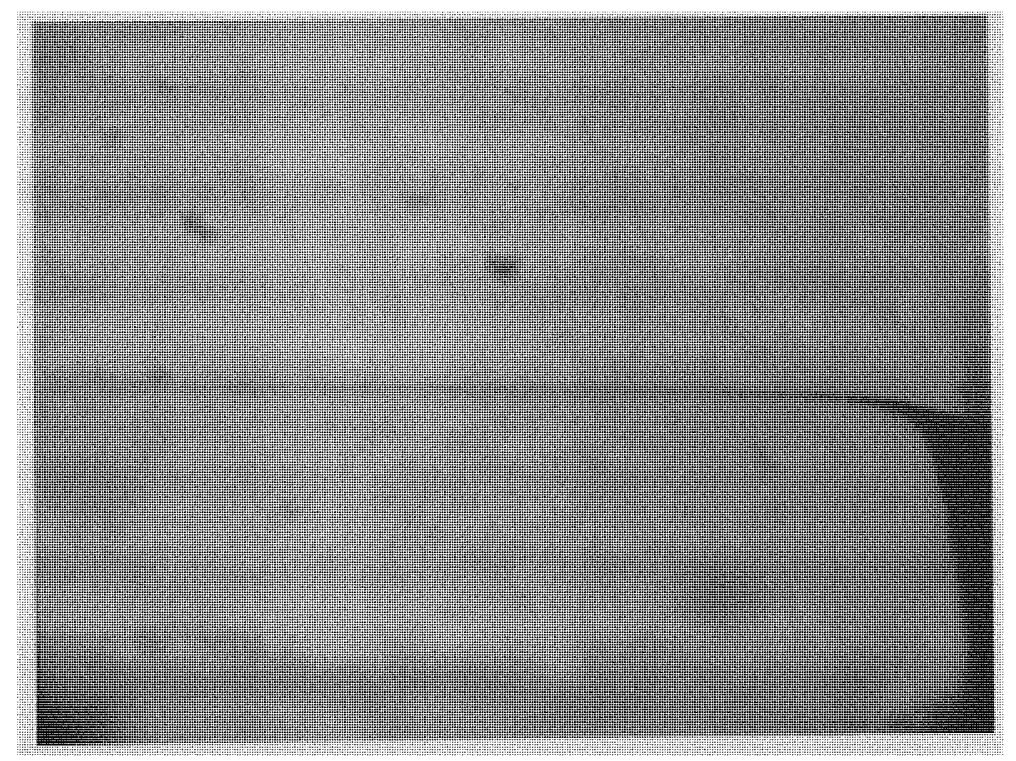

Fig 3.15 De-lamination due to the low pressure. 
From the investigation, feature size and lamination pressure are key parameter to determine the quality of the cavity. By using a multiple lamination process, sagging can be controlled for feature size smaller than 0.0625 inch. Low lamination pressure can help to control sagging but may result in de-lamination, therefore is not good for making hermetic cavity. To fabricate hermetic cavity with width larger than 0.25 inch, new techniques are needed.

\section{Use of insert material}

The problem of sagging comes from the uneven compression of the green material. Thus the logical solution to sagging is the use of an insert material so that all of the tape material is compressed uniformly.

Bauer et $\mathrm{al}^{29}$., 1997 proposed using dummy inserts to fill the cavities during the lamination process. The inserts are removed prior to firing the ceramic. In fact, the use of inserts is typical for large open-faced cavity structures where the ceramic is fired with the cavity exposed, and sealed after the firing process by means of a metal cover plate. However, since our heat spreader is fully embedded within the substrate and hence there would be no way to remove the insert prior to firing, this method was not suit for fabricating heat spreader.

The insert material must provide necessary support during lamination step and can be removed without destroying the structure. One of the ideal insert materials would be fugitive material, which can be burned off during the sintering process.

Patrici Espinoza-vallejos et al. (1998) tried to control sagging by inserting sacrificial material in the lamination process. The researchers tried two kinds of insert material: 
glass and carbon. By using glass, they hope to deposit glass underneath a bridge structure to control sagging. Then the glass was etched away by buffered hydrofluoric acid. However no conclusion was drawn on this method. Another sacrificial material they used was graphitic carbon. The carbon was inserted to control the sagging. During the sintering process, they firstly control the oxidation of carbon so that little graphite was lost before LTCC tapes become rigid. This was achieved by injecting nitrogen into the furnace to adjust the air to nitrogen ratio. When the LTCC become rigid, they increase the oxygen partial pressure or sintering time to completely burn off carbon. They found that this method is effective to control the sagging.

Although carbon is a proven insert material, it requires careful control of the oxygen partial pressure in the oven, thus special facilities are needed. Also the sintering profile is too complex. Therefore in our investigation, we choose wax as the insert material. Wax is a widely used insert material in industry. It can be melted and cast to easily get the desired shape to fill in the space. When firing at high temperature in air, wax would vaporize and burn off completely; thus can serve as a perfect insert sacrificial material.

To determine whether the wax is suitable as sacrificial material and compatible with LTCC process, TGA test are performed for wax. Fig 3.16 show its TGA curve. The sample TGA curve is obtained from ambient temperature to $700^{\circ} \mathrm{C}$ using a heating rate of $2{ }^{\circ} \mathrm{C} / \mathrm{min}$. 


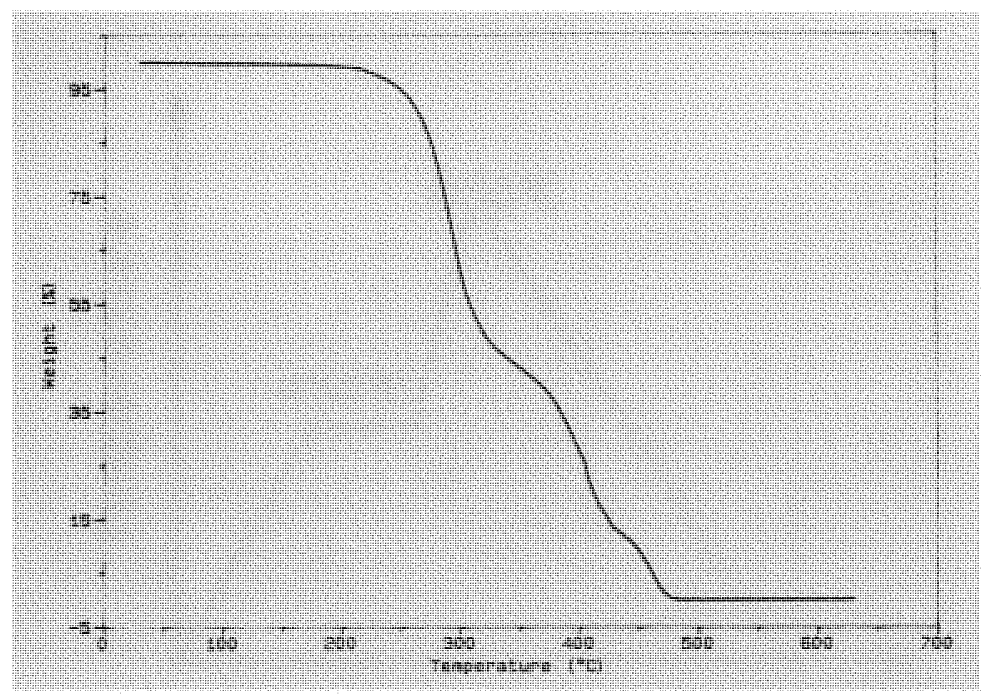

Fig 3.16 TGA curve of wax

from the TGA curve, we can see that the wax begin to lose weight at about $200{ }^{\circ} \mathrm{C}$. The weights lose rate change a little bit at about $300{ }^{\circ} \mathrm{C}$. From 200 to $300{ }^{\circ} \mathrm{C}$ the wax lose weight rapidly, after $300^{\circ} \mathrm{C}$ the weight losing slow down a little bit. The whole material is completely burned off after about $475^{\circ} \mathrm{C}$. this sintering profile is well compatible with the conventional LTCC sintering profile. Fig 3.17 show the recommended sintering profile of Dupont 951 tape. 


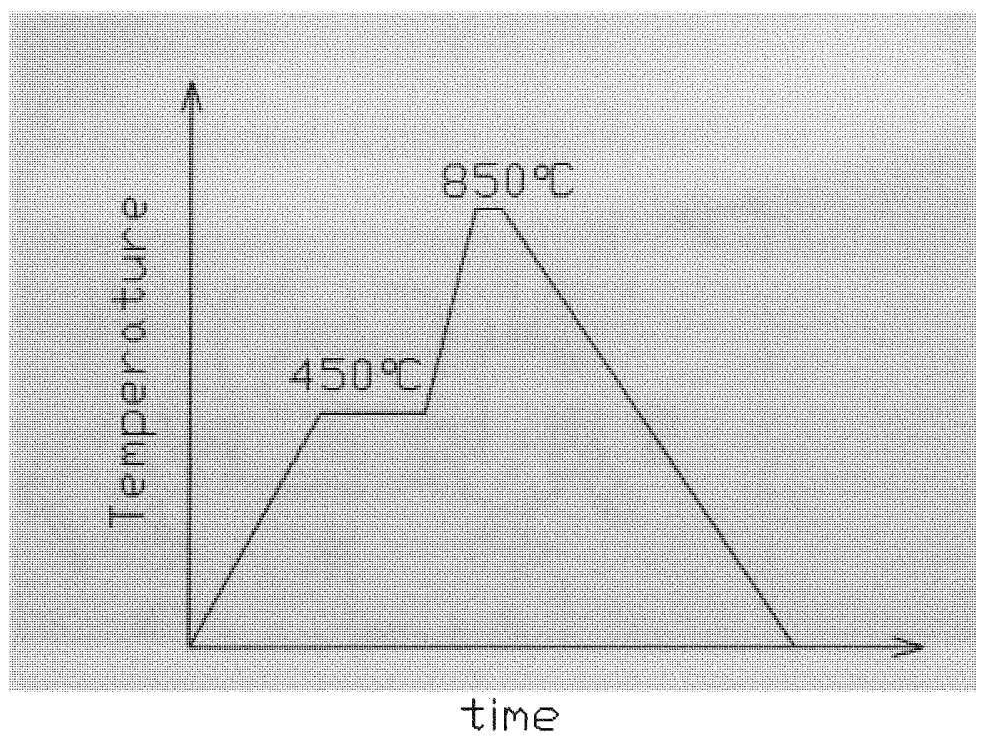

Fig 3.17 Recommended sintering profile of Dupont 951 tape

Note the recommended sintering profile for Dupont 951 tape has a burn off period at $450 \mathrm{C}$, which is used to burn off the organic material in the green tape. Wax can be completely burned off at this period. Therefore, we can still use the same conventional sintering profile.

To investigate the method of using wax to control sagging, small samples were fabricated. To combine the multiple lamination process, the top, bottom and inner pieces are pre laminated. Cavity was cut in the inner piece and the wax was then deposited into the cavity. The three parts were laminated again to bind the individual parts into the final sample. Fig 3.18 show the picture of a green state sample with the insert wax. 


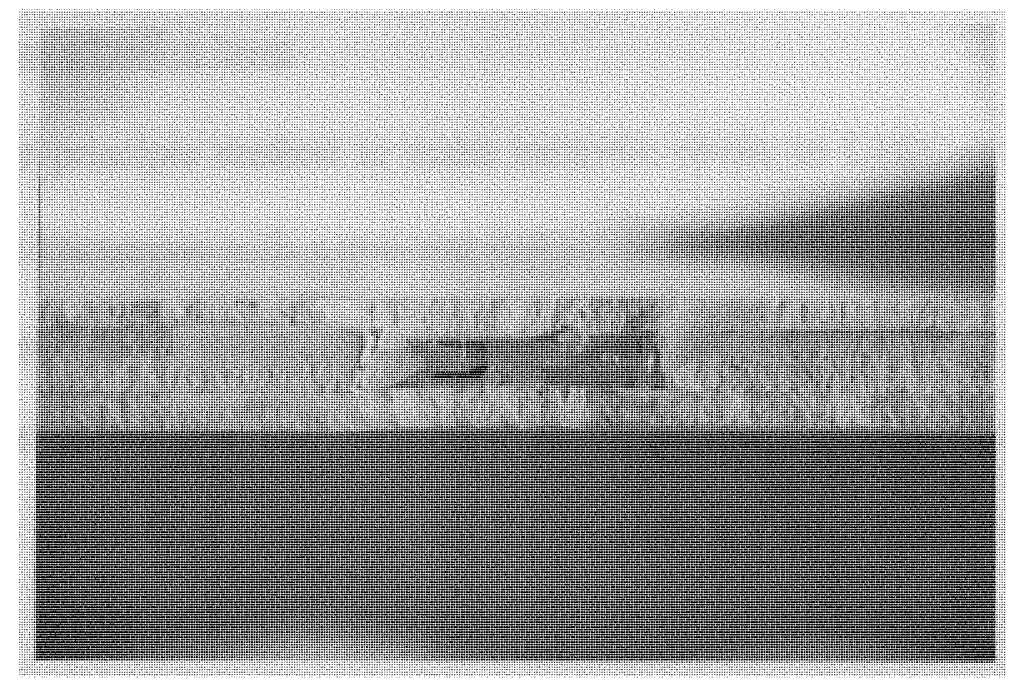

Fig 3.18 Green state sample with wax deposited in the cavity

From the picture, it can be seen that the wax effectively support the tape, and therefore no sagging occur during lamination. The sample is then put into oven and sintered using the conventional sintering profile. Fig 3.19 show the final ceramic sample after sintering. The cavity has a perfect shape without any sagging.

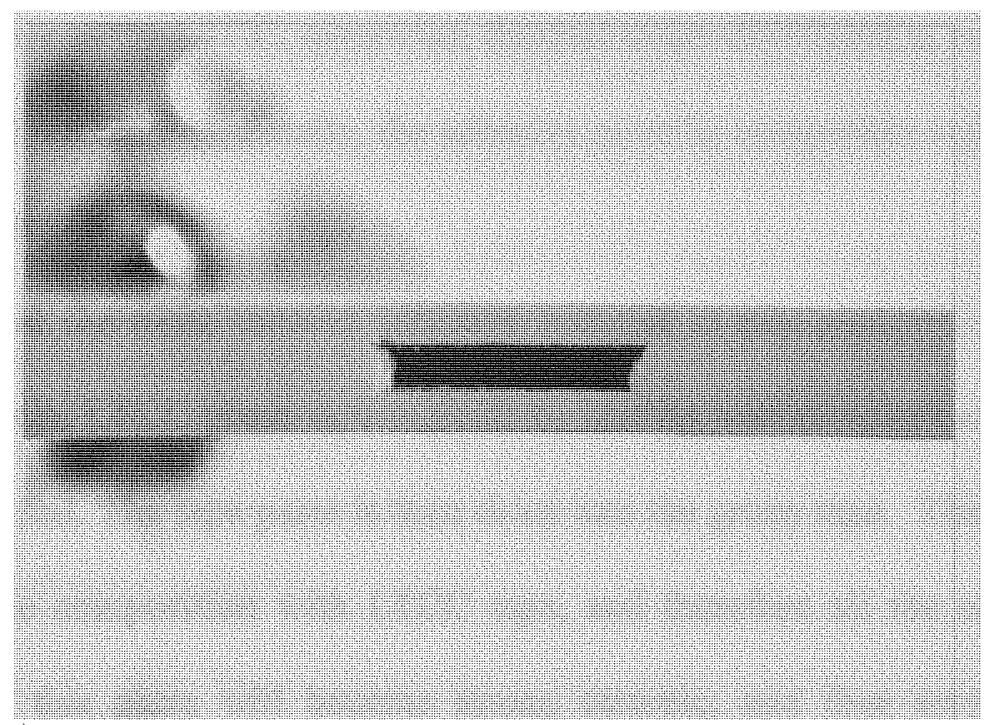

Fig 3.19 Sintered sample using insert wax 
Another principle method to make hermetic cavity in LTCC is using post fire components and assemble with a material that act as a post-fired adhesive. By using this method, the top, bottom and inner pieces are laminated using the conventional process. However these pieces are not assembled in green state. Instead, they are sintered separately into three final ceramic parts. These parts are then assembled and bonded together by an adhesive layer. Since sagging occur during the second lamination step, which bind the individual green pieces into a whole part. While this method does not laminate the three individual parts in green state, therefore it has no problem of uneven density and thus no sagging would occur. The problem of this method lies in the selection of the adhesive layer. To bind the individual parts into a hermetic cavity, the adhesive itself must be hermetic. The thermal expansion coefficient of the adhesive must be the same or very close to the LTCC, otherwise, thermal stress developed at the interface may lead to failure of the binding. Finally, the adhesive must be compatible with the electronic packaging industry.

It was found that the most suitable adhesive material in this application is the LTCC itself. As it known, LTCC green tape is made by casting a mixture of ceramic and glass paste on plastic foil. The tape paste is then dried into the green tape. This tape paste has exactly the same composition with LTCC tape, and therefore all the same properties. After sintering, this paste will become strong ceramic, and thus serve as tight and hermetic adhesive.

Small samples are fabricated using the post fire and binding method to investigate the possibility of using this method to make the heat spreader. The first step is making the 
individual top, bottom and inner pieces. Each of the pieces is laminate and sintered using the conventional LTCC process. The individual pieces is then assembled and bonded together by a thin layer of LTCC paste applied on the surface of the pieces. The final part was sintered again to fire the paste into the final ceramic. Fig 3.20 shows the final sample.

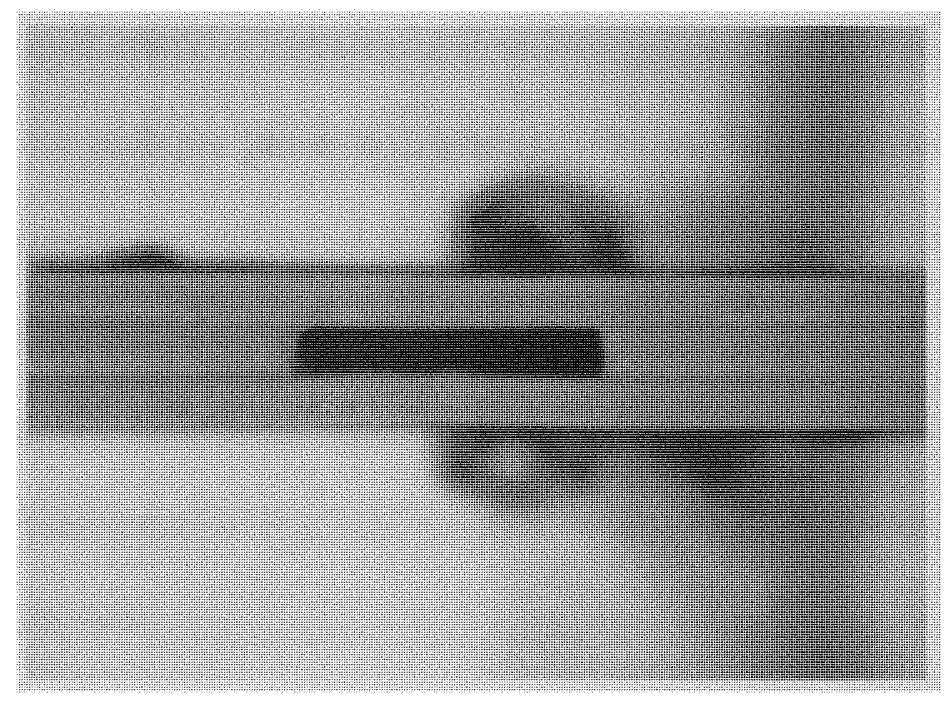

Fig 3.20 Sample fabricated by post fire process

Since the pieces have already been sintered into rigid ceramic, there is no sagging. As expected, the LTCC paste has been sintered into strong ceramic and tightly bind the individual pieces into a whole part.

\section{Co fire and use adhesive material}

Although the post fire method can totally eliminate the sagging, it needs an additional sintering process, which add cost to the whole process. Since this method eliminates sagging by using an adhesive layer instead of lamination, a logical improvement of this method is to use an adhesive layer and cofire. 
The idea is almost the same as post fire using adhesive. The top, bottom and inner pieces are laminated into three individual parts at first. Unlike the post fire method, these pieces are not sintered separately. On the contrary, they are assembled and bonded together using LTCC paste in the green state. The green part is then put into oven and cofired in one step.

Compared with the post fire method, the whole part is cofired in one step, therefore is more cost effective and adaptable to conventional LTCC process

Compared with the multiple lamination process, this method does not use the second lamination step to bind the individual pieces together. Thus the whole part has a uniform density and therefore can control sagging.

Small samples have been fabricated to investigate the possibility of using this method to make heat spreader. Fig 3.21 shows a sample made by this method. The width of the cavity is 0.25 inch.

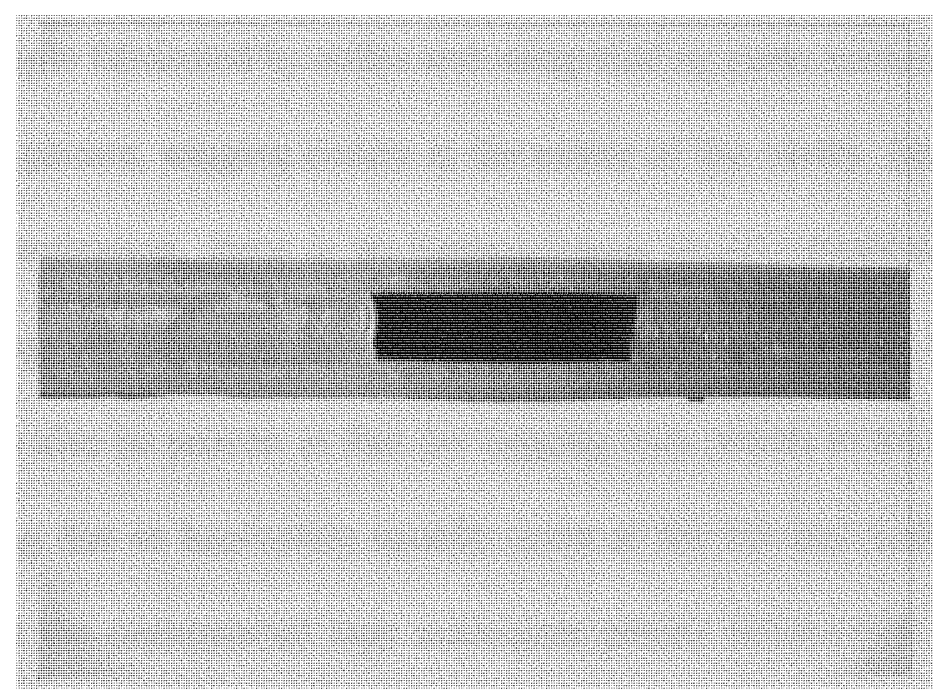

Fig 3.21 Sample fabricated by cofire and using binding paste method 
From the picture, it shows no sign of sagging. However, it was found later that sagging would occur when the cavity size is very large. Fig 3.22 shows a sample with big cavity made using this method. The width of the cavity is 0.75 inch (the width became about 0.64 inch due to the shrinkage after sintering).

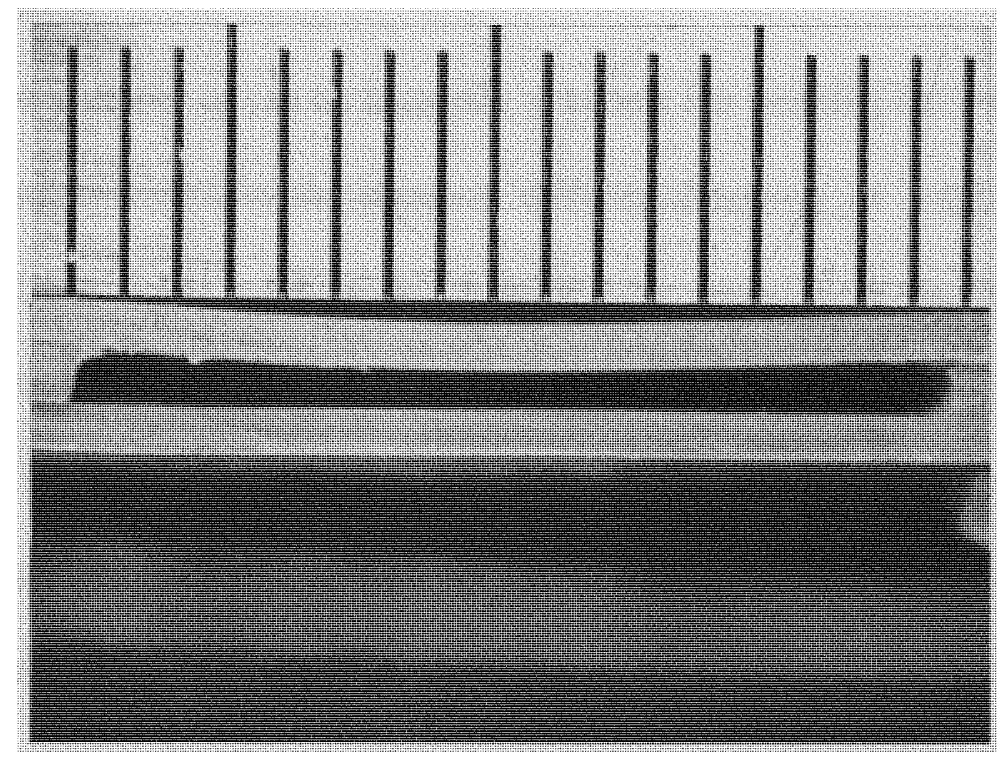

Fig 3.22 Sample fabricated by cofire and using binding paste method (big cavity)

From the picture, sagging occurs at the center of the cavity. Since the pieces are not bonded by lamination, there is no heterogeneous density distribution in this case. Therefore, the sagging occurred during the sintering process instead of the lamination process. This can also be proven in that the sagging only occurs at the top of the cavity. While the sagging due to lamination usually occur at the top and bottom of the cavity. The cause is that the unsupported tape undergoes plastic deformation under its gravity during sintering. Therefore this method has limited potential in making big cavity. To solve this problem, some insert materials are needed to be deposit in the cavity to support the tape during sintering, or using tensile over-layers to overcome the effect of gravity. 
However, since the primary purpose is only to make a prototype heat spreader for concept validation, this method was not chosen due to its possible complicity. However the study in this method is worth continued future investigation.

\section{Control of leakage}

The heat spreader has to be hermetic to isolate the working fluid from the outside environment and to maintain the pressure differential across its walls. Under normal condition, the LTCC itself is a hermetic material after sintering. In this respect, LTCC is a suitable material for embedding a heat spreader. However when via and cavity are made inside LTCC, they may introduce micro cracks and therefore result in leakage.

Based on the results of controlling sagging, the two methods were chosen as the potential methods to fabricate the heat spreader. However, in the attempt to control sagging, simple structures are used----all the samples have no thermal via, which are susceptible resources for leakage. In order to find the right method for making hermetic cavity, more complex testing structures have been fabricated using the two methods respectively. The testing structure is made of 16 layers of LTCC green tape. Each of The top and bottom pieces consists of 4 layers, while the inner piece has 8 layers. There are thermal via on the top piece. Cavity is cut in the inner piece. On the bottom piece a through hole is drilled to serve as the opening to take the vacuum. The vacuum is taken by an Edwards model e $2 \mathrm{~m} 1.5$ vacuum pump, which also has a penning gauge with a measuring range of $10^{-2}$ to $10^{-7}$ Torr. 


\section{Improved Post fire process}

Several samples have been fabricated by using the post fire method discussed in last section. Three pieces are made separately. Thermal via are fabricated on the top piece using the conventional process. The individual pieces are bonded into a whole part by LTCC paste. The sample is then post fired into the final ceramic part.

Vacuum testing was done to check hermeticity. The pressure can only barely reach $10^{-2}$ torr, indicating leakage of the sample. By leakage detection, it was found that all the leakage comes from the binding layer. A close view of the binding found some micro cracks and holes in the binding ceramic. Fig 3.23 shows a crack at the edge of the sample. The cracks exist between the ceramic part and the paste.

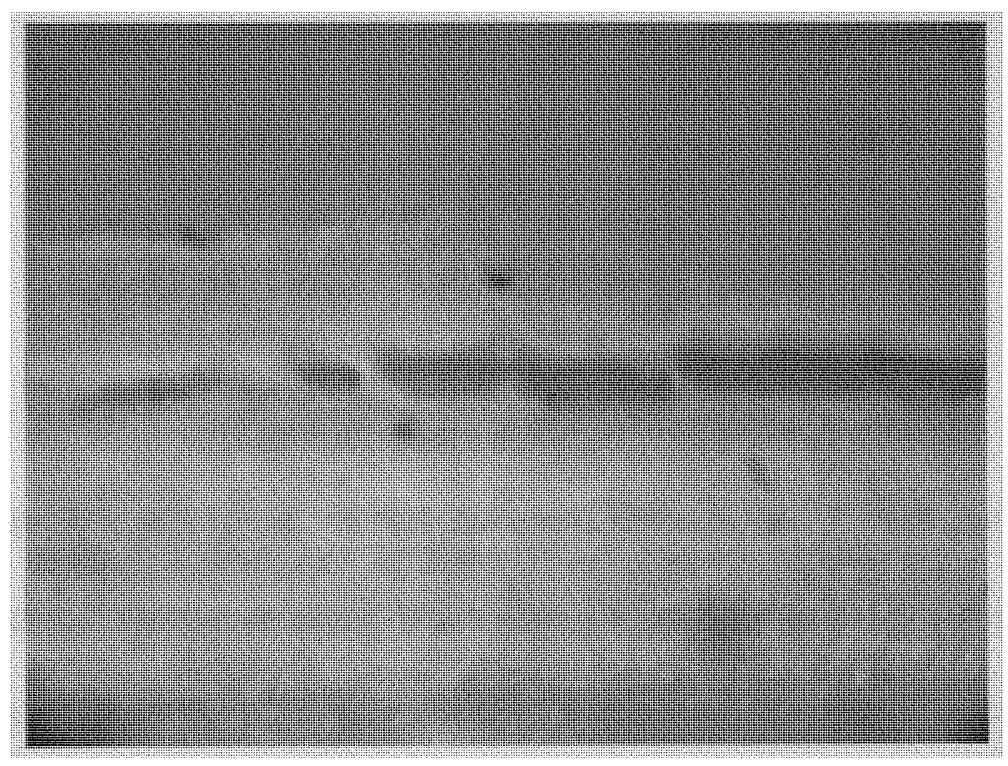

Fig 3.23 Crack between the ceramic part and the paste

The cause may be the ineffective sintering at the interface between the pate and ceramic. Normally, individual LTCC tapes can be sintered into a highly compacted monolithic structure because they intimately contact the material in each other by the lamination process. Since no force was applied to ensure the paste binds the ceramic tape tightly, the 
paste may detach from the ceramic tape in some region during sintering. This situation is similar to the de-lamination failure in the conventional LTCC process.

Also the problem comes from the binding paste itself. To further investigate the binding quality, a sample was cut to check the interface of the binding paste and ceramic part. Fig 3.24 shows the binding interface.

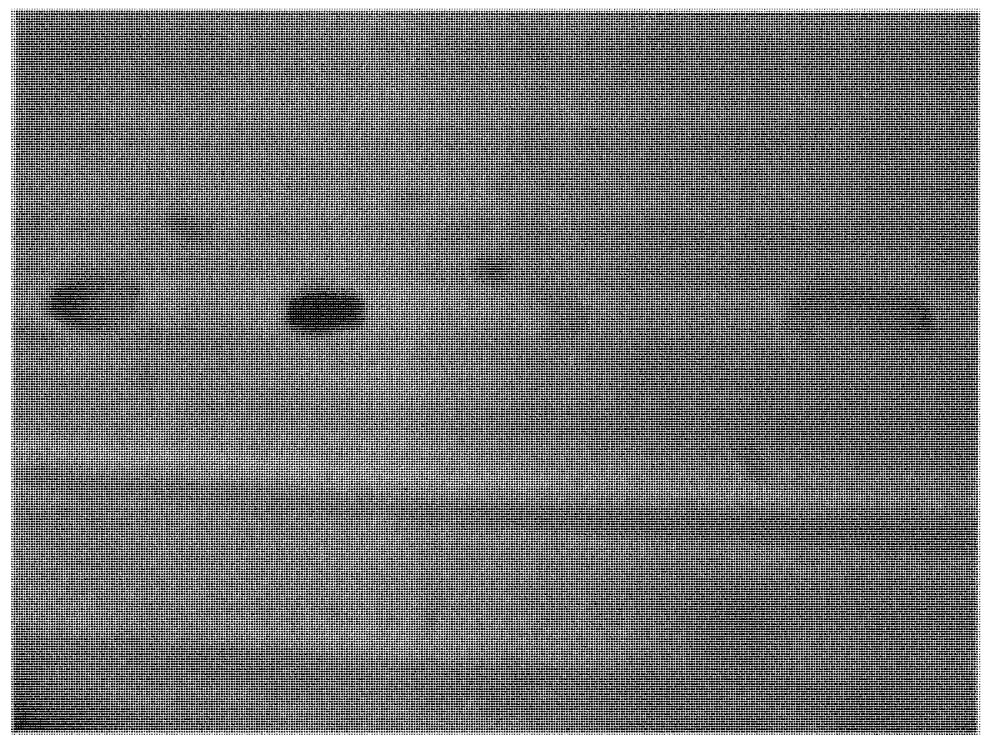

Fig 3.24 Small pores in the paste

Form the picture; it could be found that the paste did not become compact and hermetic ceramic as expected. On the contrary, there were some pores in the paste and thus it leaks by itself. Those pores in the paste were formed when the material flows and shrink in the $\mathrm{x}-\mathrm{y}$ plane during sintering. Like LTCC tape, the paste contains organic materials in the green state. During sintering, these organic materials will burn off, and the paste volume will shrink. Under free sintering condition, pores may form inside the paste due to the decrease of volume. In addition, the paste was not compacted by the laminate step and 
therefore it did not get the high density, which is necessary for the paste to be sintered into compact ceramic.

To solve this problem, some method is needed to compress the paste so that it can tightly bond the tape material and eliminate the pores in the paste. Constrained sintering is therefore a good solution for this problem.

Compare to free sintering, constrained sintering apply stress to constrain the sample during sintering. In LTCC technology, constrained sintering is often used to control the shrinkage in $\mathrm{x}-\mathrm{y}$ plane while only allow shrinkage to occur in the $\mathrm{z}$ direction. To constrain and eliminate linear in-plane $(x-y)$ during the sintering of plane LTCC substrate is attractive because near net shape forming in the $x-y$ plane can be realized, which means the feature put down in the green state will remain essentially in the same position in the $x-y$ plane throughout the firing cycle. In this investigation, constrained sintering is used to compress the paste during sintering, and thus get high quality of the binding paste.

By applying a compressing force in the $\mathrm{z}$ direction during sintering, the paste materials are forced to tightly contact with the tape material so that sintering will effectively occur between them. Furthermore, when organic materials are burned off during sintering and the paste volume shrinks, the applied force compress the paste material from $\mathrm{z}$ direction, thus eliminating the porosity resulting in the desired densification to the paste.

Stress can be applied to the sample by many methods, including hot pressure, additional weight and constrain layer. Since we only need the compress stress in $\mathrm{z}$ direction, additional weight is chosen in this application. It was found that the optimum 
pressure is between $0.08-0.24 \mathrm{psi}$. Too low pressure cannot provide enough stress to compress the paste into a compact material. However, if the pressure is too high, the compression force may drive the paste out and thus is not desired. Fig 3.25 show the cut section of binding paste using constrained sintering, note no pore was found and the paste is compact.

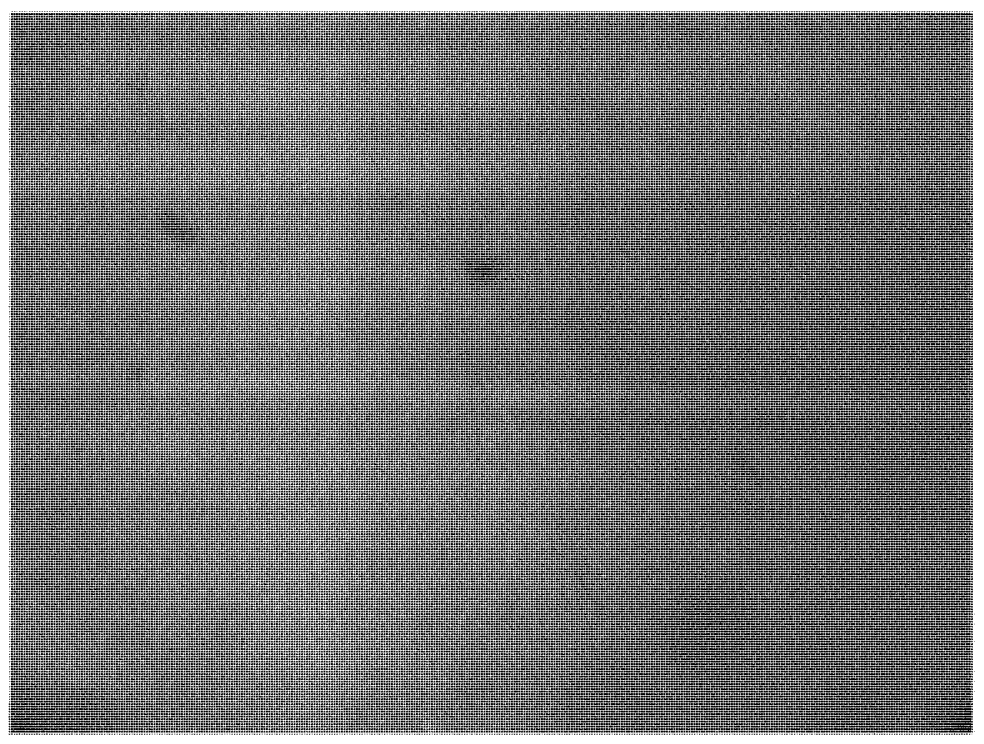

Fig 3.25 Cut section of binding paste after constrained sintering

Testing Samples have been fabricated by using this improved post fire method. The test result showed that the sample could get a vacuum of $10^{-5}$ Torr. Thus proved that this method can be used to fabricate complex hermetic structure in LTCC.

\section{Cofire use wax}

To investigate the possibility of using cofire process to make heat spreader, test samples were also made using this method. The samples have the same structure as mentioned in the opening of this chapter. The top, bottom and inner pieces were made separately using conventional lamination process. Thermal via and cavity were made on 
the pieces respectively. Wax was deposited into the cavity before the pieces are assembled and laminated into a whole part. The green part was then put into oven and sintered in one cofire step. The final part was test for its hemeticity. However, the result showed that the cavity is not hermetic. Leakage detective show that leakage is occurring at the top surface, from the thermal via. After inspecting the sample under the microscope, it was found that the leakage comes from the micro cracks in the thermal via. Fig 3.26 shows a typical micro crack in thermal via.

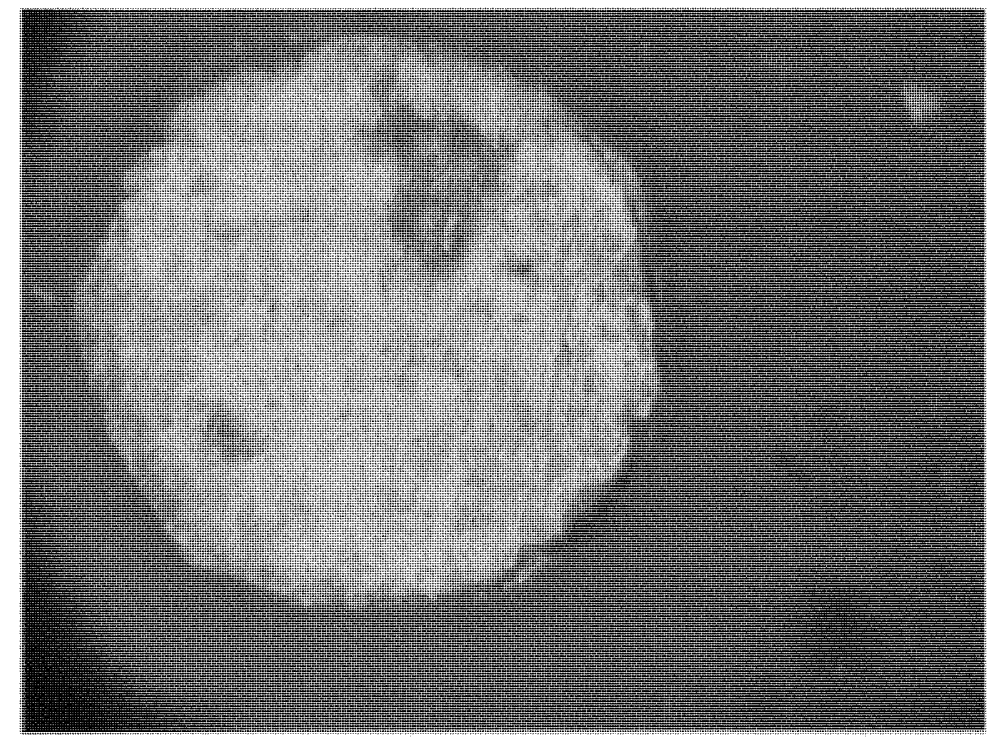

Fig 3.26 Micro crack at edge of thermal via

It was believed that these cracks are caused by the shrinkage mismatch of the via and LTCC tape. Although the via ink is designed to have the same shrinkage as the LTCC tape, it is different from tape material in many aspects such as viscosity and flow behavior under high pressure. Therefore the shrinkage match between them is very sensitive to the process. This "weak" match is easy to be broken when insert material are used and therefore uneven stress distribution are introduced. The purpose of using wax insert is to give a relatively uniform density through the tape. However it is very difficult 
to ensure uniform stress distribution through the substrate when a insert material was used, especially when the wax surface is rough or improper amount of wax is used. The uneven stress may alter the shrinkage behaviors of the via and tape. Even if the mismatch shrinkage occurs on micro scale, it is enough to result in micro cracks and thus make the whole sample non-hermetic.

It should be note that this method is able to make complex hermetic structure in LTCC in case that the all the process parameter are carefully controlled. However, since there are so many thermal vias on the tape and any micro crack in one of them would ruin the whole sample, the product rate of this method would be very low. Therefore this method was not chosen to fabricate the heat spreader in this investigation.

\section{Wick structure}

\section{Theoretical Overview}

Although a heat pipe is a very efficient heat transfer device, it has many limitations. The possible limitations of heat pipe are: continuum flow limit, frozen startup limit, viscous limit, sonic limit, entrainment limit, condenser limit, boiling limit and capillary limit. ${ }^{30}$ The operation of a specific heat pipe is limited by the limitation that has the lowest value at the working temperature. Generally, the most commonly encountered limitation of a capillary driven heat pipe is the capillary limit.

Capillary limitation can be defined as the pumping ability of a given capillary wick structure to provide the circulation for a given working fluid. Therefore, the wick structure is the key component that determines the performance of the heat pipe. 
The basic mode of operation in the heat pipe is through a cycle of evaporation and condensation. To sustain this evaporation and condensation cycle, the liquid must be continuously supplied to the evaporator section by a porous wick.

A wick structure can drive the condensate back to the evaporation section because of the capillary pressure created by its menisci. In the heat pipe, the capillary pressure exists at the liquid-vapor interface due to the surface tension of the working fluid and the curved structure of the interface. Under working condition, the curvature of the menisci along the liquid-vapor interface is not even along the heat pipe. In the evaporator section, the menisci at the liquid-vapor interface are highly curved due to the fact that the liquid recedes into the pores of the wick. On the other hand, the menisci in the condenser section are nearly flat during the condensation process. The difference in the curvature of the menisci along the liquid-vapor interface causes the capillary pressure to change along the heat pipe. This capillary pressure gradient then drive the liquid to the evaporator, against the liquid and vapor pressure losses, and adverse body forces such as gravity.

The fundamental equation for capillary pressure is the Young-Laplace equation.

$$
P_{c a p}=\Delta P=\sigma\left(\frac{1}{R_{\mathrm{I}}}+\frac{1}{R_{\mathrm{II}}}\right)
$$

Where $\sigma$ is the surface energy; $R_{I}, R_{I I}$ are two radii of curvature used to describe an arbitrarily curved surface.

In a small tube,

$$
R 1=R 2=\frac{r}{\cos \theta}
$$

Where $\theta$ is the contact angle, $r$ is the radii of the tube 
Hence

$P_{\text {cap }}=\frac{2 \sigma}{r} \cos \theta$

It can be generalized into:

$P_{c a p}=\frac{2 \sigma}{r_{e f f}}$

Where $r_{\text {eff }}$ is the effective pore radii

The stable working fluid circulation in a heat pipe can be achieved under condition such that the capillary pressure head developed by the wick structure is greater than or equal to the sum of pressure losses along the vapor-liquid path. Beyond this point, the heat pipe reaches its capillary limitation and the evaporator walls experience a sudden, continuous increase in temperature.

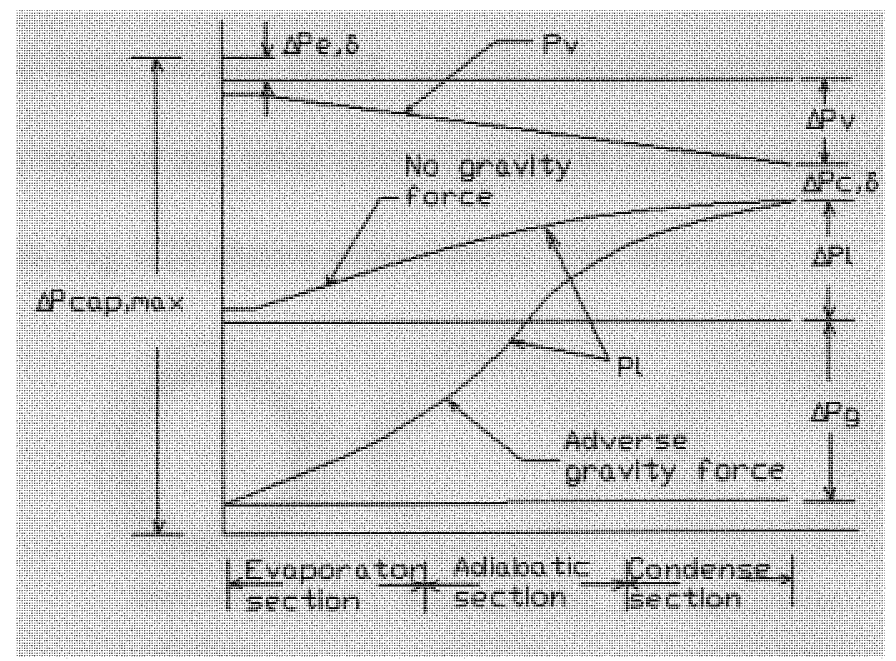

Fig 3.27 Schematic show of the pressure distributions in the vapor and liquid along the heat pipe length ${ }^{29}$

In order for the heat pipe to operate properly, the following pressure balance must be satisfied 


$$
\Delta P_{c a p, \max } \geq \Delta P_{l}+\Delta P_{v}+\Delta P_{e, \delta}+\Delta P_{c, \delta}+\Delta P_{g}
$$

Where $\Delta \mathrm{P}_{\mathrm{v}}$ is the vapor pressure drop along the heat pipe. $\Delta \mathrm{P}_{\mathrm{g}}$ is pressure drop in the liquid due to the gravitational force in the direction of the heat pipe axis. This pressure drop is a function of the inclination of the heat pipe from horizontal. $\Delta \mathrm{P}_{\mathrm{e}, 8}$ and $\Delta \mathrm{P}_{\mathrm{c}, \delta}$ are the pressure drops due to the evaporation and condensation at the liquid-vapor interface respectively. These two pressure drops can usually be neglected. $\Delta P_{l}$ is the pressure drop of the liquid flow in a wick structure due to the frictional drag. It is one of the major factors that cause the capillary limit.

\section{Choose of wick structure}

Wick structure can be constructed from a single material or from several basic materials, and thus be called homogeneous wick or composite wick respectively. Wick structure can also have various forms: gauzes, sintered porous materials, gloves on the interior heat pipe wall, or any other material capable of transporting the liquid back to the evaporator section. Fig 3.28 shows some typical wick structure.

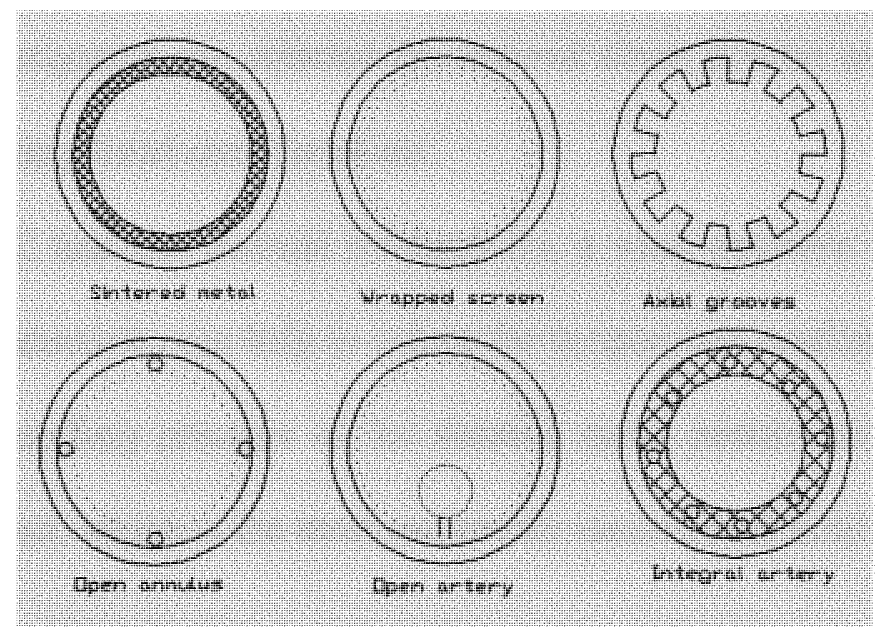

Fig 3.28 Some commonly used wick structures 
From equation (3.5), the capillary pressure is determined by three basic factors: contacting angle, surface tension and pore radii. When a certain working fluid is chosen, the structure and geometries of the wick play a great role in determining the capillary pressure, which explain why the quality and type of wick usually determine the performance of the heat pipe. According to equation (3.4), the capillary pressure generated by a wick increase with the decrease of pore radii. However it does not mean that the smaller is the pore size the better is the performance. To choose the right kind of wick structure, many other properties need to be considered such as permeability, effective thermal conductivity and compatibility with the working fluid and the container.

\begin{tabular}{|c|c|c|c|}
\hline Wick type & $\begin{array}{c}\text { Capillary } \\
\text { pressure }\end{array}$ & Permeability & $\begin{array}{c}\text { Effective thermal } \\
\text { conductivity }\end{array}$ \\
\hline Wrapped screen & High & High & Low \\
\hline Sintered metal powder & High & Low & High \\
\hline Axial groove & Low & High & High \\
\hline Open annulus & Low & Very High & \\
\hline Open artery & Low & High & High \\
\hline Integral artery & High & Relatively Low & High \\
\hline
\end{tabular}

Table 3.1 Comparison of major properties of some commonly used wick structure.

In this investigation, we selected the sintered silver powder as the wick structure based on the following listed considerations:

1. Since LTCC has low thermal conductivity, a wick structure with high effective thermal conductivity can help to reduce the temperature gradient.

2. The high capillary pressure of the sintered metal powder can help to raise the capillary limit, which is the most commonly encountered limit for mini scale heat pipe.

3. Sintering silver powder is well adaptable to LTCC technology 
The biggest disadvantage of the sintered metal powder structure is its low permeability, which is the property of a porous material that characterizes its ability to transmit liquid under the action of an applied pressure gradient.

\section{Develop of new silver powder wick}

The ideal wick should have high capillary pressure and high permeability. But they conflict with each other in that, with decrease in pore size, the capillary pressure increase while the permeability decrease.

Our solution to this problem is developing a porous silver powder to server as the wick material. The idea is combing several fine silver particles into one big particle. The big particle therefore has a rugged surface because of the small particles on it. By using this porous silver powder as the sintered powder wick structure, the small pore radii of the fine powder can provide large capillary pumping, while the high permeability of the big particles can give the heat pipe a small liquid pressure drop and therefore higher heat transport capacity.

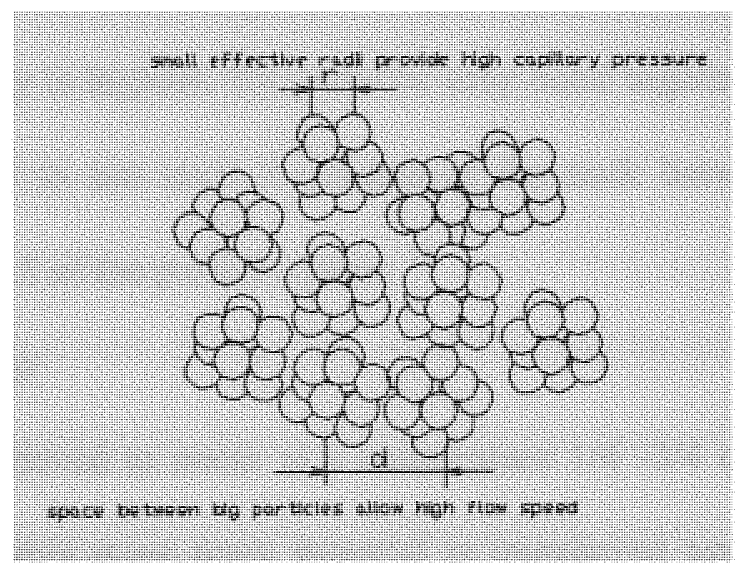

Fig 3.29 Illustration of the porous silver powders 


\section{Fabrication of porous silver powder}

From the theory of sintering, it is possible to sinter the small particles into bigger particles. As the surface is a region of high energy, there is a thermodynamic tendency for the surface to lower its surface free energy. During sintering, this tendency will drive the adjacent particles to join each other which reduces the surface area and hence the amount of surface free energy.

The first theory of sintering was rendered by Frenkel, Pines, Ivensen and Kuczynski in the middle of $20^{\text {th }}$ century ${ }^{31}$. The research work have been continued and further developed by many other scientists. According to sintering theory, the sintering process can be broadly placed into three stages ${ }^{32} 33$ :

\section{Early stage}

This stage occurs when the substance attains 1/4 of its melting point in Kelvin degree. At this stage, particles do not lose their individuality, nor merge or re-crystallize, and no appreciable shrinkage of compact powder will occur. However the particles may rearrange themselves to achieve the most points of contact. Also, at the points of contact where the surface energy is highest, the particles may bond together to form a neck. the initial stage is assumed to last until the radius of the neck between the particals has reached a value of $0.4-0.5$ of the particle radius. ${ }^{34}$

2. Intermediate stage

This stage is believed to occur at a temperature $1 / 4-3 / 4$ of its melting point in Kelvin degree. During this stage more material is transferred towards the neck of the particles causing shrinkage and a decrease in the interstitial porosity. As this happens some of the particles increase in size at the expense of others, this is known as grain 
growth. Shrinkage only occurs when material is transferred from the body of the particle or the boundary of the grain. the intermediate stage normally covers the major part of the sintering process; it is taken to end when the density is about 0.9 of the theoretical. ${ }^{35}$

\section{Final stage}

At this stage densification process will finish, and the size of the grains will continue to increase. Also most of the remaining pores are removed by vacancy diffusion along grain boundaries.

Sintering mechanisms could be one or a combination of the following mechanisms: viscous or plastic flow; evaporation and condensation; volume diffusion and surface diffusion. ${ }^{36}$ Fig 3.30 scheme two spherical particles connected by a neck.

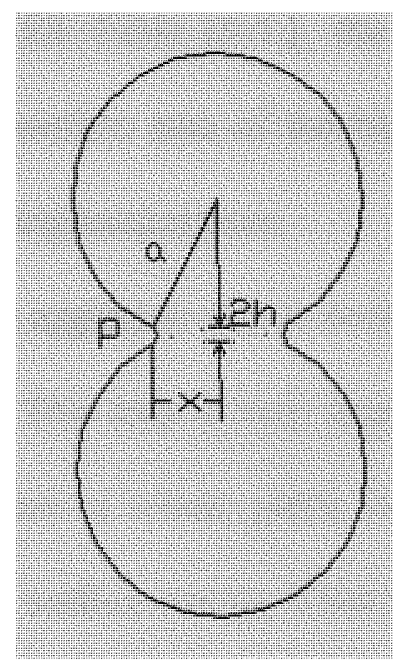

Figs 3.30 Schematically show of two spherical particles connected by a neck

While $\mathrm{X}$ is the radius of the interface; $\mathrm{t}$ is the time of heating at the given temperature. The relationship between the radii of the neck and time is determined by the mechanism and could be approximately described as below ${ }^{35}$. 
Viscous or plastic flow: $x^{2}-t$

evaporation and condensation: $\mathrm{x}^{3}-\mathrm{t}$

volume diffusion: $\mathrm{x}^{5}-\mathrm{t}$

surface diffusion: $\mathrm{x}^{7}-\mathrm{t}$

Normally it is believed that the plastic deformation occurs mostly in the early stage.

At the intermediate and final stage, the diffusion at an atomistic level controls the sintering process ${ }^{37}$.

From the review of the sintering theory mentioned above, the small sliver particles should be sintered at early or intermediate stage in order to join into big particles while keep the maximum porosity. since the melting point of silver is $1234 \mathrm{~K}$ [From Young, Hugh D., University Physics, 7th Ed. Table 15-4.], the sintering temperature should be between 34 and $651.5^{\circ} \mathrm{C}$. The surface area of the big particles can be controlled by adjust the sintering time and sintering temperature.

Before sintering, an additional aggregate step is needed to mechanically combine the small particles into big particles. This step is very important in that the small particles have a tendency of combining into a whole piece instead of many individual large particles to get the minimum free surface energy. Thus the only way to make individual large particles is to initially aggregate the small particles into big particles and sinter them separately. In addition this step can make the small particles contact each other intimately and thus ensure effective sintering to occur between them.

To bind the small particles together into a cluster, a binding material is needed. This material should provide "stickiness" so that a very thin film of this material on the surface of the silver particles can bind them together, and it is easy to burn off. Also its 
burn off temperature should be a little bit higher than the sintering temperature of the particles to make sure that the particle is ready to sinter when it is burned off.

It was found that Polyvinyl Butyral (PVB) is a good binding material for this application. PVB is commonly used in industry to provide enhanced flexibility, toughness and adhesion in solvent-borne coatings and inks, and adhesive or binder applications. Butvar resins are used in general industrial and wood coatings, wash primers, ceramic substrates, composites and structural adhesives, and gravure or flexographic inks. In LTCC industry, PVB is often used in the binding system of the green tape paste.

To use PVB as the binding material, it was firstly dissolved by acetone into saturated solution. The solution is then sprayed onto a thin layer of fine silver powders. By doing so, the tiny mist droplet can adhere the small particles into bigger particles. After that, the large particles are categorized by passing through mesh. Fig 3.31 shows the picture of a big particle congregated from many small particles.

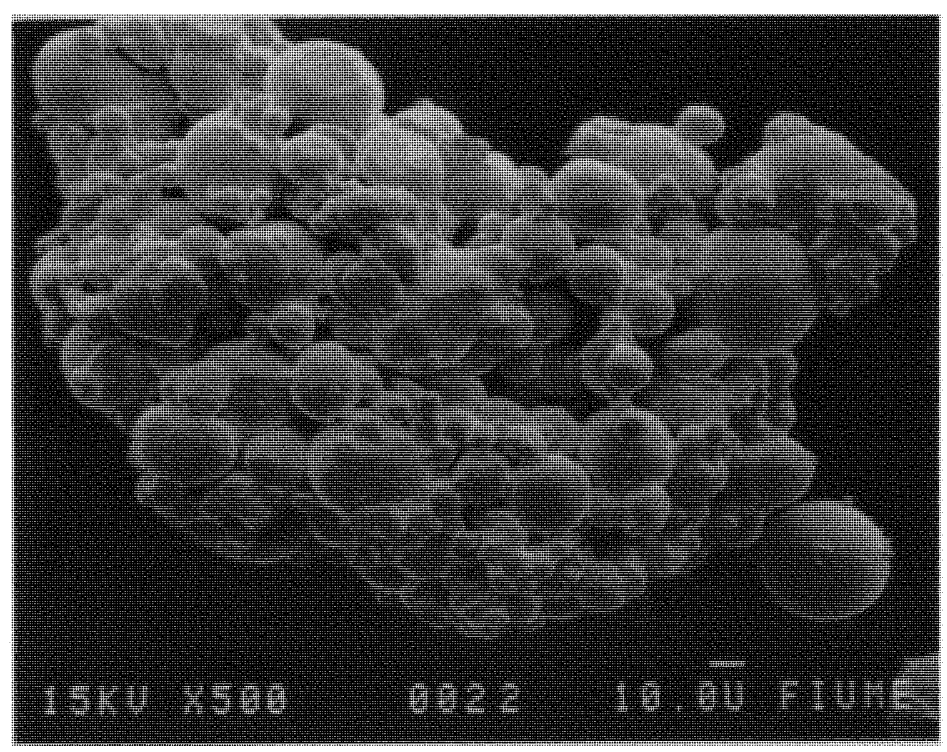

Fig 3.31 Picture of a big particle congregated from many small particles 
From the picture it could be seen that the small particles are tightly bonded together while the layer of PVB is so thin that it is almost invisible.

PVB can only provide temporary mechanical binding, which is relatively weak and thus easy to be broken. Sintering is therefore an indispensable step to get a durable lifetime binding of the small particles. To determine the sintering temperature, the TGA curve of PVB was tested. Fig 3.32 show the TGA curve of PVB.

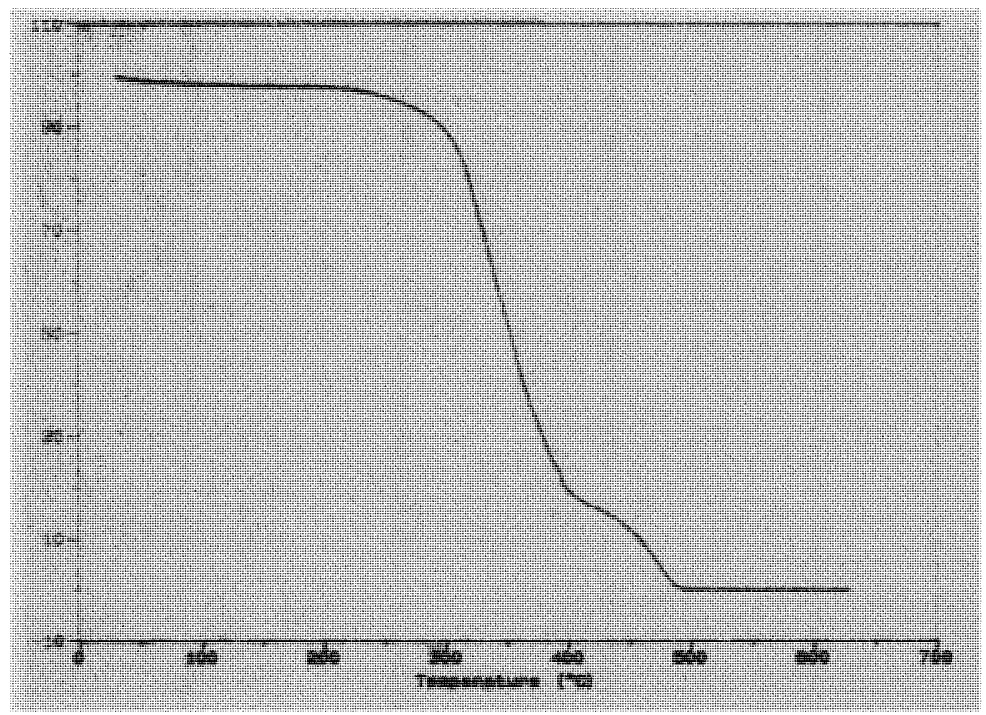

Fig 3.32 TGA curve of PVB

From the fig it could be seen that the PVB begin to loss its weight at $300{ }^{\circ} \mathrm{C}$. from 300 to $400{ }^{\circ} \mathrm{C}$, the curve drops steeply, indicating a rapid burn off process is occurring. The total weight loss during this range is as big as about $80 \%$. The rest material is burned off between 400 and $475{ }^{\circ} \mathrm{C}$ at a slower rate. The whole material is completely burned after $475^{\circ} \mathrm{C}$. Based on the TGA curve of PVB and the sintering theory mentioned above, the sintering temperature should between $475^{\circ} \mathrm{C}$ and $650^{\circ} \mathrm{C}$. From experiments, it was found that the influence of temperature is not significant as far as it is in this range. The sintering profile is determined as ramping the temperature to 
$600{ }^{\circ} \mathrm{C}$ at $5{ }^{\circ} \mathrm{C} / \mathrm{min}$, followed by a held for 2 hours to sinter the fine particles together. After cool down, the final powders go through mesh again to be categorized. Fig 3.33 shows the picture of a large silver particle after sintering. Note the rugged surface of the big particle is made of numerous small particles, just as expected. Compared with Fig 3.31 , it could be seen that the small powders are permanently bonded together by the sintered neck between the particles.

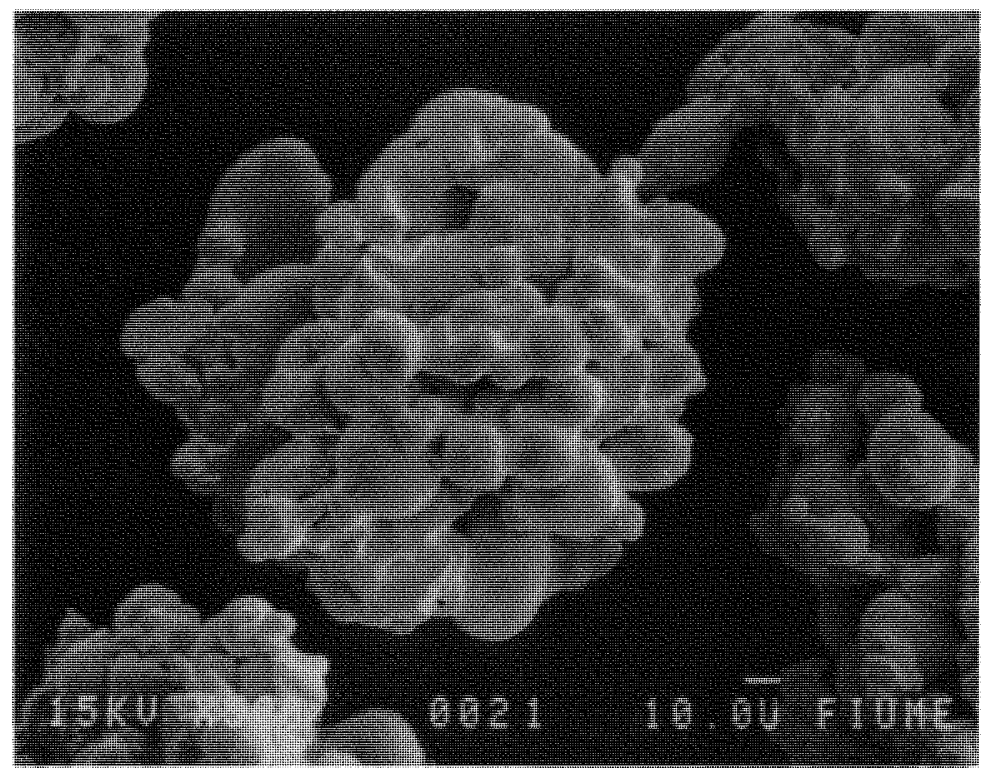

Fig 3.33 Picture of big silver particle sintered from numerous small particles

\section{Test of wick structure}

An important property of wick structure is its capillary limit, which is the capacity of the wick to supply condensate back to the evaporate section. When the wick structure cannot provide sufficient condensate back, dry out would occur at the evaporate section, and the temperature at the evaporate area would suddenly increase.

In this investigation, the capillary limit of the wick structure was characterized by testing its maximum mass transmit rate of the wick, which is determined by the 
maximum capillary pressure, permeability, and thickness of the wick. To test the maximum mass transmit rate of the porous wick structure, an experimental test structure similar to the working operation of the heat pipe was set up.

\section{Experimental setup}

The experimental setup is shown schematically in Fig 3.34

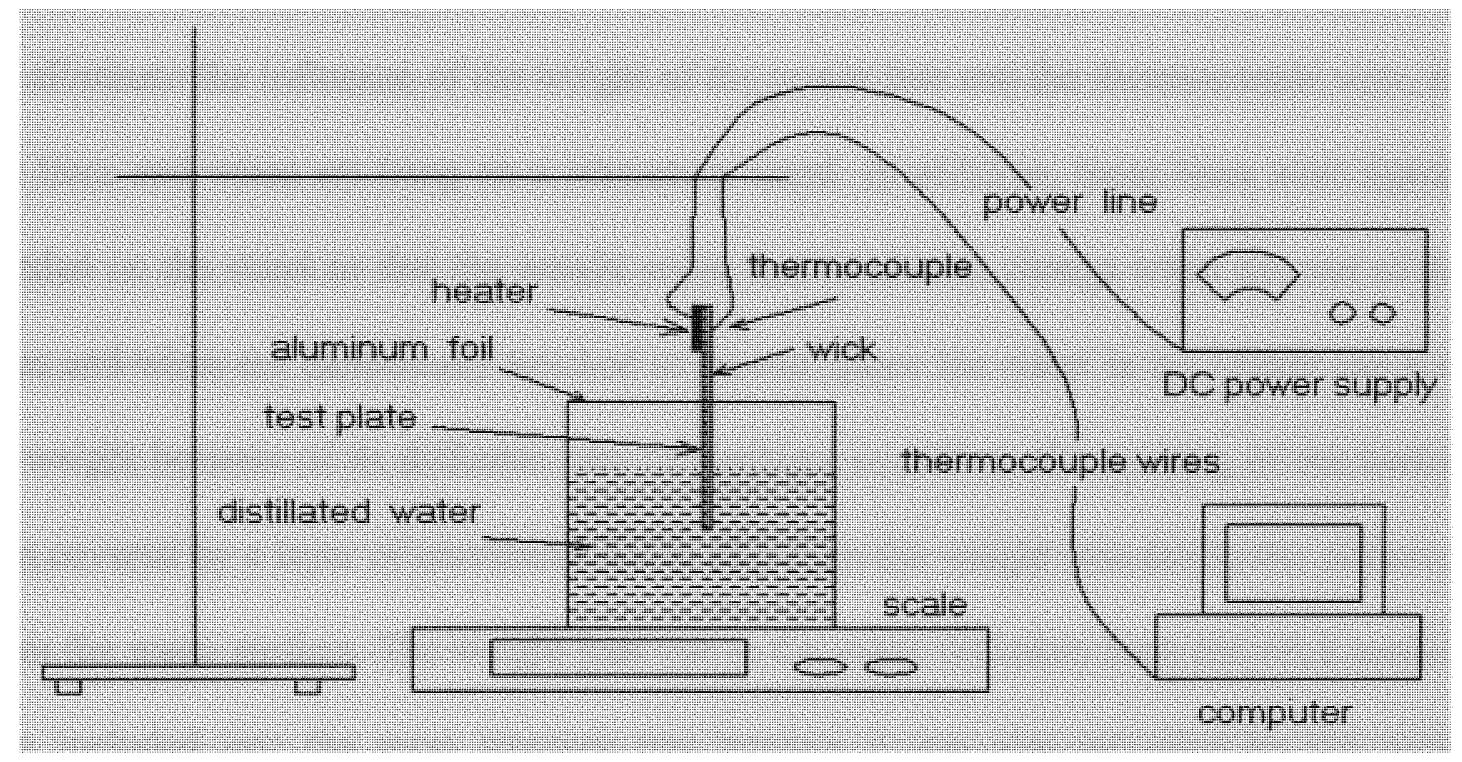

Fig 3.34 Experimental setup for testing mass transmit rate

The experimental set-up use a testing plate with the wick sintered onside. The testing plate is made of 4 layers of LTCC tape and has a dimension of $11(\mathrm{~W}) * 100(\mathrm{~L}) * 0.5(\mathrm{~T}) \mathrm{mm}$. Porous silver powder wick was sintered on one side of the testing plate. On the other side, a serpentine platinum thick film resistor was sintered at one end to act as the heat source. The heater was insulated by using fire glass blanket. The power used by the heater was supplied by a regulated DC power supply. To measure the temperature of the evaporate section; a type $\mathrm{K}$ thermocouple was bonded on the wick, right above the heater. The data of the thermocouple was collected by a Scanning 
Thermocouple thermometer. The testing plate was secured vertically on a beaker. Distilled water was added to the beaker so that certain length of the wick is dipped into the water. The height of the water level can be varied so that the maximum mass transmit rate of the wick can be tested at different wick length. The testing cell, including the beaker, testing plate and the power line, thermocouple onside, was put a Denver Instrument XP-600 digital scale. The scale has a range of $600 \mathrm{~g}$ and an accuracy of $0.02 \mathrm{~g}$. To eliminate the influence of the weight of the power line and the thermocouple wire, all the lines and wires are hung on a laboratory stand. In addition, these lines were tightly bonded on the stand so that the weight under test would not change when the rest of the lines and wires are incidentally touched or moved. Since the water in the beaker can lose its weight because of its diffusion into the ambient condition, the opening of the beaker was covered by a layer of aluminum foil to eliminate the weight loss due to the diffusion from the water surface. The weight lose due to the water diffusion from the wick surface was included into the mass transmit rate because it was also provided by the wick. However it was found to be as small as $0.018 \mathrm{~g} / \mathrm{min}$, and thus was negligible anyway.

Experimental procedure and results:

When power is input into the heater, the test setup would loss weight due to the evaporation of the water in the wick. Unless its maximum capacity was meet, the capillary force of the wick can continuously supply water to the evaporate area. The mass transmit rate at given input power level can be tested by measuring the loss of the water over a certain period of time of operation. At any one of the power levels, the power was 
set and the wick allowed to reach steady state. The steady state means the temperature did not change with time. However, during test it was found that the temperature data oscillated in a range of $0.1 \sim 1{ }^{\circ} \mathrm{C}$ due to the dynamic local temperature change and the resolution of the data acquisition system. Steady state is reached when the temperature did not change in a steady perceivable direction (up or down). After the wick reach the steady state, it was allowed to operate over a certain period of time, 10 minutes in our case. Since the temperature oscillated in a range of $0.1-1^{\circ} \mathrm{C}$, so the temperature was recorded every minute and the even temperature during the testing period was used. The weight loss during this period of time was recorded, and the mass transmit rate was calculated by relation: $\mathrm{m}=\mathrm{M} / \mathrm{t}$

The primary objective of the test is to find the maximum mass transmit rate of the wick at different wick length. To do this, the input power level was slowly increased and the mass transmit rate at each of the power level was tested. The maximum mass transmit rate is the one when the dry out occur, which can be monitored from the temperature at the evaporate section.

From the experiment data, it was found that, with the increase of the input power, the temperature rise steadily at the beginning. However when temperature approach to $100^{\circ} \mathrm{C}$, it reach a plateau. During this period the temperature rise very slowly with the increase of the input power. This is because the evaporation of the water removed enormous heat from the wick, thus keep the temperature almost constant. The plateau can continue as long as the wick can provide enough water for evaporating. When the maximum mass transmit rate was met, the dry-out occurred and the temperature was 
found to jump suddenly. Table 3.2 list the temperature and the mass transfer rate at various input power level for wick height of $7.5 \mathrm{~cm}$.

\begin{tabular}{|c|c|c|c|c|}
\hline Current $(\mathrm{A})$ & Voltage $(\mathrm{V})$ & Power $(\mathrm{W})$ & $\begin{array}{c}\text { Mass transmit } \\
\text { rate }(\mathrm{g} / \mathrm{min})\end{array}$ & $\begin{array}{c}\text { Even } \\
\text { temperature }\left({ }^{\circ} \mathrm{C}\right)\end{array}$ \\
\hline 0.9 & 4.5 & 4.05 & - & 65 \\
\hline 1 & 5 & 5 & - & 70 \\
\hline 1.1 & 5.5 & 6.05 & - & 75.1 \\
\hline 1.2 & 6 & 7.2 & - & 80 \\
\hline 1.3 & 6.5 & 8.45 & - & 84 \\
\hline 1.4 & 7 & 9.8 & - & 87.6 \\
\hline 1.5 & 8 & 12 & 0.292 & 90 \\
\hline 1.6 & 8.5 & 13.6 & 0.256 & 93.2 \\
\hline 1.7 & 9 & 15.3 & 0.276 & 94.7 \\
\hline 1.8 & 9.5 & 17.1 & 0.284 & 96.6 \\
\hline 1.9 & 10 & 19 & 0.332 & 97.2 \\
\hline 2 & 10.5 & 21 & 0.38 & 98.1 \\
\hline 2.1 & 11 & 23.1 & 0.42 & 98.6 \\
\hline 2.2 & 11 & 24.2 & 0.42 & 99.1 \\
\hline 2.3 & 11.5 & 26.45 & 0.48 & 99.4 \\
\hline 2.4 & 12 & 28.8 & 0.53 & 99.7 \\
\hline 2.5 & 12 & 30 & 0.54 & 99.9 \\
\hline 2.6 & 12.5 & 32.5 & dry & 120 \\
\hline
\end{tabular}

Table 3.2 Mass transmit rate at different input power level (wick height $=7.5 \mathrm{~cm}$ ) 


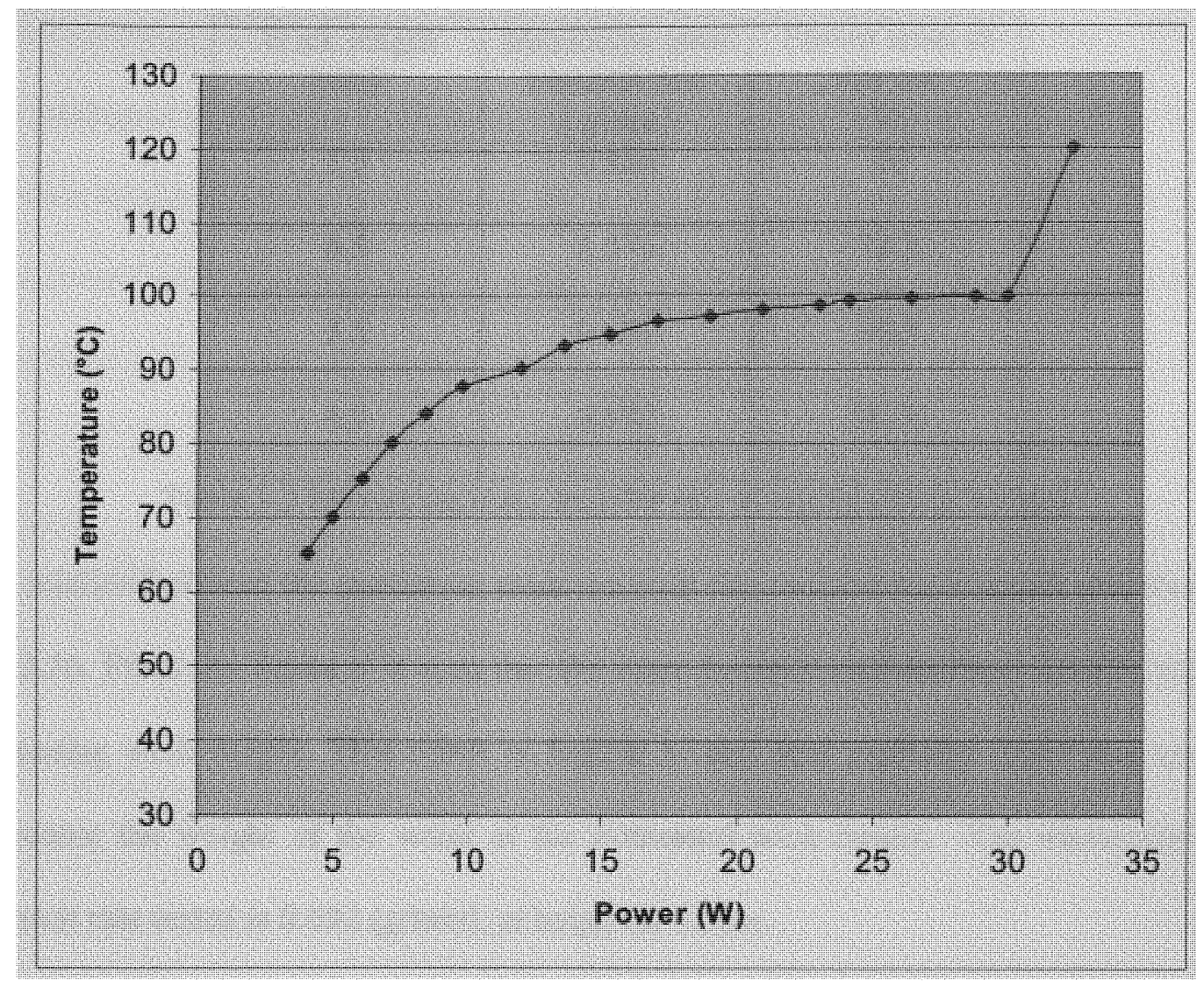

Fig 3.35 Mass transmit rate at various power levels, for wick height $=7.5 \mathrm{~cm}$

The relation between the input power and the temperature was also shown in fig 3.35. From the data it could be seen that, at the beginning, the temperature rise steadily with the input power. At the power level of about $18 \mathrm{~W}$, it met the plateau. During this period, the input power increased $20 \mathrm{~W}$ while the temperature only rise about $2{ }^{\circ} \mathrm{C}$, indicating that most of the heat was removed by the evaporating of water. The dry-out state was found to occur at the input power level of $39.9 \mathrm{~W}$. At that moment the temperature was found to suddenly jump to over $120^{\circ} \mathrm{C}$. To prevent the heater burnout; the power was then immediately turned off.

To test the maximum mass transmit rate of various wick lengths, the test was repeated at various water levels. The result is listed in Table 3.3. 


\begin{tabular}{|c|c|c|}
\hline $\begin{array}{c}\text { Wick length } \\
(\mathrm{cm})\end{array}$ & $\begin{array}{c}\text { Maximum mass } \\
\text { transmit rate } \\
(\mathrm{g} / \mathrm{min})\end{array}$ & $\begin{array}{c}\text { Power level at } \\
\text { dry out } \\
(\mathrm{W})\end{array}$ \\
\hline 7.5 & 0.540 & 30 \\
\hline 6.5 & 0.576 & 32.2 \\
\hline 5.5 & 0.631 & 36.5 \\
\hline 4.5 & 0.692 & 38.36 \\
\hline
\end{tabular}

Table 3.3 Maximum mass transfer rate at various wick heights

The relation between the maximum mass transmit rate and the wick length was shown in Fig 3.36. From the figure it is seen that the mass transmit rate decrease lineally with the increasing wick height. This result is logical in that less capillary force was spent to overcome the weight of the water at the decreased wick height. The maximum mass transmit rate tested is $0.692(\mathrm{~g} / \mathrm{min})$, at height of $4.5 \mathrm{~cm}$.

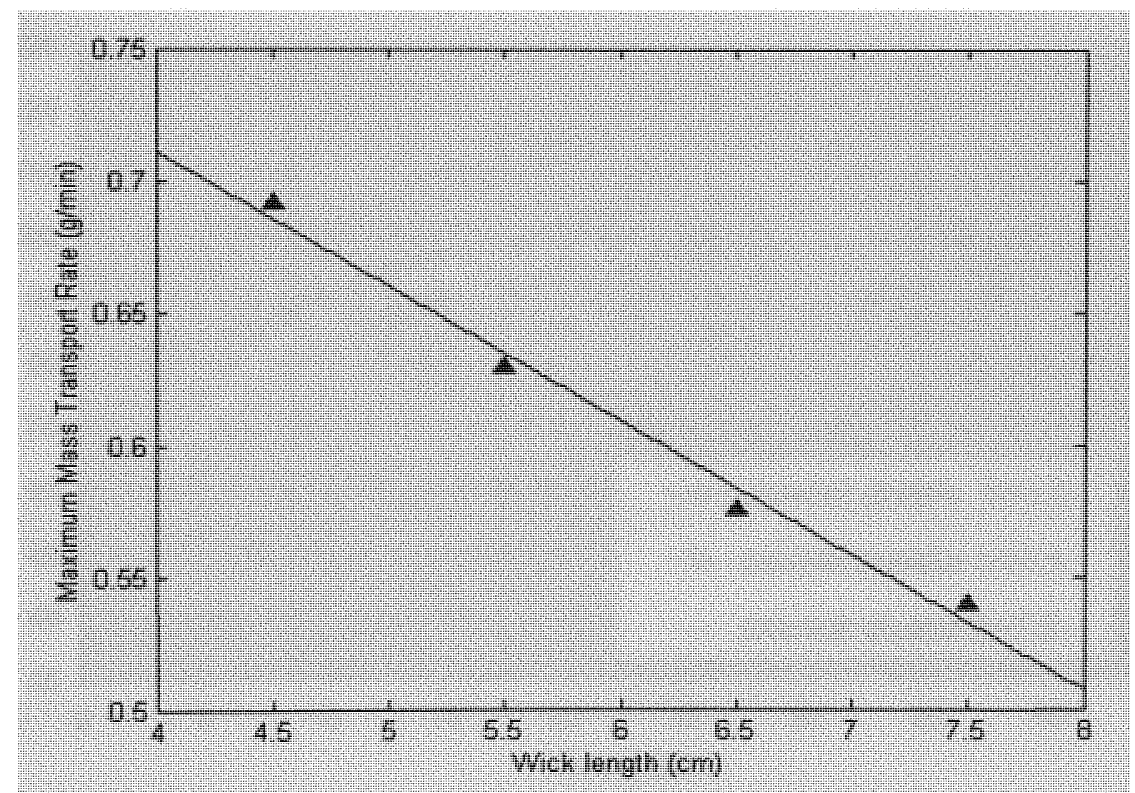

Fig 3.36 Maximum mass transmit rate at various wick heights 
In this investigation, a wick made by normal sintered silver powder (mesh size $=100)$ was also fabricated to compare with the porous powder cluster wick. The experimental data for wick height of $4.5 \mathrm{~cm}$ were plotted in figure 3.37 . To provide comparisons, the data of the porous powder cluster wick at height of $4.5 \mathrm{~cm}$ and $7.5 \mathrm{~cm}$ were also plotted in the same figure. The experimental data were also listed in table 3.4 .

\begin{tabular}{|c|c|c|c|}
\hline Wick type & $\begin{array}{c}\text { Wick length } \\
(\mathrm{cm})\end{array}$ & $\begin{array}{c}\text { Maximum mass } \\
\text { transmit rate } \\
(\mathrm{g} / \mathrm{min})\end{array}$ & $\begin{array}{c}\text { Power level at } \\
\text { dry out } \\
(\mathrm{W})\end{array}$ \\
\hline $\begin{array}{c}\text { Normal silver } \\
\text { powder }\end{array}$ & 4.5 & 0.44 & 22.05 \\
\hline $\begin{array}{c}\text { Silver powder } \\
\text { cluster }\end{array}$ & 4.5 & 0.692 & 38.36 \\
\cline { 2 - 4 } & 7.5 & 0.540 & 30 \\
\hline
\end{tabular}

Table 3.4 Compare powder cluster wick with normal powder wick

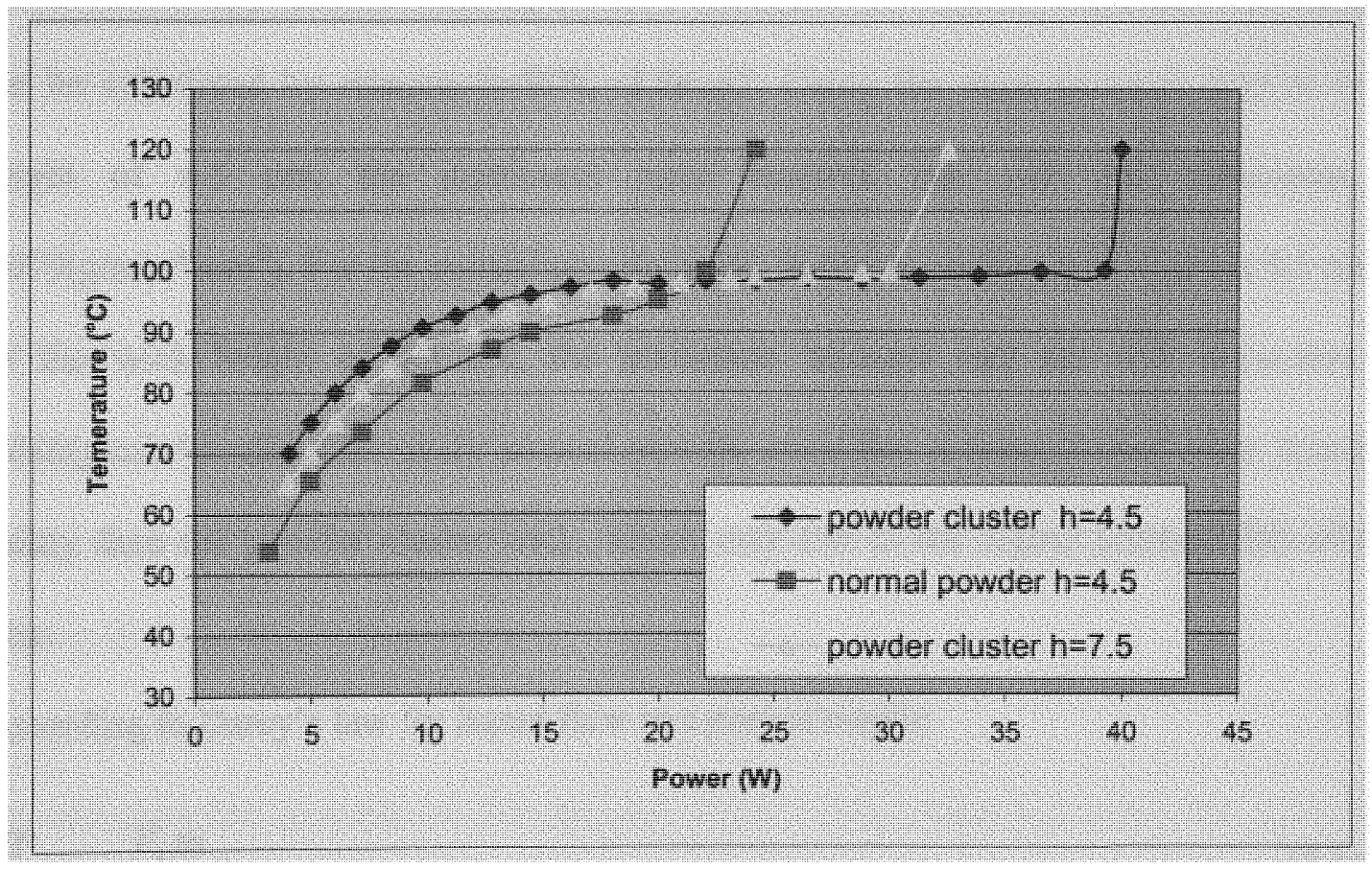

Fig 3.37 Temperature plateau in powder cluster wick and normal powder wick 
From the figure it could be seen that the wick made by normal silver powder has a much shorter plateau. The dry out was found to occur at input power level of as low as $22 \mathrm{~W}$. The according maximum mass transmit rate was $0.44(\mathrm{~g} / \mathrm{min})$. While for the wick made by silver powder cluster, the plateau is very long, indicating large mass transfer ability----0.692 $(\mathrm{g} / \mathrm{min})$ for $\mathrm{h}=4.5 \mathrm{~cm}$. Also it could be noticed that the plateau is shorter for wick height of $7.5 \mathrm{~cm}$. This is because the mass transmit rate increased with the decreased wick height. However its maximum mass transmit rate $(0.54 \mathrm{~g} / \mathrm{min})$ is even higher than the $4.5 \mathrm{~cm}$ normal powder wick.

Note the maximum transmit rate is also a function of the cross section area of the wick structure. To get the maximum transmit rate per unit area, the cross section areas of the wicks were measured. For the wick made by silver powder cluster, the cross section of the wick is approximate rectangle with a dimension of $0.8(\mathrm{~W})^{*} 11(\mathrm{~L}) \mathrm{mm}$. So the area can be calculated by relation $\mathrm{S}=\mathrm{W}^{*} \mathrm{~L}=8.8 \mathrm{~mm} 2$. Using the mass transmit data at wick height of $4.5 \mathrm{~cm}$, the maximum mass transmit rate per unit cross-area is $0.079\left(\mathrm{~g} / \mathrm{min}^{*} \mathrm{~mm}^{2}\right)$. For the normal powder wick, the cross section area is about $9.1 \mathrm{~mm}^{2}$. At the wick height of $4.5 \mathrm{~cm}$, the maximum transmit rate per unit cross-area is $0.048\left(\mathrm{~g} / \mathrm{min}^{*} \mathrm{~mm} 2\right)$. Obviously normal powder wick has a much lower mass transmit ability than the powder cluster wick, which may due to the higher permeability of the later.

According to Darcy's law for liquid flow in a porous media:

$$
\frac{d P}{d Z}=-\frac{V_{l} \dot{m}}{\rho_{l} A_{w} K}
$$

Where $V_{l}$ is the local volume-averaged velocity; $\rho_{l}$ is the liquid density. 
$\mathrm{K}$ is the permeability of a porous medium

Rearranging eqn. (3.1), get

$\frac{\dot{m}}{A_{w}}=-\frac{d P}{d Z} \frac{\rho_{l}}{V_{l}} K$

Based on this equation, given certain fluid and pressure gradient, the mass transmit rate per unit cross-area is a function of the permeability. The higher the permeability, the larger is the mass transmit rate per unit cross-area.

For wick structure with simple geometries, the permeability can be determined analytically. Although the analytical expression for the permeability of sintered metal powder wick is not available, it was believed that the higher permeability of the powder cluster wick is due to its larger porosity.

The porosity of a porous medium can be defined as the fraction of the total volume of the medium that is occupied by void space.

$\dot{\varphi}=\frac{V_{p}}{V_{t}}$

Where $V_{p}$ is the pore volume; $V_{t}$ is the total volume

The powder cluster wick has a larger porosity because its total pore volume $\left(\mathrm{V}_{\mathrm{p}, \mathrm{t}}\right)$ is the combination of the pore volume among the small powders $\left(\mathrm{V}_{\mathrm{p}, \mathrm{s}}\right)$ and the pore volume among the big clusters $\left(\mathrm{V}_{\mathrm{p}, \mathrm{b}}\right)$. ie.

$\mathrm{V}_{\mathrm{p}, \mathrm{t}}=\mathrm{V}_{\mathrm{p}, \mathrm{b}}+\mathrm{V}_{\mathrm{p}, \mathrm{s}}$

To calculate the porosity of the powder cluster wick, assuming there are n powder clusters in wick with a total volume of $\mathrm{V}_{\mathrm{t}}$, the pore volume among the cluster $\left(\mathrm{V}_{\mathrm{p}, \mathrm{b}}\right)$ can get by 
$\mathrm{V}_{\mathrm{p}, \mathrm{b}}=\eta_{1} * \mathrm{~V}_{\mathrm{t}}$

Where $\eta_{1}$ is the porosity of the powder cluster

Since each of the powder clusters is made from small powders, given the porosity of the small powder as $\eta_{2}$, the pore volume in each of the powder cluster is:

$\mathrm{V}_{\mathrm{p}, \mathrm{c}}=\eta_{2}\left(1-\eta_{1}\right) \mathrm{V}_{\mathrm{t}} / \mathrm{n}$

So, the total pore volume among the small particles is

$\mathrm{V}_{\mathrm{p}, \mathrm{s}}=\mathrm{n} \mathrm{V}_{\mathrm{p}, \mathrm{c}}=\eta_{2}\left(1-\eta_{1}\right) \mathrm{V}_{\mathrm{t}}$

Hence

$\mathrm{V}_{\mathrm{p}, \mathrm{t}}=\mathrm{V}_{\mathrm{p}, \mathrm{b}}+\mathrm{V}_{\mathrm{p}, \mathrm{s}}=\left(\eta_{1}+\eta_{2^{-}}-\eta_{1} \eta_{2}\right) \mathrm{V}_{\mathrm{t}}$

The total porosity of the powder cluster wick is:

$\eta_{\mathrm{w}}=\eta_{1}+\left(1-\eta_{1}\right) \eta_{2}$

While for the normal powders, there is no $V_{p, s}$ term.

Assume the big particles are the same size as the powder clusters.

$\mathrm{V}_{\mathrm{p}, \mathrm{t}}=\mathrm{V}_{\mathrm{p}}=\eta_{1} * \mathrm{~V}_{\mathrm{t}}$

The total porosity of the normal powder wick is:

$\eta_{\mathrm{w}}=\eta_{1}$

Compare expression (3.9) with (3.11). It could be seen that even if the powder size is the same, the porosity of the powder cluster is larger than the normal powder.

Both the porosities of the wick powders were measured in this investigation. For the normal silver powder, the porosity is about 0.517 , while for the silver powder cluster it is about 0.81 . The experiment result agrees with the theoretical analysis. 


\section{Working fluid}

In the heat pipe, the wick structure is saturated by the working fluid. The fluid goes through an evaporation-condensation cycle, thus transporting heat from input to output end. Selection of a suitable working fluid is a very important issue in heat pipe design and based on many considerations. The prime requirements of working fluid are listed below.

1. Compatibility with wick and wall material

The working fluid must be compatible with the container, wick and welding material to assure the longevity of a heat pipe. Incompatible material may cause chemical reaction between parts or galvanic cell, or, at operating temperature; the container material may be solvable in the working fluid or may catalyze its decomposition.

2. Good thermal stability

A heat pipe cannot work if its working fluid decomposes at the operating temperature. A good thermal stability is therefore a necessary feature of the working fluid.

3. Wet-ability of wick and wall materials

For effective capillary pumping through the heat pipe wick. A fluid that has good wetting ability must be used. Since the maximum capillary pressure is reached when the angle of contact is zero for a wetting fluid, fluid with very small contact angle with the wick and the container material is desired.

4. Vapor pressure of the working fluid is not too high or low over the operating temperature rang. 
When working, the vapor pressure should be high enough to push the vapor to travel from the evaporator section to the condensate section. But if the vapor pressure is too high, large temperature gradient and flow instability may occur due to the high vapor velocity.

\section{High latent heat}

To maintain low-pressure drop within the heat pipe, minimum fluid is used. Therefore a high latent heat of vaporization is desired in order to transfer large amount of heat with minimum fluid flow.

6. High thermal conductivity

The thermal conductivity of the working fluid should be high in order to minimize the radial temperature gradient and to reduce the possibility of nucleate boiling at the wick or wall surface,

7. Low liquid and vapor viscosities

In order to minimize the resistance to flow, fluids with low vapor and liquid viscosities are desired.

8. High surface tension

A high surface tension can generate high capillary driving force. Thus help to avoid the capillary limitation and enable the heat pipe to operate against gravity.

9. Acceptable freezing point.

Heat pipe usually start from the ambient temperature, which is either lower or higher than the operating temperature, thus a proper freezing point is required.

To choose a suitable working fluid, the first consideration is the operating temperature range. According to their operating range, heat pipe can be classified into four categories: 
cryogenic, low, medium, and high temperature range. Within each of the approximate temperature range several possible working liquid may exist; and various characteristics must be examined to determine the most acceptable fluid. Table 3.2 list the melting and boiling point of some common working fluids for low temperature heat pipe and their recommended operating range.

\begin{tabular}{|c|c|c|c|}
\hline Working fluid & $\begin{array}{c}\text { Melting point, } \mathrm{K} \text { at } \\
1 \mathrm{~atm}\end{array}$ & $\begin{array}{c}\text { Boiling point, } \mathrm{K} \text { at 1 } \\
\text { atm }\end{array}$ & Useful Range, $\mathrm{K}$ \\
\hline Ethane & 89.9 & 184.6 & $150-240$ \\
\hline Freon 22 & 113.1 & 232.2 & $193-279$ \\
\hline Ammonia & 195.5 & 239.9 & $213-373$ \\
\hline Freon 21 & 138.1 & 282.0 & $233-360$ \\
\hline Freon 11 & 162.1 & 296.8 & $233-393$ \\
\hline Pentane & 143.1 & 309.2 & $253-393$ \\
\hline Freon 113 & 236.5 & 320.8 & $263-373$ \\
\hline Acetone & 180.0 & 329.4 & $273-393$ \\
\hline Methanol & 175.1 & 337.8 & $283-403$ \\
\hline Flutec PP2 & 223.1 & 349.1 & $283-433$ \\
\hline Ethanol & 158.7 & 351.5 & $273-403$ \\
\hline Heptane & 182.5 & 371.5 & $273-423$ \\
\hline Water & 273.1 & 373.1 & $303-473$ \\
\hline Touene & 178.1 & 383.7 & $323-473$ \\
\hline Flutec PP9 & 203.1 & 433.1 & $273-498$ \\
\hline Naphthalene & 353.4 & 490 & $408-478$ \\
\hline Dowtherm & 285.1 & 527.0 & $423-668$ \\
\hline
\end{tabular}

Table 3.5 Typical working fluids and temperature ranges

In electronic cooling applications where it is desirable to maintain junction temperature below $125-150^{\circ} \mathrm{C}$, Low temperature range heat pipe are typically used. Among the available low temperature working fluid, water, methanol, Ethanol and acetone are most widely used. Because the excellent stability and compatibility of ceramic, Any of these fluids is compatible for the heat spreader in our investigation. To 
choose the most suitable one, more properties are examined and compared. Table 3.6 listed the their thermo physical properties of saturated fluids at $100^{\circ} \mathrm{C}$

\begin{tabular}{|c|c|c|c|c|c|}
\hline Liquid & $\begin{array}{c}\text { Surface } \\
\text { tension } \\
\left(10^{-3} \mathrm{~N} / \mathrm{m}\right)\end{array}$ & $\begin{array}{c}\text { Saturation } \\
\text { pressure } \\
\left(10^{5} \mathrm{~Pa}\right)\end{array}$ & $\begin{array}{c}\text { Latent } \\
\text { heat } \\
(\mathrm{kJ} / \mathrm{kg})\end{array}$ & $\begin{array}{c}\text { Vapor/liquid } \\
\text { Thermal } \\
\text { conductivity } \\
(\mathrm{W} / \mathrm{m} . \mathrm{K})\end{array}$ & $\begin{array}{c}\text { Vapor/liquid } \\
\text { Viscosities } \\
\left(10^{-7} \mathrm{~N} . \mathrm{s} / \mathrm{m}^{2}\right)\end{array}$ \\
\hline Acetone & 13.4 & 4.43 & 689.6 & $0.0178 / 0.148$ & $98 / 1700$ \\
\hline Methanol & 15.7 & 4.0 & 1030.0 & $0.004 / 0.714$ & $123 / 2140$ \\
\hline Ethanol & 15.5 & 2.260 & 927.0 & $0.0219 / 0.167$ & $109.2 / 3180$ \\
\hline Water & 58.91 & 1.013 & 2251.2 & $0.0248 / 0.680$ & $121.0 / 2790$ \\
\hline
\end{tabular}

Table 3.6 thermo physical properties of saturated water, methanol, Ethanol and acetone at $100^{\circ} \mathrm{C}$

Based on the data, water is the most appropriate fluid in our application. Water's largest latent heat can yield the lowest mass transport rates in both liquid and vapor phases, which result in low pressure-drops and high power throughput. The surface tension of water is much higher than other fluids. This can allow it to generate higher pumping pressures than what can be achieved with any other fluid. Also water's high thermal conductivity can help to lower the temperature gradient. Another important benefit of water is that it is very safe in handling; while other fluids are flammable and have harmful vapors. 


\section{IV.Development of prototype embedded heat spreader}

\section{Heat spreader design}

In this investigation the heat spreader involved is actually an array of heat pipe with a joint evaporator section. Therefore the heat spreader works under the same principle as heat pipe. Fig 4.1 shows the design of a heat spreader.

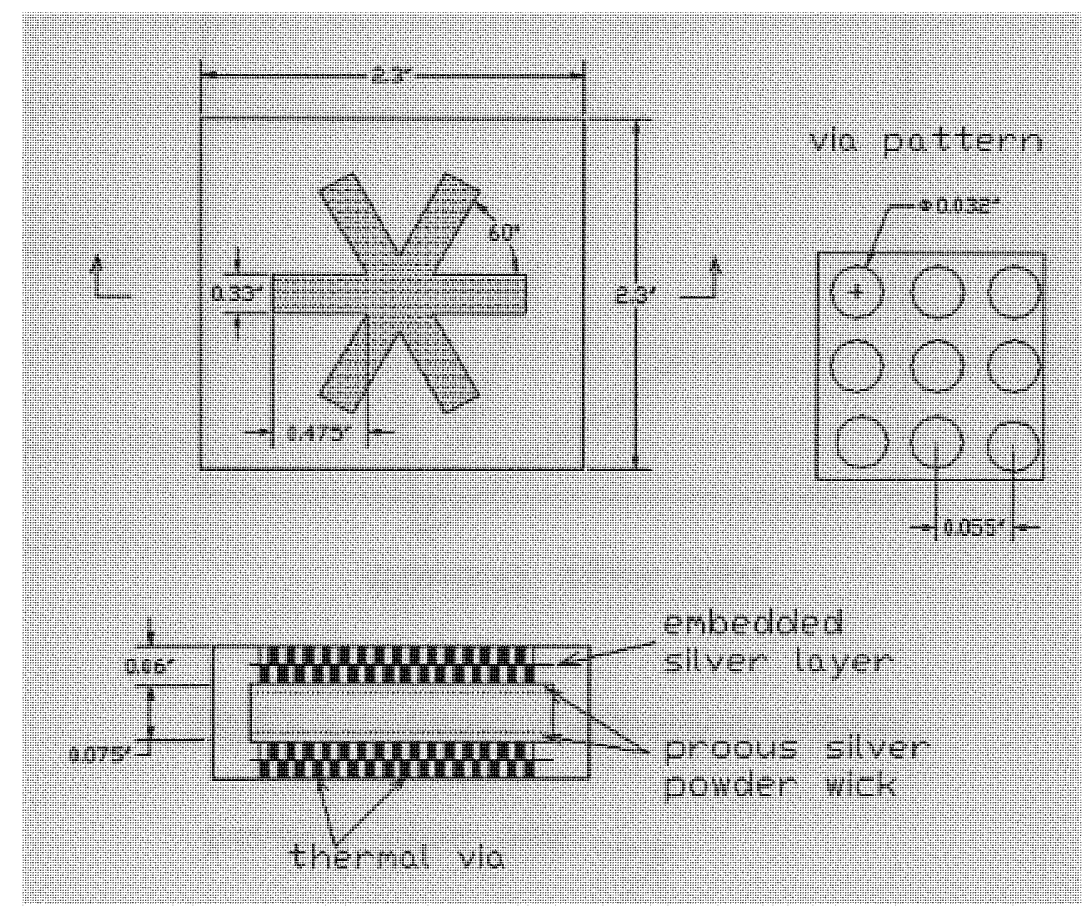

Fig 4.1 Design of a typical heat spreader

The heat spreader consists of six heat pipes which joint together in the center. The whole heat spreader is embedded in LTCC substrate. Each of the top and bottom of the heat spreader consists of eight layers of LTCC tape with thermal via designed onside to lower the heat resistance between the wick and the heat resource. Porous silver powders are sintered on the surface of inner wall, severing as the wick structure of the heat spreader. Distilled Water is used as the working fluid. The design of the heat spreader can 
be varied by changing the number and the arrangement of the heat pipes. Of course more heat pipes are preferred so that heat can be distributed to larger area for removal. To get the maximum heat distribute area, a logical solution is using a single large vapor chamber..

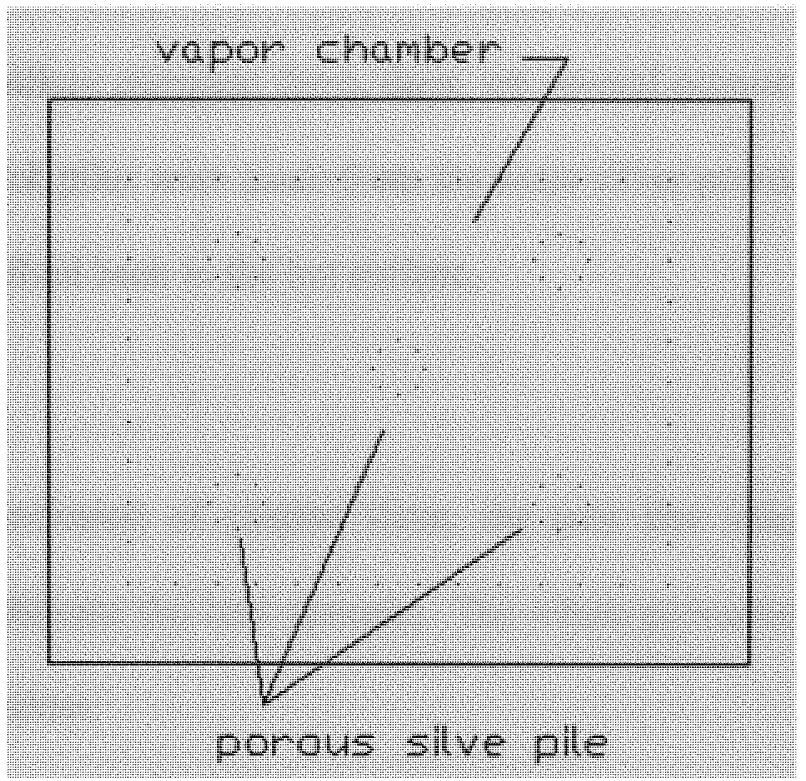

Fig 4.2 Single vapor chamber heat spreader

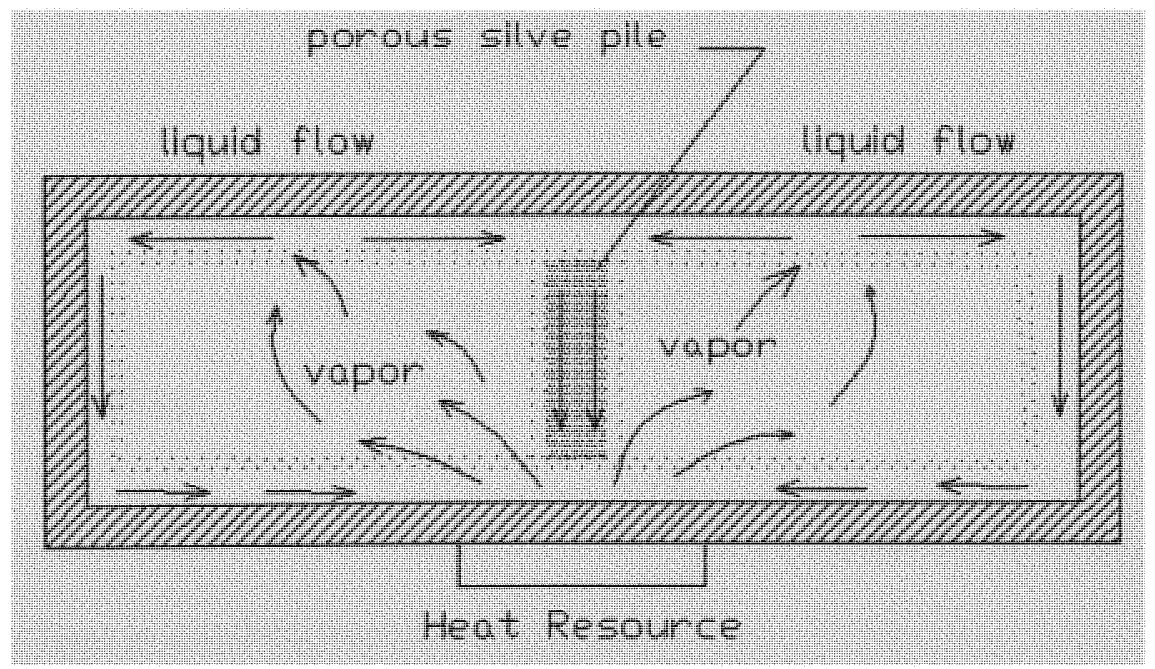

Fig 4.3 Schematic showing vapor chamber heat spreader operation 
The whole heat spreader is a single large evacuated vapor chamber with a saturated wick structure inside. As heat is applied, the working fluid at that location vaporizes, and the vapor rushes to fill the vacuum. Wherever the vapor comes into contact with a cooler surface it will condense, releasing its latent heat of vaporization. The condensed fluid returns to the heat source via capillary action in the wick structure. To provide sufficient capillary pumping force, there are several porous wick piles in the vapor chamber. These wick piles were made from the same silver powder cluster and can help to return condensed fluid back to the hot surface.

\section{Fabrication procedure}

Based on the conclusion of chapter three, the post fire using adhesive layer process was chosen to fabricate the heat spreader. The whole procedure is illustrated in fig 4.3 and summarized below. 


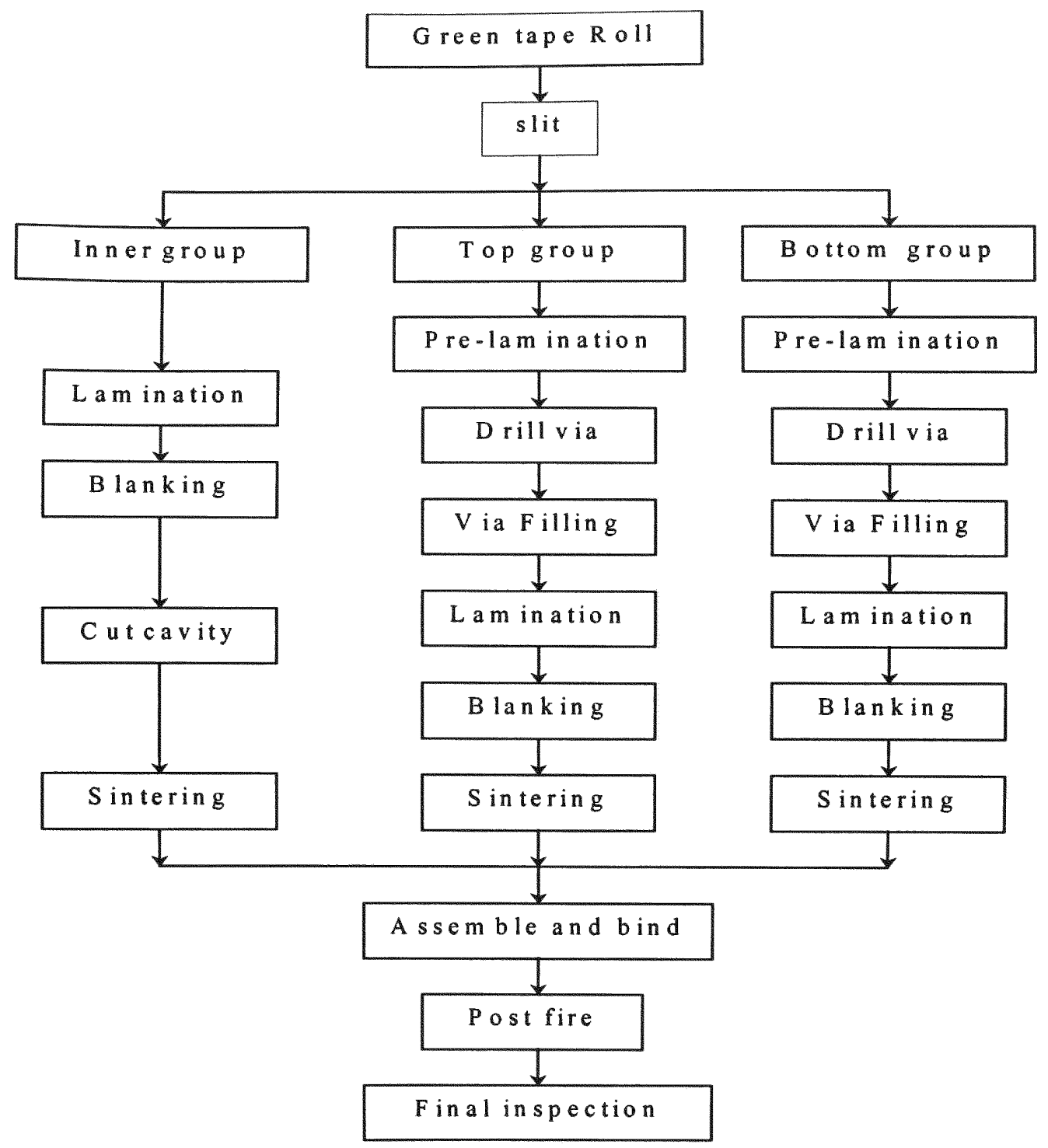

Fig 4.4 Heat spreader fabrication procedure

Slitting and blanking

This step is used to get the green sheets with the working dimension. A portion of Dupont 951 Green Tape is unrolling from the shipping roll, then it is cut with a razor into sections with dimension of $2.5 * 2.5$ inch. 
Grouping

The green sheets are grouped into top, bottom and inner groups. Each of the top and bottom group consists of 8 layers of green tapes and is further divided into 2 sub-groups. The inner group consists of 20 layers of green tapes.

\section{Lamination}

Lamination is performed using a PHI model sp-0021 manual compression press, which has $40000 \mathrm{lb}$ capacity and an $8 * 8$ inch heat platen. As recommended by the tape manufacturer, the laminate is pressed at $70^{\circ} \mathrm{C}, 3000$ psi for 10 minutes.

\section{Pre-Lamination}

This step is used to bind the individual green sheets into pieces so that via holes can be drilled on the pieces in one step. The lamination pressure is slightly lower than the recommended process. The laminate is pressed at $70^{\circ} \mathrm{C}, 2000$ psi for 10 minutes.

\section{Blanking}

The laminate is cut into the final working dimension of the green state. Also cutting off the edges helps to prevent cracks to occur at edge of the sample.

\section{Via form}

The via holes are drilled by using an OZO Divasfied model 17 micro $\mathrm{CNC}$ manufacture system. The diameter of via hole is $0.015 \mathrm{inch}$; the distance between vias is 0.032 inch 
Via fill

Via Fill is performed using a conventional thick film screen printer. Via fill ink is Dupont 6141. At the same step, a layer of via ink is printed on the surface of green tape to serve as silver layer.

Via Drying:

Via drying are accomplished in a box oven at $120^{\circ} \mathrm{C}$ for 5 minutes.

Second lamination

This step is used to get stacked via and embedded silver layer in the top and bottom green part. The process parameters are the same as the first lamination step.

Cavity cutting

Cavity is routed in the inner pieces by using the OZO Divasfied model 17 micro CNC manufacture system.

Sintering

The laminates are fired in a Fisher Scientific isotemp programmable muffle furnace using the conventional LTCC cofire profile. Temperature is ramped up at a rate of $1.5^{\circ} \mathrm{C}$ /minute Organic burnout takes place at $450^{\circ} \mathrm{C}$ for 2 hours. Peak temperature is $850^{\circ} \mathrm{C}$ for 15 minutes. 
Input Wick

To make the wick structure, porous silver powders are pasted onto the inside surface of the cavity by a thin layer of silver ink. In addition, 5 porous silver piles are fabricated inside the cavity.

Assembling and binding

The individual ceramic parts are assembled and bind together by using 951 tape paste.

Constrained Post fire

The assemblage is post fired to sinter the paste into final ceramic, and thus ensure durable binding. To eliminate the porosity of the paste, constrained sintering is used. The applied pressure is $0.2 \mathrm{psi}$. The process is performed in the Fisher Scientific isotemp programmable muffle furnace using the conventional LTCC sintering profile: Temperature is ramped up at a rate of $1.5^{\circ} \mathrm{C} /$ minute Organic burnout takes place at $450^{\circ} \mathrm{C}$ for 2 hours. Peak temperature is $875^{\circ} \mathrm{C}$ for 15 minutes

Final Inspection

The final parts are inspected under microscope. Vacuum leak testing was performed to ensure that the sample was hermetical. 


\section{V.Thermal performance testing}

The performance of the embedded heat spreader has been tested to provide conceptual validation of this technology.

\section{Experimental setup}

The experimental setup is shown schematically in Fig 5.1. The heat spreader under test was secured on a laboratory stand by a three-prong grip. The heat spreader was secured horizontally with the heating side face down, and was charged with approximately $0.8 \mathrm{ml}$ of distillated water (about $10 \%$ of the chamber volume). A serpentine pattern platinum thick film resistor with a dimension of $5 * 5 \mathrm{~mm}^{2}$ was bonded on the surface of the heat spreader to act as the heat source. The power used by the platinum heater was supplied by a regulated DC power supply with $3 \mathrm{~A}$ and 60 Volt capacities. The heat load was adjusted by varying the input voltage and current used by the heater, which were measured by two digital multi-meters. Power (P) was then calculated using the measured voltage (V) and current (I) by the relation $\mathrm{P}=\mathrm{V}^{*} \mathrm{I}$.

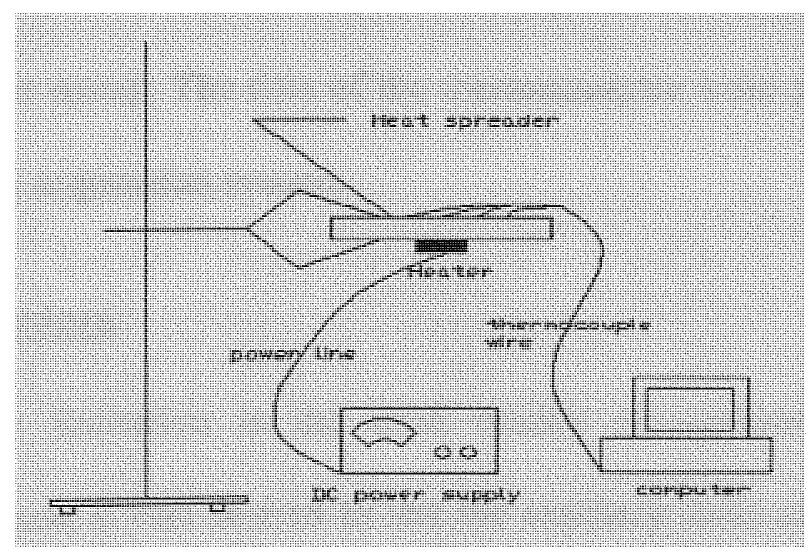

Fig 5.1 Experimental setup for testing thermal performance of heat spreader 
The heater was bonded at the center of the heat spreader by epoxy. To reduce the contact heat resistance, thermal grease was used between the heat spreader and the heater. To minimize the transfer of heat to the ambient conditions or the test fixture, an insulation fiberglass blanket was packed on the heater side of the heat spreader. The whole system was cooled by air convection without any additional heat sinks. To get the temperature distribution of the heat spreader, temperatures at different location along the diagonal line of the heat spreader were measured by using type $\mathrm{K}$ thermocouples. The location of the thermal couples was listed in table 5.1

\begin{tabular}{|c|c|}
\hline Thermocouple & Distance from center \\
\hline$\# 1$ & 0 \\
\hline$\# 2$ & 0.5 \\
\hline$\# 3$ & 0.75 \\
\hline$\# 4$ & 1 \\
\hline
\end{tabular}

Table 5.1 Location of the thermocouples

All the thermocouples were bonded on the cooling side of the heat spreader by using thermally conductive epoxy. The data of the thermocouples were acquired by a personal computer based data acquisition system.

\section{Experimental procedure}

Since the capillary limitation is the most readily encountered limitation for low temperature heat pipes, it was desired to test the capillary limit of the heat spreader. In theory, it could be done by slowly increasing the amount of the input heat until dry out occurred, which is marked by a sudden increase of the temperature near the heater 
location. However, it was found to be difficult to get the dry-out state, due to the fear of introducing heater burnout at high power level. Hence the power level was increased until the maximum temperature exceeds $90{ }^{\circ} \mathrm{C}$, beyond which the solder on the heater and the epoxy may encounter mechanical failure.

For convenience, the thermal load was adjusted according to the current used by the heater. The current was adjusted over a range of 0.3 to $1.3 \mathrm{~A}$, in a $0.1 \mathrm{~A}$ increments. At any one power level setting, the power was set and then the heat spreader was allowed to reach steady condition, which can be defined as the state when temperature at all the thermocouples locations did not change with time. The time necessary to reach the steady state varies with the size of the heat spreader, the thickness of the wall and the insulation used. During test, it was found that the steady state was typically achieved within 10 minutes. However, a period of at least 20 minutes was given prior to any data being recorded.

\section{Testing Result and analysis}

Data for the heat spreader working under various input power level was obtained and listed in table 5.2

\begin{tabular}{|c|c|c|c|c|c|c|c|}
\hline $\begin{array}{c}\text { Cooling } \\
\text { condition }\end{array}$ & $\begin{array}{c}\text { Voltage } \\
(\mathrm{V})\end{array}$ & $\begin{array}{c}\text { Current } \\
(\mathrm{A})\end{array}$ & $\begin{array}{c}\text { Power } \\
(\mathrm{W})\end{array}$ & $\begin{array}{c}\text { Temperature } \\
\text { at Thermal } \\
\text { couple \#1 }\end{array}$ & $\begin{array}{c}\text { Temperature } \\
\text { at Thermal } \\
\text { couple \#2 }\end{array}$ & $\begin{array}{c}\text { Temperature } \\
\text { at Thermal } \\
\text { couple \#3 }\end{array}$ & $\begin{array}{c}\text { Temperature } \\
\text { at Thermal } \\
\text { couple \#4 }\end{array}$ \\
\hline \multirow{2}{*}{$\begin{array}{c}\text { Nature } \\
\text { convection }\end{array}$} & 5.22 & 0.7 & 3.65 & 59.5 & 58.4 & 57.6 & 56.8 \\
\hline \multirow{2}{*}{$\begin{array}{c}\text { Forced air } \\
\text { convection }\end{array}$} & 7.47 & 0.8 & 5.18 & 77.4 & 75.6 & 74.3 & 73.4 \\
\cline { 2 - 8 } & 8.76 & 1.0 & 8.76 & 69.4 & 58.7 & 58.5 & 56.3 \\
\cline { 2 - 8 } & 10.09 & 1.1 & 11.10 & 81.9 & 79.9 & 76.6 & 64.1 \\
\cline { 2 - 8 } & 14.26 & 1.3 & 18.54 & 92.7 & 91.1 & 89.7 & 87.2 \\
\hline
\end{tabular}

Table 5.2 Temperature data of heat spreader at various power levels

The temperature distribution at various input power levels are also shown in fig 5.2 


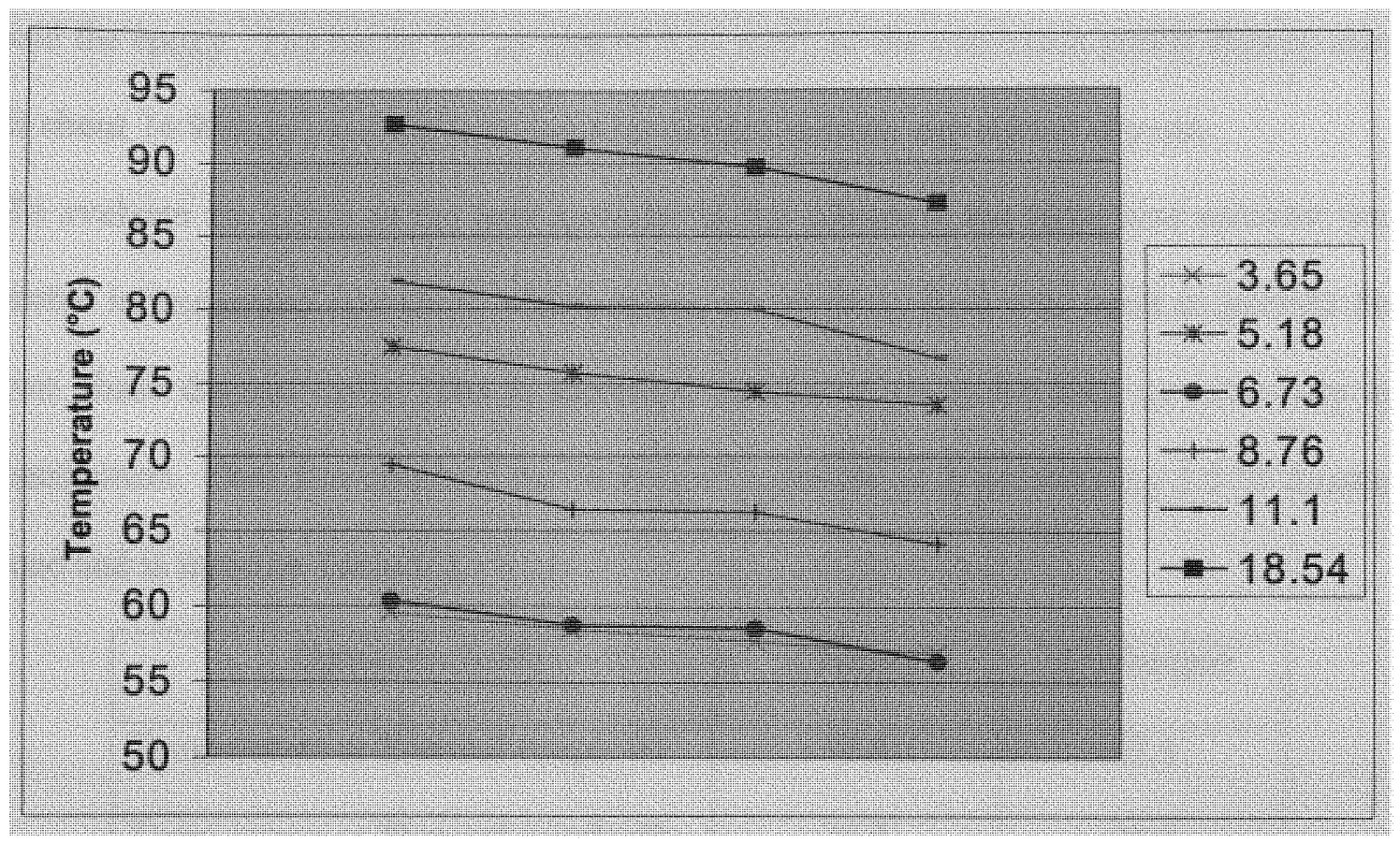

Fig 5.2 Temperature distribution at various input power levels

It should be note that the system is in nature convection condition for the test below $10 \mathrm{w}$. However, for input power higher than $6 \mathrm{w}$, an electronic fan was used to provide forced air convection. The reason is that the heat cannot be readily dissipated only through nature convection when tested in high power level. While in a low power level, it is not necessary to use the forced air convection. From the data, it can be seen that the heat spreader worked very well at low power level; the temperature is almost uniform through the heat spreader. The temperatures are higher at locations closer to center, right above the heater. With the increase of the input power, the temperature difference increases to a maximum of $5.5^{\circ} \mathrm{C}$. However this temperature difference is not significant, indicating the heat spreader did not reach its limit. In additional, the temperature at the evaporate section increase stably, compared to the sudden rise of temperature when dry out occur. 
The test was stopped at power level of $18.54 \mathrm{~W}$, due to the fear of the failure of the heater and the epoxy. The heater has an area of $0.25 \mathrm{~mm}^{2}$, so the maximum power density used is about $74 \mathrm{~W} / \mathrm{mm}^{2}$, and the heat spreader did not indicate any sign of dry out.

To evaluate the effect of the heat spreader to the substrate, the same heat spreader was tested in uncharged operation, which means no working fluid was input to provide the two phase thermal cycle. Heat is therefore transferred along the heat spreader only by conduction. Data was obtained for uncharged operation at approximately $5.2 \mathrm{~W}$ thermal load and is listed in Table 5.3.

\begin{tabular}{|l|c|c|}
\hline \multicolumn{1}{|c|}{ Operation mode } & Charged & Uncharged \\
\hline Temperature at Thermal couple \#1 & 77.4 & 87.8 \\
\hline Temperature at Thermal couple \#2 & 75.6 & 83.2 \\
\hline Temperature at Thermal couple \#3 & 74.3 & 80.0 \\
\hline Temperature at Thermal couple \#4 & 73.4 & 75.6 \\
\hline
\end{tabular}

Table 5.3 Comparison of temperature data of charged mode and uncharged mode at power level of $5.2 \mathrm{~W}$

The temperature distribution is also shown in Figure 5.3. To compare the charged mode and uncharged mode, data for charged operation at approximately $5.2 \mathrm{~W}$ thermal load was also shown in the same table and figure. 


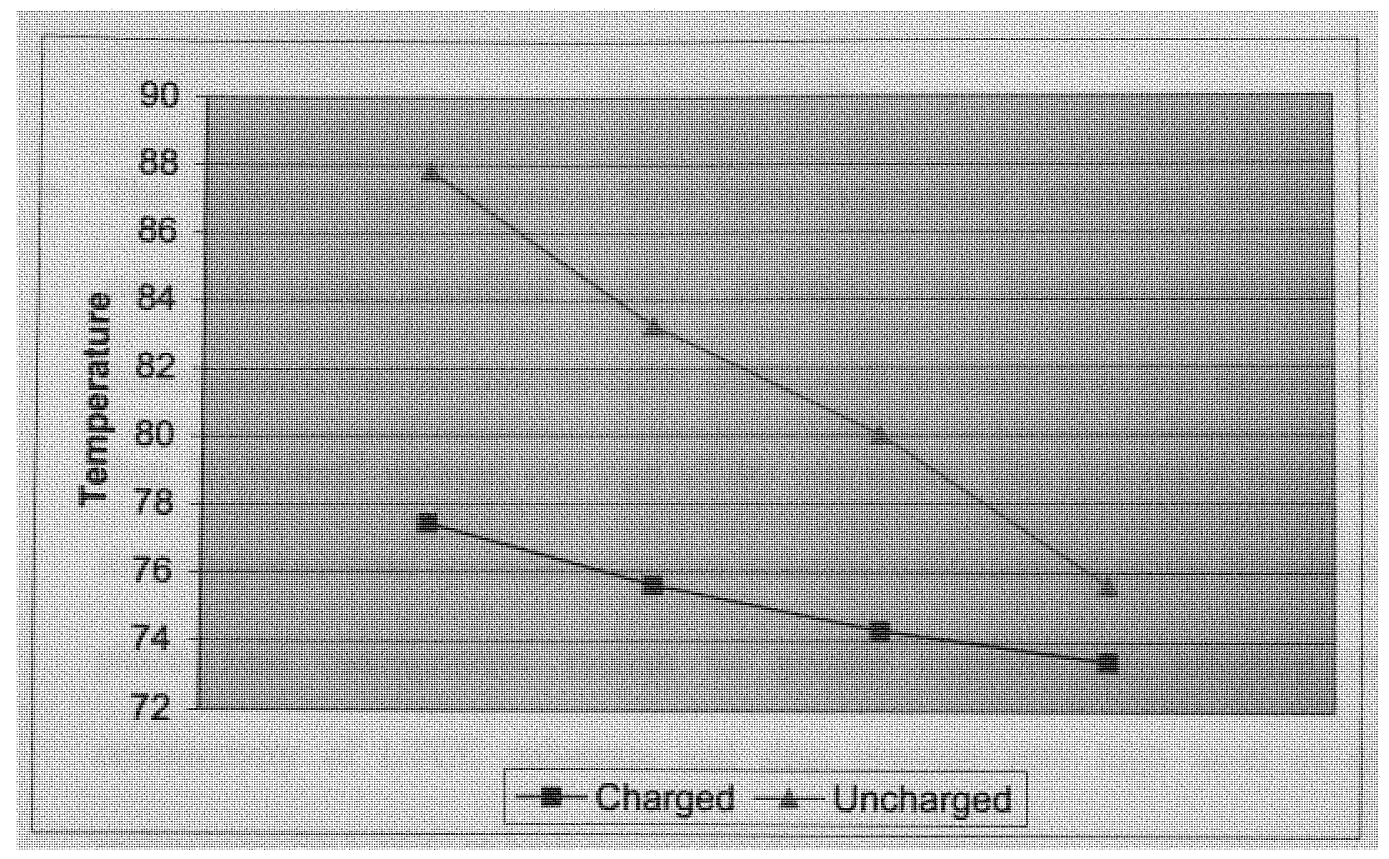

Figure 5.3 Comparison between charged and uncharged operation mode of heat spreader Form the data, it could be seen that the maximum temperature difference for the uncharged operation is as high as $14^{\circ} \mathrm{C}$, while the maximum temperature difference for the charged operation is only $2.2^{\circ} \mathrm{C}$. Also the temperature in charged mode is about 10 ${ }^{\circ} \mathrm{C}$ lower than in the uncharged operation mode. This dramatic difference is because the charged heat spreader uses the latent heat of vaporization as the principal means of energy transfer. This also proved that the developed heat spreader is very effective in transporting heat from concentrate heat source to large area for dissipating. 


\section{VI.Conclusion}

- The miniature heat spreaders have been successfully fabricated inside a LTCC substrate using modified LTCC process. The thermal performance test demonstrated that the heat spreader could work properly at power density of more than $70 \mathrm{~W} / \mathrm{mm}^{2}$ without any sign of dry out occur. The successful fabrication of the integrated heat spreader provides concept validation of using advanced twophase heat management system to greatly improve the effective thermal conductivity of LTCC substrate and thus provide very high level of cooling technology for LTCC in high power density applications.

- The overall objective of the research was satisfied with the development and testing of the prototype heat spreaders. Furthermore the key topics related to the fabrication of embedded heat spreaders in LTCC substrate were studied. Conclusions for these fabrication issues were drawn and briefly listed below.

- Drilling via holes on pre-laminated pieces instead of individual tapes can prevent bad alignment and via distortion. Also adding a pre-lamination step make the via drilling process much more cost effective.

- Cracks in the LTCC substrate usually occur during the lamination and sintering process. The cause of cracks could be uneven density through the substrate, mismatched shrinkage between via and tape material or improper sintering profile.

- Sagging of LTCC tape above the interior cavity is function of the cavity size and the lamination pressure. Multiple lamination process is effective to reduce the 
amount of sagging compare to conventional method. But sagging cannot be totally controlled only by multiple lamination process.

- Deposit of wax in a cavity can control sagging and get the desired cavity quality. However micro cracks may occur in the thermal via due to the local uneven density and stress distribution. Thus the roughness of wax surface and the amount of wax are very critical in this method. Fabricating embedded heat spreader using this method is possible while very difficult.

- Post fire using binding paste is a simple and effective method to fabricate hermetic cavity inside LTCC substrate. This method has no problem of sagging, and can ensure the quality of thermal via at the same time. The major problem of this method lies in the leakage form the binding paste. Fortunately this problem was successfully solved by using constrain sintering. Therefore this method was finally chosen as the method to fabricate the heat spreader.

- Cofire using binding paste is attractive in that it is more cost effective than the post fire method. In addition it is more adaptable to the LTCC industry. However this method cannot control sagging when the interior cavity is too big (wider than 0.75 inch). This problem is possible to be solved by printing tensile layer above the cavity. Therefore study in this method is worth to be continued in future.

- A novel sintered porous silver powder wick structure was successfully developed for the heat spreader. The wick uses novel porous silver powder, which is fabricated by sintering fine silver powders into coarse powders. The resulting porous nature can provide high capillary pressure and permeability for the wick. 
- The maximum mass transport rate of the wick structure was successfully tested at different wick height. Mass transport of $0.692(\mathrm{~g} / \mathrm{min})$ was obtained at wick height of $4.5 \mathrm{~cm}$. The corresponding mass transport rate per unit cross-area is $0.079\left(\mathrm{~g} / \mathrm{min}^{*} \mathrm{~mm}^{2}\right)$.

- The conclusion above also lead to better understands on how to make complex three-dimension structure using LTCC technique. These structures can be used not only in cooling systems but also in complex sensors and micro systems. 


\section{List of References}

${ }^{1}$ Donald P.Seraphim, Ronald Lasky and Che-Yu Li, Principles of electronic packaging

${ }^{2}$ T.P. Cotter "Principles and Prospects for micro Heat Pipes", Proc. $5^{\text {th }}$ Int. Heat Pipe Conf., Tsukuba, Japan.

${ }^{3}$ B.R.Babin, G.P.Peterson and D.Wu, 1989,"Analysis and Testing of a Micro Heat Pipe During Steady-state Operation", Proc. ASME/AIChE National Heat Tansfer Conf., 89HT-17, August 5-8, Philadelphia, Pennsylvania.

${ }^{4}$ D.Wu and G.Peterson, 1990, "Experimental Investigaion of the Transient Behavior of Miocro Heat Pipes", Proc. AIAA/ASME $5^{\text {th }}$ Joint Thermophysics and Heat Transfer Conf., June 18-20, Seattle, WA.

${ }^{5}$ D.Plesch, W.Bier, D.Seidel, and K.Schubert, 1991,"Miniature Heat Pipes for Heat Removal from Microelectronic Circuits", Proc. ASME Annual Meeting, Atlanta, GA.

${ }^{6}$ Y.S.Lee, Y.P.Lee, and Y,Lee, 1992,"An experiment Study on Micro Two-Phase Closed Thermosyphons with Insert", Proc. $8^{\text {th }}$ Int. Heat Pipe Conf., Beijing, China.

${ }^{7}$ H.Chen, M.Groll, and S.Rosler, 1992,"Micro Heat Pipes: Experimental Investigation and Theoretical Modelling," Proc. $8^{\text {th }}$ Int. Heat Pipe Conf., Beijing, China.

${ }^{8}$ J.Zhou, Z.Yao, and J.Zhu, 1992, "Experimental Investigation of the Application Characters of Micro Heat Pipe," Proc. $8^{\text {th }}$ Int. Heat Pipe Conf., Beijing, China.

${ }^{9}$ T.Li, L.Cao and L, Xiang 1992, "Research and Application for the Heat Tansfer Performance of Small Heat Pipes", Proc. 8th Int. Heat Pipe Conf., Beijing, China

${ }^{10}$ Cao, Y., Faghri, A., and Mahefky, E.T., 1993, "Micro/Miniature Heat Pipes and Operating Limitations”, ASME HTD-Vol. 236, pp. 55-62.

${ }^{11}$ Cao, Y., Gao, M., Beam, J.E., and Donovan, B., 1997, "Experiments and Analyses of Flat Miniature Heat Pipes", AIAA Journal of Thermophysics and Heat Transfer, Vol. 11, No. 2, pp. 158-164.

${ }^{12}$ Gao, M. and Cao, Y., Beam, J.E., and Donovan, B., 1999, "Structural Optimization of Axially Grooved Flat Miniature Heat Pipes," Proc. 1999 AIChE Symposium Series in Heat Transfer, Vol. 93, Baltimore.

${ }^{13}$ Koichiro Tke, Yuichi Furukawa, and Shunta Ushioda., "Fundamental Investigation of Roll Bond Heat Pipe as Heat Spreader Plate for Notebook Computers", 2000 IEEE Transactions on Components and Packaging Technologies, Vol.23, No.1 pp80-85 
${ }^{14}$ Zuo, Z.J.; North, M.T.; Wert, K.L." High heat flux heat pipe mechanism for cooling of electronics",2001 IEEE Transactions on Components and Packaging Technologies, Volume 24 , pp. $220-225$

${ }^{15}$ Kenichi Namba, Jun Niekawa, Yuichi Kimura, and Nobuyuki Hashimoto, "Heat Pipes for Electronic Devices and Evaluation of Their Thermal Performance", 2000 IEEE Transactions on Components and Packaging Technologies, Vol. 23. No.1. pp91-94

${ }^{16}$ I. Yusuf, A. Watwe and H.Ekhlassi, "Intergrated Heat Sink-Heat Pipe Thermal Cooling Device", 2000 Intersociety Conference on Thermal Phenomena, Vol 2 pp. 27-30

17 Seok Hwan Moon, Choon Gi Choi, Gunn Hwang and Tae Goo Choy, "Experimental Study on Performance of a Miniature Heat Pipe with Woven-Wired Wick", 2000 Intersociety Conference on Thermal Phenomena, Vol 2 pp. 129-133

${ }^{18}$ Rengasamy Ponnappan, "A Novel Micro-capillary Groov-wick Miniature Heat Pipe", Intersociety Energy Conversion Engineering Conference, Vol 2. pp.818-826

${ }^{19}$ Khrustalev. D., and Faghri. A., 1994, "Thermal Analysis of a Micro Heat Pipe." ASME Journal of Heat Transfer. Vol. 116. pp189-198

${ }^{20}$ J.M.Ha, G.P.Peterson, "The Heat Transport Capacity of Micro Heat Pipes", 1998 Transactions of the ASME vol. 120, pp. 1064-1071

${ }^{21}$ G.P.Peterson, H.B. Ma "Temperature Resonse of Heat Transport in a Micro Heat Pipe", 1999 Transactions of the ASME vol. 121, pp. 438-445

${ }^{22}$ Patricio espinoza-vallejos, Jihua Zhong, M. Gongora-rubio, Luis Sola-laguna, J.J.Santiago-aviles., 1998,"Meso-scale Electromechanical Systems For the Measurement and Control of Sagging in LTCC Structures", Material Research Society Symposia Proceedings, Vol.518. pp. 73-79

${ }^{23}$ Torsten Thelemann, Heiko Thust, Gernot Bischoff, Torsten Kirchner., 1999, "Liquid Cooled LTCC Substrates for High Power Applications", Proceeding. of SPIE, v3906 p.636.

${ }^{24}$ Lars Rebenklau, Klaus-Jürgen Wolter, Steffen Howitz, 2000 "Realization of hybrid microfluidic systems using standard LTCC process", Proceedings - Electronic Components and Technology Conference 2000. IEEE pp 1696-1700 
${ }^{25}$ Jaroslaw Kita, Andrzej Dziedzic, Leszek J. Golonka. "Three Dimensional Structures in LTCC Ceramics”, VII Konferencja Naukowa,, Technologia Elektronowa, ELTE 2000, Polanica Zdroj,

${ }^{26}$ Barry E. Taylor, Larry Bidwell, Angela Lawrence, "Novel Ceramic Packages and Architectures for MST Applications Made Possible with Photoimageable LTCC", 34thIMAPS conference, Baltimore, October 9-11, 2001

${ }^{27}$ Patricia Espinoza and Jorge J. Santiago-Aviles 2000,"Photolithographic Feature Fabrication In LTCC", The International Journal of Microcircuits and Electronic Packaging, Volume 23, Number 3, Third Quarter 2000

${ }^{28}$ Zampino, Marc A, "Embedded Heat Pipes in Cofired Ceramic Substrates for Enhanced Thermal Management of Electronics" Dissertation for Doctor of Philosophy

${ }^{29}$ Bauer, R., Luniak, M., and Rebenklau, L., 1997, "Realization of LTCCMultilayer With Special Cavity Applications," Proceedings of 1997 International Symposium on Microelectronics, IMAPS, Philadelphia, PA.

${ }^{30}$ Faghri, A., 1995, Heat Pipe Science and Technology, Taylor and Francis, Washington, D.C.

${ }^{31}$ Upadhyaya, 1995 G.S., Science of Sinterig,

${ }^{32}$ Ristic, M.M, 1990, science of sintering

${ }^{33}$ Ristic, M.M, Int. Symp. On Science and Technology of Sintering, Tokyo, 1987

${ }^{34}$ Rahaman, M. N., 1995 ,Ceramic processing and sintering

${ }^{35}$ Rahaman, M. N., 1995 ,Ceramic processing and sintering

${ }^{36}$ Hery H.Hausner, handbook of powder metallurgy, D.Eng

${ }^{37}$ X.Kuang, G.Carotenuto, L.Nicolais, A Review of Ceramic Sintering and Suggestions on Reducing Sintering Temperatures, 1997, Adv. Perf. Mater. 4, 257-274, 